Aspects of Flow and Viscoelasticity in a Model Elastohydrodynamically Lubricated Contact

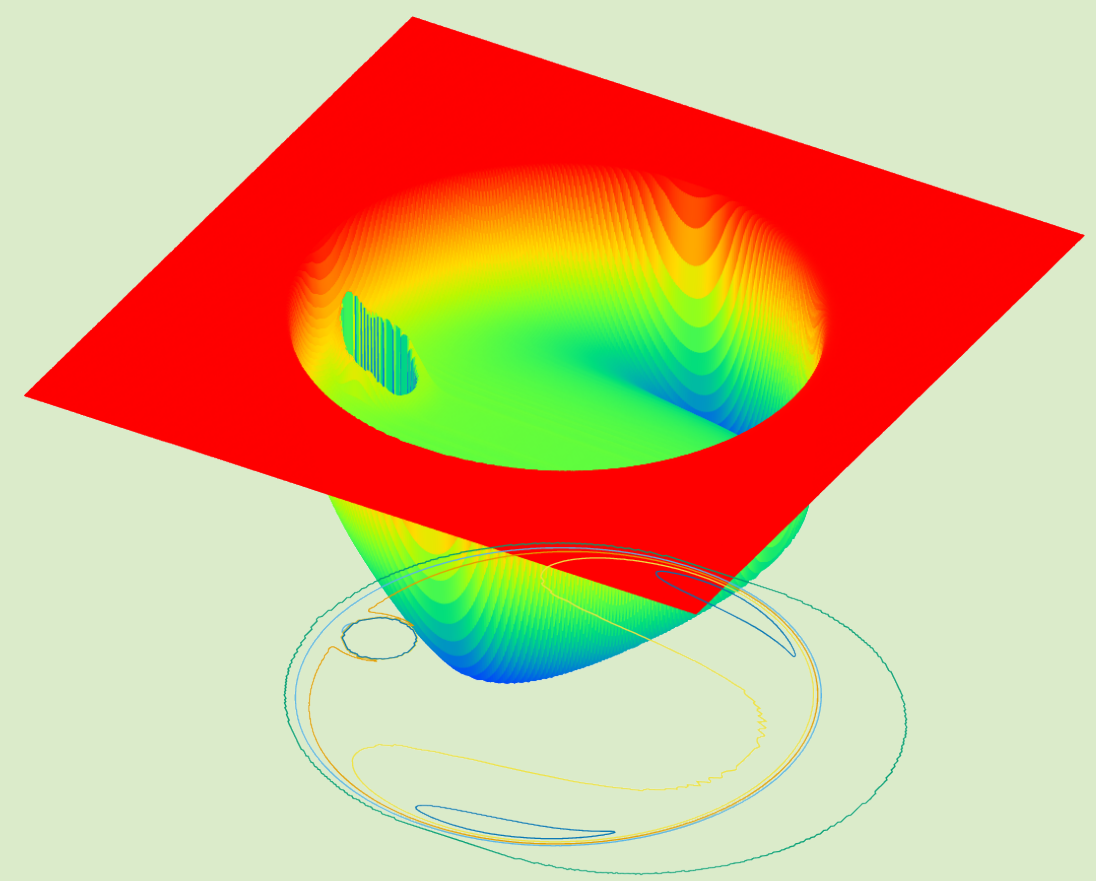

Ellen van Emden 
Aspects of Flow and Viscoelasticity in a Model Elastohydrodynamically

Lubricated Contact

E. van Emden 
Aspects of Flow and Viscoelasticity in a Model Elastohydrodynamically Lubricated Contact E. van Emden

Thesis University of Twente, Enschede, The Netherlands April 2017

ISBN: 978-90-365-4334-7.

DOI: $10.3990 / 1.9789036543347$

URL: https://dx.doi.org/10.3990/1.9789036543347

Printed by: Ipskamp printing - The Netherlands

Copyright (C) 2017 by E. van Emden 


\section{ASPECTS OF FLOW AND VISCOELASTICITY IN A MODEL ELASTOHYDRODYNAMICALLY \\ LUBRICATED CONTACT}

\section{PROEFSCHRIFT}

ter verkrijging van

de graad van doctor aan de Universiteit Twente, op gezag van de rector magnificus, prof.dr. T.T.M. Palstra,

volgens besluit van het College voor Promoties in het openbaar te verdedigen op donderdag 20 april 2017 om 12.45 uur

$$
\text { door }
$$

\section{Ellen van Emden}

geboren op 7 juni 1971

te Deurne 
Dit proefschrift is goedgekeurd door de promotor:

prof.dr.ir. C.H. Venner 


\section{SUMMARY}

In order to extend the service life of rolling bearings and other heavily loaded lubricated contacts, the need of lubricant film thickness control significantly increases under more extreme conditions of mechanical and thermal loading and with reduced lubricant supply. To ensure maximum service life, all lubricated contacts should be designed such that under all circumstances a sufficiently large protective layer of lubricant is present to prevent direct contact between the moving parts. Pressures in the order of several gigapascals can be encountered in the contact zone between the moving parts. The field of ElastoHydrodynamic Lubrication (EHL) studies cases for which the elastic deformation of (one of) the solids is of the same order of magnitude, or larger, than the film thickness of the lubricant.

This thesis focuses on the reseach of highly-loaded circular-shaped EHL contacts, under pure rolling conditions in the low velocity regime. Experimental results for film thicknesses under these conditions show discrepancies with the results from the conventional EHL model. The conventional EHL model assumes that there is always a sufficient supply of lubricant to the contact zone. Extensions of this model for the situation of mixed lubrication (i.e. when one or more parts of the contact do not have a protective lubricant layer present) are not based on first principles and their results depend on the employed computational grid density.

The purpose of the present study is to gain more knowledge about how the flow of lubricant around the contact influences the ability to form an enduring lubricant film in the contact zone. A second objective is the development of a model for mixed lubrication from first principles regarding the physics of contact and flow. The model should open a way to better predict EHL contacts in bearings operating in the extreme thin film regime.

The approach taken in this research is threefold and involves experimental, analytical and numerical aspects.

\section{1: Optical interferometry ball-on-disc experiments}

To investigate the ability to form an enduring lubricant film in elasto-hydrodynamic contacts and how it depends on the flow of lubricant around the contact, optical interferometry experiments with a ball-on-disc apparatus have been performed and the aspects of the flow in the vicinity of a lubricated EHL contact have been studied.

Two flow states can be recognized. The first state, flow pattern I, appears when the lubricant supply at the inlet side is sufficient. A flooded region envelopes the entire Hertzian contact region, and the outer meniscus of the flooded region is closed. Furthermore, a cavitation bubble is present at the outlet side of the contact. The bubble length depends on the rolling velocity and the lubricant viscosity. A dimensionless relation has 
been derived that relates the ratio of cavitation bubble length and Hertzian contact radius to a combination of the Reynolds, cavitation and Weber number. After a sudden stop this bubble breaks up into smaller bubbles that subsequently escape the flooded region.

The second state, flow pattern II, appears for decreased lubricant supply, e.g. when the rolling velocity is increased and no extra lubricant is added. Typical for this state is a concave-shaped inlet meniscus and an open downstream wake. In a starved situation, state II dominates and has a butterfly-shaped flooded region.

\section{2: Cavitation modeling}

A standard EHL-model has been coupled with an elementary 2-phase pressure-density model, which yields a strong density decrease for sub-atmospheric pressures. The extended EHL model is able to predict a cavitation bubble. However, its length is highly underpredicted when compared with available experimental results. This suggests a lack of essential physics included in the model. So, more advanced fluid modeling, e.g. including more detailed physics of cavitation and aspects of three-dimensional two-phase flow is needed for accurate prediction.

\section{3: A viscoelastic layer model}

A new viscoelastic layer model has been developed. This model is based on first principles and a 'bottom-up' approach that allows for a natural transition to dry contact.

When oil is trapped in a loaded rolling contact and subjected to high pressures, the lubricant behaves as a 'solid' layer that is transported from the inlet side towards the outlet side of the contact. This assumption agrees with the velocity distributions in the contact region obtained with a standard fluid-based EHL model. Inspired by this observation, an exploratory model is proposed which predicts the thickness- and pressure- distribution of a thin lubricant layer inside the contact zone of an elasto-hydrodynamically lubricated ball-on-plate contact.

The new model is based on a standard dry contact model with a solid layer added to the gap equation. The layer is modeled with multiple one-dimensional viscoelastic elements, only allowing displacements in the direction of the layer thickness. Each viscoelastic element consists of a pressure- and strain-dependent spring connected in parallel to a pressure-dependent viscous damper.

Various simulations of fully flooded-, squeeze-, and mixed-lubrication conditions have been performed. In general, the proposed model applies to thin layers and it shows the characteristic behaviour of an EHL contact in these situations remarkably well. The results indicate a good prospect for developing alternative EHL models that can predict local/partial/mixed surface separation and do not have the disadvantages of Reynolds based fluid film models.

Furthermore, simulations with a region with zero layer thickness show that the proposed model can be used to simulate mixed contact situations. However, the model predictions for features fixed on the ball geometry show local differences with physical expectations. 
Since this model is meant as an exploratory model, the results are an invitation to search for viscoelastic element properties that drive the model towards more accurate physical behaviour. The developed model has the potential to predict mixed lubrication conditions for which the contact consists of multiple isolated contacts on a local scale. Therefore, further development including parametrical studies is recommended. 



\section{SAMENVATTING}

Om de levensduur van kogellagers (wentellagers) en andere hoog belaste gesmeerde contacten te garanderen, ook onder extreme mechanische en thermische belastingen en verminderde hoeveelheid smering, is het noodzakelijk de smering te beheersen onder alle omstandigheden. De contacten tussen de bewegende onderdelen dienen zo worden ontworpen dat de hoeveelheid smeerfilm in het contact in alle situaties voldoende is om direct contact tussen de bewegende delen te voorkomen en verzekerd te zijn van een maximaal mogelijke levensduur. In het contact gebied, tussen de loopvlakken, kunnen drukken optreden in de orde van enkele gigapascals. Als de elastische vervormingen van één of beide onderdelen van dezelfde orde of groter zijn dan de dikte van de smeerfilm, spreken we van elasto-hydrodynamische gesmeerde contacten (EHL).

In dit proefschrift worden cirkelvormige EHL contacten onder hoge belastigen tijdens puur rollen met lage rolsnelheden bestudeerd. In dit regime worden er verschillen in filmdikte gevonden tussen de resultaten uit metingen en voorspeld met het conventionele EHL model. Het conventionele EHL model gaat uit van een volledig gevulde inlaat conditie van het contact gebied. Uitbreidingen van het EHL model voor berekeningen van gemengde smering (een situatie waarbij het contact niet volledig voorzien is van een beschermde smeringslaag) zijn niet gebaseerd op de natuurkundige basisvergelijkingen en de resultaten zijn afhankelijk van de fijnheid van het rekengrid.

Het doel van dit onderzoek is meer kennis op te doen over de manier waarop de stroming van het smeermiddel om het contact invloed heeft op het vermogen een blijvende film op te bouwen in het contact gebied. Een tweede onderwerp is de ontwikkeling van een model opgebouwd met basisvergelijkingen uit de fysica welke in staat is gemengde smering te voorspellen. Dit heeft als doel een manier te vinden dat een aanzet geeft tot betere modellering van de gemengde smering.

De aanpak in dit onderzoek is drievoudig and het maakt gebruik van experimentele, analytische en numerieke aspecten.

\section{1: Optische interferometrie bal-op-plaat experimenten}

Om te onderzoeken hoe een blijvende smeerfilm wordt gevormd in een elasto-hydrodynamisch contact en hoe dit afhangt van de stroming van het smeermiddel om het contact heen, zijn optische interferometrie experimenten op een modelcontact (bal-op-plaat) gedaan. De stromingsaspecten in de buurt van het EHL contact zijn bestudeerd en twee stromingstoestanden zijn herkend.

De eerste toestand, stromingspatroon I, treedt op bij voldoende aanvoer van smeermiddel bij de inlaatzijde van het contact. Het Hertze contact is volledig omhuld met 
smeermiddel en de meniscus aan de buitenrand is gesloten. Aan de uitlaatzijde van het contact bevindt zich een cavitatiebel. De lengte van de bel hangt af van de rolsnelheid en de viscositeit van het smeermiddel. Een dimensieloze functie is afgeleid die de ratio tussen de bellengte en de Hertze contact radius relateert aan de dimensieloze Reynolds, cavitatie en Weber getallen. Wanneer accuut wordt gestopt met rollen breekt de cavitatiebel op in kleinere belletjes die vervolgens het bevloeide gebied verlaten.

De tweede toestand, stromingspatroon II, treedt op bij verminderde (onvoldoende) aanvoer van smeermiddel, bijvoorbeeld wanneer de rolsnelheid wordt verhoogd en er geen extra smeermiddel wordt toegevoegd. Karakteristiek voor deze toestand is de concaaf vormige inlaatmeniscus en het open spoor aan de uitlaatzijde. In een 'starved' toestand domineert situatie II en het contact wordt omhuld door een volledig met smeermiddelgevuld gebied in de vorm van een vlinder.

\section{2: Cavitatie modellering}

Een elementaire twee-fase druk-dichtheid relatie, met een sterke dichtheidsafname voor drukken onder atmosferische druk, is gekoppeld aan een standaard EHL model. Dit uitgebreide EHL model voorspelt een cavitatiebel, maar de voorspelde lengte is veel te klein wanneer deze wordt vergeleken met experimentele resultaten. Dit wekt de suggestie dat er essentiële aspecten van de fysica ontbreken in dit model en daarmee vele andere smeringsmodellen. Om nauwkeurige voorspellingen te kunnen doen is meer gedetailleerde vloeistof modellering nodig met bijvoorbeeld meer details over de fysica van cavitatie en de driedimensionale twee-fase stroming.

\section{3: Een visco-elastische-laag model}

Een nieuw visco-elastische-laag model is ontwikkeld. Dit model is gebaseerd op de basisvergelijkingen en volgt een 'bottom-up' benadering waarbij het mogelijk is een natuurlijke overgang naar droog contact te maken.

In een belast rollend contact waar hoge drukken heersen gedraagt olie zich als een vaste stof, een laag die in het contact van de inlaat- naar de uitlaatzijde getranporteerd wordt. De snelheidsprofielen in de contactfilm berekend met een standaard EHL model gebaseerd op stromingsvergelijkingen ondersteunen deze aanname. Het nadeel van de vloeistofmodellen zijn de fundamentele problemen om deze modellen uit te breiden naar de zogenaamde gemengde smering waarbij de film locaal wegvalt. Geïnspireerd door deze observatie, is een alternatief verkennend model voorgesteld om de dikte- en drukverdelingen van een dunne smeerlaag in een contact gebied te voorspellen van een elastisch-hydrodynamisch bal-op-plaat contact.

Het nieuwe model is gebaseerd op een standaard droog-contact model, met een extra laag toegevoegd aan de hoogte vergelijking. De laag is gemodelleerd met meervoudige ééndimensionale visco-elastische elementen, die alleen vervormingen in de laagdikterichting toestaan. Elk visco-elastisch element bestaat uit een druk- en rek-afhankelijke veer parallel aan een drukafhankelijke viskeuze demper. 
Verschillende simulaties zijn gedaan onder volledig gesmeerde condities, pure drukbelasting en gemengde-smering condities. In het algemeen is het model bedoeld voor dunne lagen en het geeft een kwalitatief juiste voorspelling van het karakteristieke gedrag van een EHL contact.

Daarnaast laten de resultaten van simulaties met een gat in de laag zien dat het voorgestelde model kan worden toegepast in gemengde smering situaties. In andere situaties zoals locale oppervlakte defecten zijn er belangrijke verschillen met modellen op basis van vloeistofgedrag hetgeen nog verder onderzoek behoeft.

Één van de volgende stappen is met dit verkennend model en de resultaten op zoek te gaan naar passende eigenschappen van de visco-elastische elementen om het fysisch gedrag van de laag nog nauwkeuriger te kunnen voorspellen. Het ontwikkelde model heeft de potentie om gemengde-smeringscondities waarbij het contact bestaat uit meerdere geïsoleerde contacten op locale schaal te voorspellen. Daarom wordt het aanbevolen om het model verder te ontwikkelen en meer parameter studies te doen. 



\section{Contents}

Summary iii

Samenvatting vii

Contents $\quad$ xi

\begin{tabular}{lll}
\hline & Introduction & $\mathbf{1}$
\end{tabular}

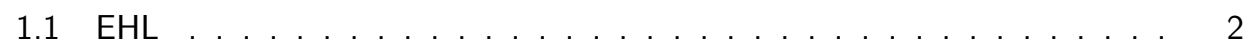

1.2 Objective . . . . . . . . . . . . . . . . . . . . . . . 7

1.3 Approach . . . . . . . . . . . . . . . . . . . . . . . . 8

1.4 Outline . . . . . . . . . . . . . . . . . . . . . . . . . 8

2 Aspects of flow and cavitation around an EHL contact 9

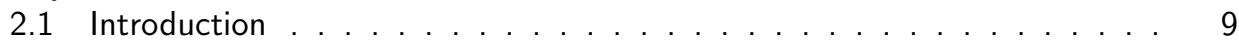

2.2 Experimental setup . . . . . . . . . . . . . . . . . . . . . . . . . . . . . . . . . . . . . . . . . . . . . . . .

2.3 Results . . . . . . . . . . . . . . . . . . . . . . . . . . 13

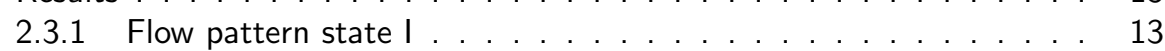

2.3.2 Transition between flow pattern states . . . . . . . . . . . . . . 18

2.3.3 Starting up and film formation . . . . . . . . . . . . . . . . . . . . . . . . . 19

2.3 .4 Film breakdown . . . . . . . . . . . . . . . . . . . . . . . . . . . . . . . 22

2.4 Theoretical results . . . . . . . . . . . . . . . . . . . . . . . 25

2.4.1 Dimensional analysis . . . . . . . . . . . . . . . . . 25

2.4.2 Discussing the effects contributing to cavitation . . . . . . . . . . 26

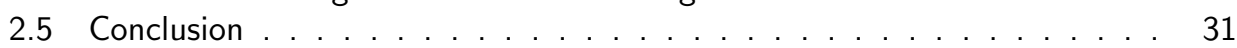

Nomenclature . . . . . . . . . . . . . . . . . . . . . . . . . . . 32

Appendix A: Dimensional analysis . . . . . . . . . . . . . . . . . . . . . 33

Appendix B: Model equations . . . . . . . . . . . . . . . . . . . . . . 36

3 A challenge to cavitation modeling in the outlet flow 39

3.1 Introduction . . . . . . . . . . . . . . . . . . . . 39

3.2 Model . . . . . . . . . . . . . . . . . . . . . . . . . . . . . . 43

3.2 .1 Equations . . . . . . . . . . . . . . . . . . . . 43

3.2 .2 Constitutive Equations . . . . . . . . . . . . . . . . . 45

3.3 Numerical Calculations . . . . . . . . . . . . . . . . . . . . . 47

3.3 .1 Computational Method . . . . . . . . . . . . . . . . . . . . . 47

3.3 .2 Input Parameters . . . . . . . . . . . . . . . . . . . . . . . 48

3.3 .3 Computational Details . . . . . . . . . . . . . . . . 48 
3.4 Results . . . . . . . . . . . . . . . . . . . . . . . . . . . . . 49

3.4.1 Typical Solution for Pressure and Film Thickness . . . . . . . . . 49

3.4.2 Minimal Pressure- and Density Results . . . . . . . . . . . . . . 52

3.4 .3 Cavitation Bubble Length . . . . . . . . . . . . . . . . . 54

3.4 .4 Velocitv Distribution ... . . . . . . . . . . . . . . . . 57

3.4.5 Cavitation Criterion Based on Principal Stresses . . . . . . . . . . 61

3.5 Conclusion . . . . . . . . . . . . . . . . . . . . . . . . . 64

Nomenclature . . . . . . . . . . . . . . . . . . . . . . . . . . 65

Appendix A: Grid Convergence Test . . . . . . . . . . . . . . . . . . 67

Appendix B: Domain size Test . . . . . . . . . . . . . . . . . . . . 68

4 Viscoelastic behaviour in an EHL contact 69

4.1 Introduction . . . . . . . . . . . . . . . . . . . . . . . . 69

4.2 Viscoelastic laver model . . . . . . . . . . . . . . . . . . . . . . 71

4.2 .1 Model equations . . . . . . . . . . . . . . . . . . . . . . 72

4.2 .2 Laver material . . . . . . . . . . . . . . . . . . . . . . . . 74

4.2.3 Dimensionless element equations . . . . . . . . . . . . . 75

4.3 Numerical solution . . . . . . . . . . . . . . . . . . . . . . . . . . . . 76

4.3 .1 Input parameters . . . . . . . . . . . . . . . . . 77

4.4 Results . . . . . . . . . . . . . . . . . . . . . . . . . . 78

4.4.1 Development of a steady rolling contact . . . . . . . . . . . 78

4.4 .2 Squeeze . . . . . . . . . . . . . . . . . . . . . . . . . 82

4.4 .3 Irregularities on the ball . . . . . . . . . . . . . . . 86

$4.4 .4 \quad$ A hole in the layer . . . . . . . . . . . . . . . . . . . 90 90

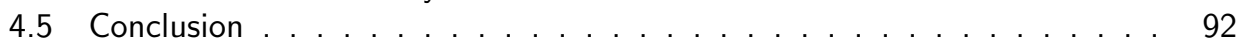

Appendix A: Derivation of the oedometric modulus of elasticity . . . . . . . 95

Appendix B: Discretization . . . . . . . . . . . . . . . . . . . . . 98

Appendix C: Description solution method . . . . . . . . . . . . . . . . . 99

Appendix D: Grid convergence . . . . . . . . . . . . . . . . . . . . . . . . 101

5 Conclusions and Recommendations 105

5.1 Conclusions . . . . . . . . . . . . . . . . . . . . . . 105

5.1.1 Flow in and around an EHL contact . . . . . . . . . . . 105

5.1 .2 Viscoelastic laver model . . . . . . . . . . . . . . . . . . . . . 107

5.2 Recommendations . . . . . . . . . . . . . . . . . . . . . . 107

5.2 .1 Flow in and around an EHL contact . . . . . . . . . . . . 108

5.2 .2 Viscoelastic layer model . . . . . . . . . . . . . . . . . . 108

\begin{tabular}{ll}
\hline Bibliography & 109
\end{tabular}

\begin{tabular}{ll}
\hline Acknowledgement & 117
\end{tabular} 


\section{Chapter 1}

\section{INTRODUCTION}

Everywhere in mechanical-engineering applications parts, are moving relatively to each other while transmitting a force. This also applies to natural and artificial joints in bio-mechanics, see figure 1.1. The most widely used machine elements allowing the transmission of a force while permitting motion are bearings, and in particular rolling bearings. Bearings are used to facilitate these movements: a bearing supports loads, guides motion and reduces friction between parts in relative motion. To minimize friction and avoid wear the bearing is lubricated so that the moving parts are separated, e.g. by oil. In the case of biomechanical joints this lubricant is the synovial fluid.

To ensure maximum service life of a bearing, all lubricated contacts should be designed such that under all circumstances a sufficiently large protective layer of lubricant is present. Accurate prediction of the lubricant layer thickness and service life is one of the important aspects in the design of bearings, as the consequences of failure of bearings in complex and or large machines are significant (safety, downtime, financial). The significance of film thickness control in lubricated contacts increases under extreme conditions of mechanical and thermal loading and with reduced lubricant supply. Nowadays, control of motion, friction and minimizing wear are more important than ever. As the 'price' of sustainable energy is higher, frictional losses are more 'expensive' and minimizing energy losses is more important.
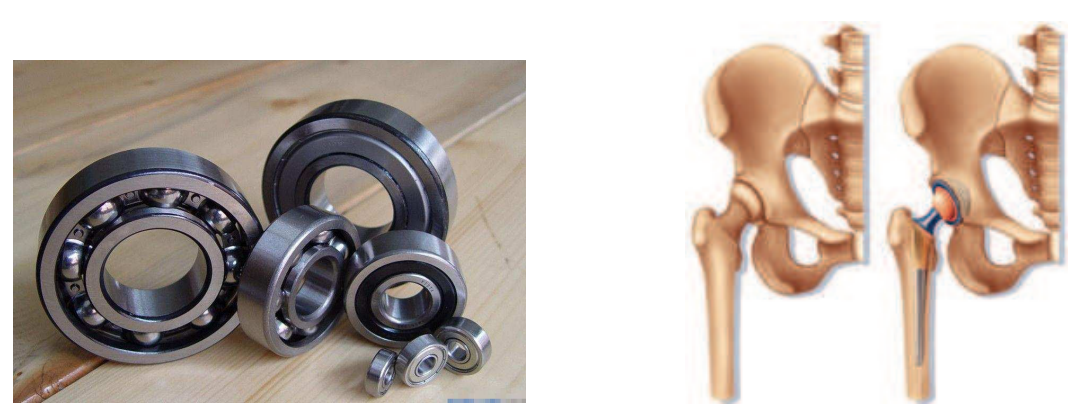

Figure 1.1: Bearings (left), original and artificial hip (right). 
This thesis focuses on the reseach of highly loaded contacts, referred to as ElastoHydrodynamic Lubrication (EHL). EHL describes a contact situation of highly loaded solids separated by a pressure-dependent viscous lubricant. The elastic deformation of (one of) the solids is of the same order of magnitude, or larger, than the film thickness of the lubricant. The understanding of these highly loaded contacts involves several disciplines such as mechanics, fluid dynamics, physics and chemistry.

A well known example of an EHL contact can be found in a rolling bearing between roller and raceway, see figure 1.1 (left). In the simplest case it is a circle, a model contact situation. This circular contact, under pure rolling conditions, is the subject of the investigations presented in this thesis. In such applications, pressures up to $3 \mathrm{GPa}$ can be encountered in the contact zone between a rolling ball and the raceway. Figure 1.2 shows a generic sketch of a ball in a raceway together with the pressure distribution of an EHL contact under fully flooded conditions.

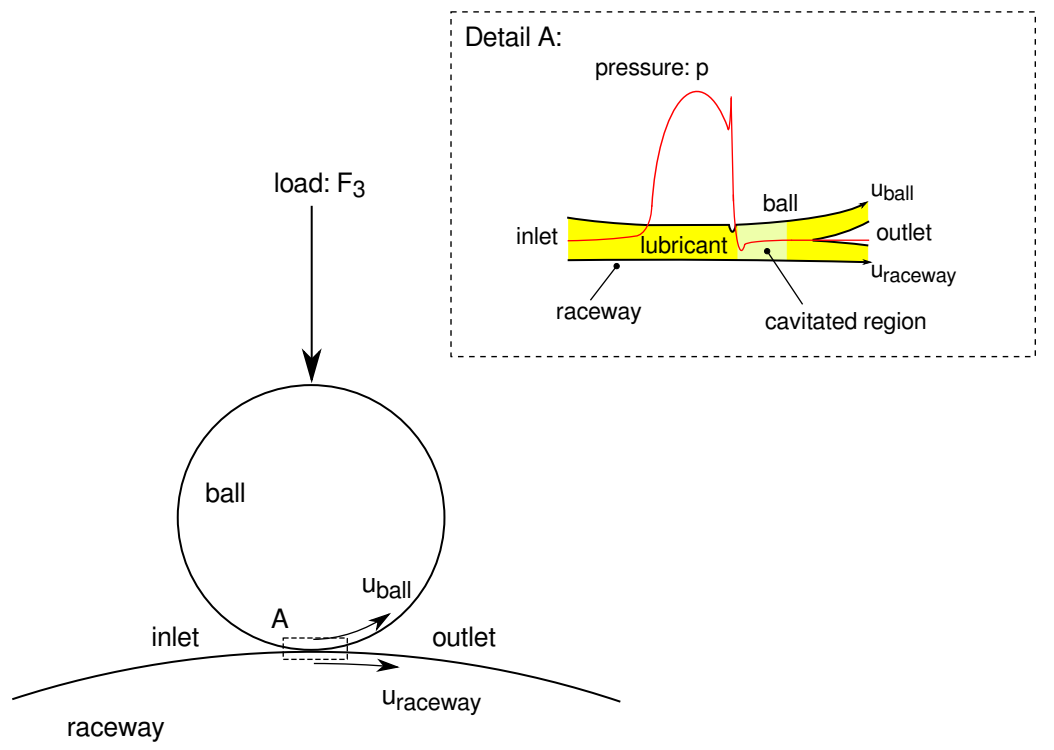

Figure 1.2: Generic sketch of a circular shaped EHL contact (fully flooded).

\section{$1.1 \quad \mathrm{EHL}$}

The Elasto Hydrodynamic Lubrication (EHL) model is commonly used for predicting film thickness in the contact zone between the rolling elements and the raceway of bearings.

The foundation of lubrication analysis was laid in the $19^{\text {th }}$ century. Inspired by the experiments of Beauchamp Tower, Reynolds [1] derived an equation to describe the flow of a fluid in a gap between the surfaces using a narrow gap assumption. This approach 
is known as 'the lubrication assumption'. It is also widely used in physics of bubble interaction, surface wetting and coalescence of drops. The Reynolds equation forms the base of the lubrication theory [2].

Furthermore, the solution for the pressure distribution and contact diameters under dry contact conditions between two spherical bodies as given by Hertz [3] is also very important for the development of EHL theory.

Martin [4] and Gümbel [5] solved the Reynolds equation for the flow of isoviscous lubricant between two contraformal undeformable rigid bodies. They derived a relation for the minimum film thickness as a function of the operating conditions. However, when applied to gears it was observed that the predicted film thickness was below the surface roughness hence full separation as observed (no wear) could not be explained.

Ertel [6] and Grubin [7] combined the Reynolds equation, using a pressure dependent viscosity relation for the lubricant behaviour, with the elastic deformation equation for the solid bodies. They derived an approximate analytical relation to predict the central film thicknesses for (infinitely wide) line contacts. The obtained film thickness values were realistic to explain the occurence of lubrication and full surface separation in contraformal contacts.

Pertusevich [8] was the first to publish a numerical solution of the EHL problem, showing the pressure spike in the pressure distribution. He used the exponential pressure dependent viscosity relation for oil attributed to Barus [9]. The results showed all the characteristic features in the pressure- and film thickness distributions in an EHL contact.

Dowson and Higginson [10] combined the numerical solutions of the line contact problem for a wide range of parameters and constructed a film thickness equation based on these solutions, valid for different operating conditions. Hamrock and Dowson [11] solved the circular contact problem and constructed an equation for the central film thickness for a circular contact under steady state conditions. This equation is still widely used in engineering today.

These investigations have led to the development of the conventional Elastic Hydrodynamic Lubrication model (EHL) [10], that is still widely used. It can be used to predict the local pressures, gap heights and film thickness for lubricated contact situations, and is applicable to fully lubricated contacts. The modeling equations are a combination of: a flow equation, e.g. the Reynolds equation, an integral equation for the elastic deformation of the solid surfaces, a force balance equation stating that the integral over the contact pressures must equal the external load, two constitutive equations for the lubricant viscosity, $\eta$, and the density, $\rho$, and a cavitation condition, forcing the pressure to remain larger or equal to 'ambient'. For a more detailed description of the history of EHL, see Dowson [10, 12].

The problem can not be analytically solved and many numerical techniques are used to solve the EHL equations. For instance, there are direct methods to calculate the pressure distribution for a given film thickness. Iterative procedures, like Gauss-Seidel and Newton-Raphson algorithms, are used to solve the Reynolds and elasticity equation simultaneously, see for example Hamrock and Dowson [11], Chittenden et al. [13, 14] and Okamura [15]. Evans and Snidle [16] proposed an inverse method originally developed 
by Dowson and Higginson for line contacts and applied it to circular contacts. With the introduction of multilevel methods by Lubrecht and Venner [2], the efficiency to solve the EHL problem increased enormously. Nowadays computing power makes it possible to perform calculations with transient loads, surface roughness, features moving through the contact, and other phenomena.

EHL contacts are extensively studied using optical interferometry on a model contact, introduced by Cameron and Gohar [17]. Thereby, it became possible to measure the oil film thickness inside the EHL contact and visualise a contact and the flooded region, i.e. the oil trapped between the ball and the disc and the oil surrounding the contact. With further development of a spacer layer on the glass disc, it became possible to measure a film thickness below the limitation of wavelength of visable light down to $O(10 \mathrm{~nm})$. The design is based on the works of Foord et al. [18], Cameron and Gohar [17, 19], Wedeven [20], Johnston, Wayte and Spikes [21] and Cann et al. [22]. This technique is also widely used today, e.g. to study the effect of surface roughness and groove topography, time varying effects, or the transition from EHL to mixed lubrication, see Krupka et al. [23] and Touche et al. [24].

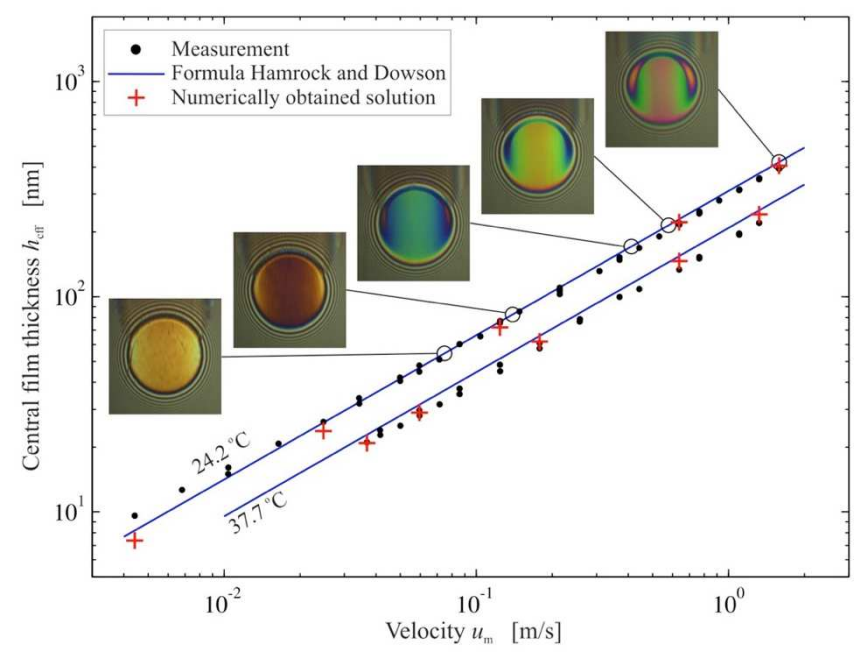

Figure 1.3: Central film thickness as a function of the rolling velocity operating under fully flooded conditions [25]. HVI60, $F=20 \mathrm{~N}, T=37.7^{\circ} \mathrm{C}$

Figure 1.3, taken from van Zoelen [25], shows the measured central film thickness between a ball and a disc as a function of the rolling velocity for two temperatures (pure rolling, fully flooded conditions). The predictions obtained numerically with a conventional EHL model and by using the Hamrock and Dowson film thickness formula [11] are shown as well. Furthermore, the accompanying interferometric images are shown for five speeds at $24{ }^{\circ} \mathrm{C}$. The figure shows that the central film thickness predictions for the steady state simulations at fully flooded conditions are quite good. 

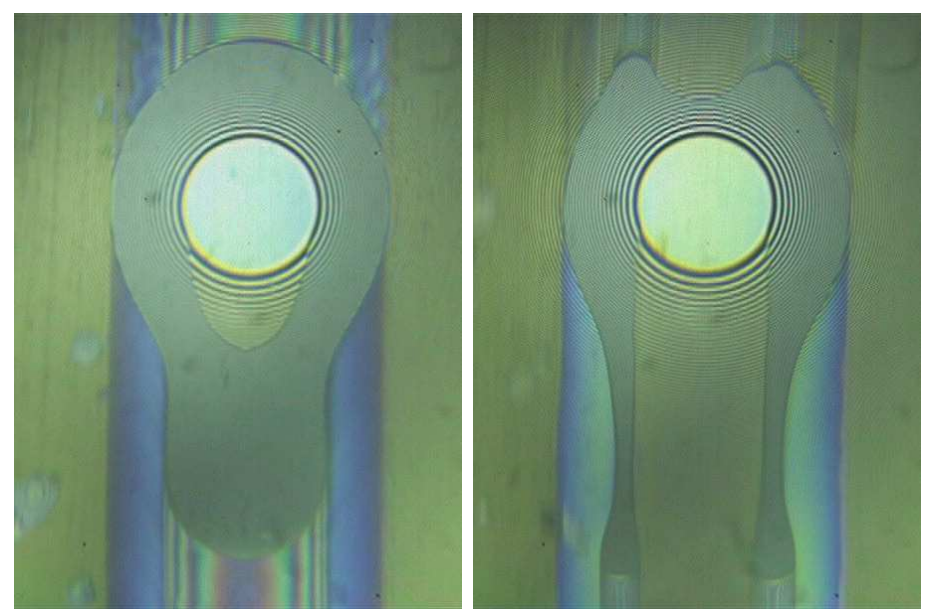

Figure 1.4: Optical interferometry images of an EHL contact at pure rolling. Flow pattern state I: $u_{1}=8 \mathrm{~mm} / \mathrm{s}$ (left) and flow pattern state II: $u_{1}=17 \mathrm{~mm} / \mathrm{s}$ (right). HVI60, $F=20 \mathrm{~N}, T=40^{\circ} \mathrm{C}$ (lens: $5 \times$ ).

In reality the operating conditions are not always fully flooded and steady. The significance of the flow around the contact for the film formation inside the contact region was noted by Pemberton and Cameron [26]. Two types of surrounding flow patterns can be observed: the enclosed wake as shown in figure 1.4 (left), ensuring the track to be completely replenished, and the butterfly shape as shown in 1.4 (right) which can lead to starved situations. The lubricant supply of EHL contacts in rolling bearings consists of the thin layers of oil present on both the roller and the raceway surfaces. Where these layers merge in the inlet, pressure build-up starts and a lubricant film can be formed. For the first flow pattern a cavitation bubble is observed at the outlet side of the contact in the closed wake, see figure 1.4 (left). This bubble elongates when the rolling velocity is increased as noted bu Chiu [27] and Stadler et al. [28].

The rolling velocity at which the transition from the first to the second state occurs depends on the lubricant viscosity, see Chiu [27].

Under the condition of insufficient supply of lubricant between successive overrollings, for instance at high rolling speeds, the inlet meniscus approaches the contact. This leads to a reduced film thickness, and the contact is said to operate in the starved regime. Among others, Wedeven et al. [20], Chevalier et al. [29] and Popovici [30] studied starvation of elasto-hydrodynamically lubricated contacts. Venner et al. [31] studied film thickness decay in starved EHL contacts using a thin-layer flow model. Starvation is likely to occur at high speed. Figure 1.5 from [31], shows the film thickness decay in a starved circular EHL contact as a function of time at constant rolling velocity and prevention of lubricant reflow from the contact sides. Jacod [32] analysed contact replenishment under severely starved conditions, distinguishing, 'out-of-contact' and 'in-contact' reflow. 
Most EHL studies are dedicated to oil. However, $80 \%$ of the bearings are lubricated with grease. Grease behaviour is much more difficult to model. Grease is a multi-phase material consisting of a soap matrix filled with oil, Lugt [33]. Its rheological behaviour is characterized by two regimes: fully flooded where the grease acts as the lubricant and starved in case the bleeded oil acts as the lubricant, which is often more realistic. In this case most of the grease is pushed to the sides in early overrollings and the long term operation is determined by a thin layer of low viscous material, e.g. bleeding of oil on the track, possibly mixed with worked grease thickener. So in reality many contacts can be treated as starved, and thus starved contacts are extremely important.

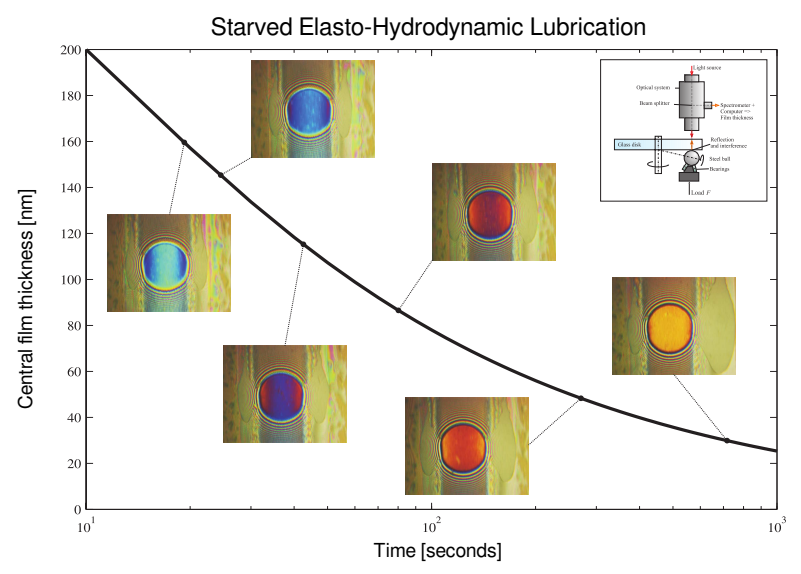

Figure 1.5: Central film thickness decay in a starved circular EHL contact as a function of time, from Venner, van Zoelen and Lugt [31].
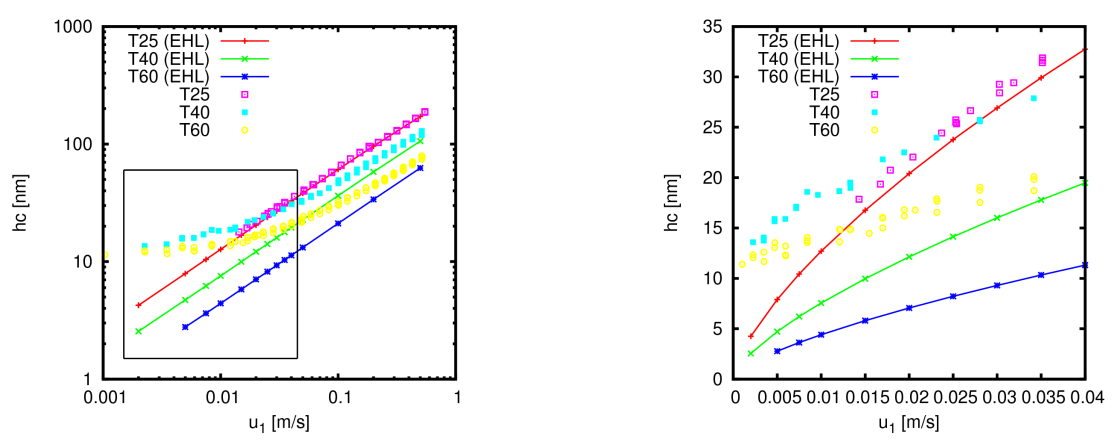

Figure 1.6: Numerical (EHL) and experimental results of central film thickness versus pure rolling velocity for different temperatures, $h_{c}(u, T, F=20 \mathrm{~N})$. Complete velocity regime (left), low velocity regime (right). HVI60, $F=20 \mathrm{~N}$. 
Figure 1.6 shows optical interferometry measurements and predictions for film thickness based on the conventional EHL theory under reduced lubricant supply caused by e.g. lower rolling velocities. As can be seen in the figure 1.6, the predictions from the conventional EHL model match the measured values for the central film thickness very well in the higher speed regime where the film thickness is sufficiently large. For the lower speeds, associated with lower central film thicknesses, the numerically predicted values for the film thickness are lower than the measured ones. There are various possible causes of this behaviour, one of them can be mixed lubrication conditions. So, discrepancies are shown at lower rolling velocities between the central film thickness measurements and predictions based on the conventional EHL theory. Transition from EHL to mixed lubrication conditions can be a possible cause of these discrepancies.

To improve the predictions in the low velocity regime, the conventional EHL model has been extended for mixed lubrication situations. In a mixed lubrication situation the contact area consists of regions of dry metallic contact together with wet islands of thin layer flow. Some failure modes like 'micro-pitting' can be associated with this situation, see for example Dawson [34] and Olver et al. [35, 36]. With the current models (topdown approach) it can be risky to attempt any serious modeling of these failure modes. The usual approach to study mixed lubrication, proposed by $\mathrm{Hu}$ and Zhu [37], is to take a conventional EHL model and when, in the numerical solution process, locally the film thickness drops below a certain level, 'contact' is said to occur and the pressure flow terms are artificially eliminated from the Reynolds equation. A similar approach has been taken by Holmes et al [38] and Zhao and Sadeghi [39]. The results seem impressive, however, the Reynolds equation is an equation of mass conservation for a fluid treated as a continuum. Under steady state conditions this equation will always predict a positive film thickness. Most of these models are based on the Reynolds equation combined with a cut-off criterion for the film thickness, see Venner [40]. Therefore, the ability of mixed lubrication models to predict contact is grid-dependent. There is always a finer computational grid on which no contact may be predicted. Due to a locally large discretization error in the approximation, these mixed lubrication models are able to predict contact in steady-state. This is pointed out in detail by Venner [41] and Morales-Espejel et al. [42. They argue that, in the same way as the Reynolds equation is based on the first principle of mass conservation, a mixed lubrication model should be based on first principles as well and it should lead to results that when numerically solved, exhibit grid convergence.

As mentioned above, the contacts encountered in bearings typically operate in the mixed lubrication regime during start-up, towards the end of slowing down and in lowvelocity situations. Furthermore, mixed lubrication conditions become more severe when the temperature increases and the viscosity of the lubricant as a result decreases.

\subsection{Objective}

Many aspects of EHL are well understood, we know what happens inside the contact given the flow at the periphery. The situation at dry contact is also well known, but transition to mixed lubrication is not well understood and modelled yet, see also Krupka et al. [23]. 
The EHL model is based on the assumption that a sufficient amount of lubricant is present, i.e. a top-down approach. However, much is still unknown about how much lubricant is present at which point in time at which location.

The objective of this study is to fill gaps in the knowledge regarding the transition from full film to mixed lubrication and is focussed two aspects. The first aspect is the flow around the contact because it determines the inflow of lubricant to the next contact. The second aspect is the solid-like behaviour of the lubricant inside the contact region. This is used to develop an alternative model based on thin-layer viscoelastic behaviour.

\subsection{Approach}

First, an experimental study on the aspects of the flow in the vicinity of a lubricated EHL contact is performed using optical interferometry and high-speed camera imaging on a model contact (EHL ball on disc). Inlet and outlet flow phenomena in relation to the operating conditions are investigated to acquire more understanding of the flow mechanisms contributing to film formation and break down.

Secondly, numerical simulations are performed using a standard EHL-model with modifications for the pressure-density relation to predict cavitation behaviour. Finally, the experimental observations together with the lubrication theory and information provided by published studies in literature are used to explore the possibility to model a thin oil film in the contact zone by a viscoelastic layer model. This model uses a bottom-up approach, starting from the dry contact equations for which the layer thickness is zero inside the contact. Then, a viscoelastic layer is added to the gap-height equation to open the possibilities for mixed-lubrication modeling in pure rolling as it allows a natural transition to dry contact.

\subsection{Outline}

In chapter 2, the aspects of flow and cavitation around an EHL contact are presented based on experimental observations. The lubricant flow phenomena inside and outside the contact zone are studied together with a cavitation bubble observed at the outlet side of the contact when the lubricant supply at the inlet side is sufficient. An optical interferometry ball-on-disc apparatus is used in the experiments.

In chapter 3, a numerical study is presented on the prediction of a cavitation bubble in the wake of an elasto-hydrodynamically lubricated ball-on-disc contact as observed in experiments at low velocity.

Chapter 4 presents an investigation of the viscoelastic behaviour of a thin lubricant layer in an EHL contact. Furthermore, a model is proposed describing the lubricant behaviour inside the contact by a viscoelastic thin layer with possibilities to create inlet conditions that lead to mixed lubricated contacts.

Finally, the conclusions following from this reseach together with recommendations for further study are given in chapter 5 . 


\section{Chapter 2}

\section{ASPECTS OF FLOW AND CAVITATION AROUND AN EHL CONTACT}

This paper focuses on the flow around an elasto-hydrodynamically lubricated ball-on-disc contact. Experiments in the low velocity regime with a small amount of lubricant show two flow states. When the lubricant supply at the inlet side is sufficient, a cavitation bubble is observed at the outlet side of the contact. The bubble length depends on the rolling velocity and the lubricant viscosity. After a sudden stop this bubble breaks up into smaller bubbles that subsequently escape the flooded region. A dimensionless relation is presented that describes the length of the cavitation bubble relative to the contact radius. A theoretical study shows that the length of the bubble can not be predicted with common EHL models based on a pressure criterion.

The work in this chapter has been published as: E. van Emden, C.H. Venner and G.E. Morales-Espejel, Tribology International 95 (2016) 435-448.

DOI: http://dx. doi.org/10.1016/j. triboint.2015.11.042

\subsection{Introduction}

The need of film thickness control in lubricated contacts significantly increases under more extreme conditions of mechanical and thermal loading and with reduced lubricant supply. The lubricant supply of EHL contacts in rolling bearings consists of the thin layers of oil present on both the roller and the raceway surfaces. Where these layers merge in the inlet pressure build-up starts and a lubricant film can be formed. Under the condition of insufficient (re-)supply between successive overrollings, for instance at high rolling speeds, the inlet meniscus approaches the contact. This leads to a reduced film thickness, and the contact is said to operate in the starved regime.

The significance of the flow around the contact for the film formation inside the contact region was already noted by Pemberton and Cameron [26]. They observed two flow patterns: the enclosed wake, ensuring the track to be completely replenished, and the butterfly shape for starved situations and at very low speeds. The rolling velocity at which the transition from the first to the second state occurs depends on the oil viscosity, see Chiu [27]. For the first flow pattern a cavitation bubble is observed at the outlet side of the 
contact in the enclosed wake. Stadler et al. [28], developed an empirical equation for the cavity length based on experimental observations and a numerical parametric study. They found the dimensionless cavity length to be determined by the viscosity, the entrainment velocity, the cavitation pressure, and the geometry of the contact. Furthermore, Stadler et al. state that in a normal unidirectional rolling contact, after a short time, the early stage of a cavity breaks through the oil meniscus and an atmospheric pressure can be assumed, which is the transition to the second state. Jacod [32] analysed contact replenishment under severely starved conditions, distinguishing, 'out-of-contact' and 'in-contact' reflow.

Revisiting the work of Pemberton and Cameron and Stadler et al. in this paper, the flow around the contact, and some inlet and outlet flow phenomena in relation to the operating conditions are investigated. The contact and the flow patterns, are visualised using a high speed camera. In particular, the dependence of the closed cavition bubble on the operating conditions is investigated with experiments and a dimensional analysis is presented. Furthermore the transitions between the flow states, film formation, and film breakdown are illustrated.

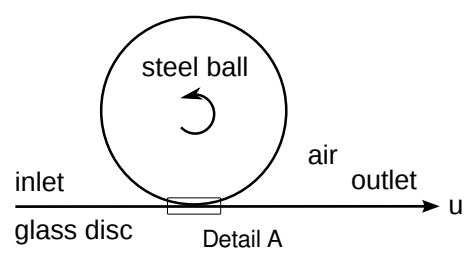

Detail A: state I

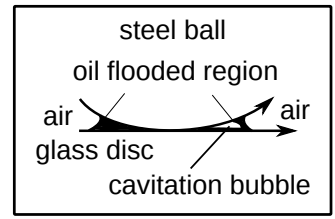

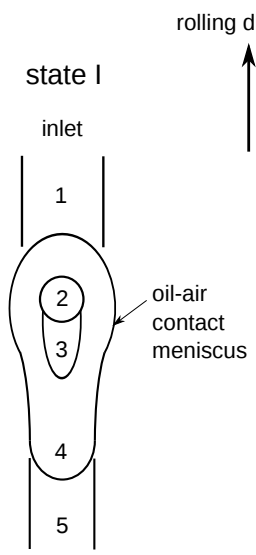

outlet state II

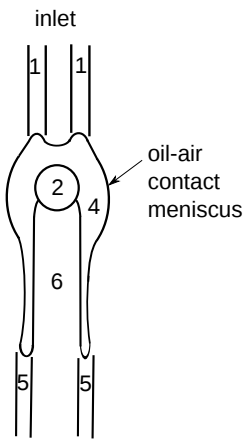

outlet

\footnotetext{
1: oil track at the inlet side

2: Hertzian contact circle

3: cavitation bubble

4: flooded region

5: oil track at the outlet side

6: open wake
}

Figure 2.1: Generic sketches of ball on disc (left) and the steady state lubricant distribution patterns (right), as observed in experiments.

In general, for mineral oil, one can distinguish two steady flow patterns as sketched in figure 2.1. At low speeds, when there is sufficient lubricant and time for the lubricant to enclose the contact region, flow pattern state I develops. This flow pattern is representative of the fully flooded situation. Typical for state $I$ is the closed shape of the flooded 
region enveloping the entire circular shaped (Hertzian) contact area. Inside the flooded region, on the outlet side of the Hertzian contact region, a cavitation bubble appears. This bubble elongates when the rolling velocity is increased, as noted by Chiu [27] and Stadler et al. [28]. Upstream of the Hertzian contact the menicus of the flooded region is convex.

Differences in the shape of the flooded region, the size of the cavitation bubble and the oil patterns on the downstream track can be observed when the rolling velocity changes. This is illustrated in figure 2.2, in which the velocity increases from left to right. The characteristic features are numbered from 1 to 5 . A bubble is important for inflow in the following contact in rolling bearings as it can reach a length of many times the contact radius. At high speeds there is a possibility of insufficient oil supply to the next following contact which leads to a starved contact situation. This has been confirmed by Chennaoui [43] with optical interferometry measurements on a model rolling bearing with a sapphire bearing ring.

rolling direction
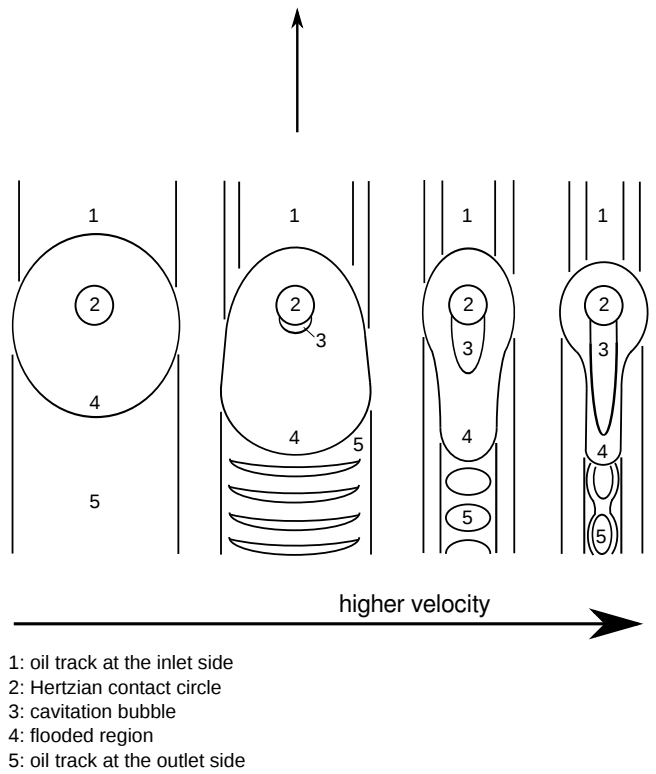

higher velocity

$$
\begin{aligned}
& \text { 1: oil track at the inlet side } \\
& \text { 2: Hertzian contact circle } \\
& \text { 3: cavitation bubble } \\
& \text { 4: flooded region } \\
& \text { 5: oil track at the outlet side }
\end{aligned}
$$

Figure 2.2: Sketch of region change (state I), velocity increases to the right, as observed in experiments.

When the speed is increased state II appears. This state is characterized by an open downstream wake and a concave shaped inlet meniscus. The outer shape of the flooded region exhibits the characteristic butterfly shape, see [26]. The distance from the upstream meniscus to the Hertzian contact decreases with decreasing replenisment by, for instance, increasing the rolling velocity. Often the supply is still large enough for the fully flooded film thickness limit to be reached. When the inlet meniscus approaches the 
Hertzian contact region the film thickness is reduced gradually, see Jacod et al. [32. When it actually touches the Hertzian contact region, significant film thickness variations (reductions) inside the Hertzian contact region are observed. The contact is heavily starved and both the central- and minimum film thickness are reduced, see Wedeven et al. [44], Cann et al. [22], Chevalier et al. [29] and Damiens et al. [45, 46].

Detailed knowledge of the lubricant flow around the contact, including cavitation bubble development, is important for predicting the (starved) inflow conditions to the next contact (overrolling) and the consequences for film formation in the contact region, in repetitive contact situations such as in roller bearings and in gears. This paper focuses on the physical phenomena of the flow around the contact region, when a flow pattern state I applies with a cavitation bubble at the outlet side. Also, the transition from one state to the other is investigated.

The experiments are performed with an optical interferometry ball on disc apparatus as introduced by Gohar and Cameron [17]. A schematic drawing of the setup is shown in figure 2.3 .

\subsection{Experimental setup}

A high speed camera with different lenses is used to record the contact images and the surrounding flow. Recordings have been made of an oil lubricated model contact rolling at very low speeds under steady state and dynamic flow conditions. The experiments have been repeated several times to confirm the observations.

The experiments focus on contacts lubricated with a very small amount of oil under pure rolling. No extra oil is added during an experiment. The test conditions are given in table 2.1. The temperature of the setup is measured in the surrounding region near the contact. For each temperature, the setup is thermally equilibrated during a long time (at least 4 hours) before starting the experiments.

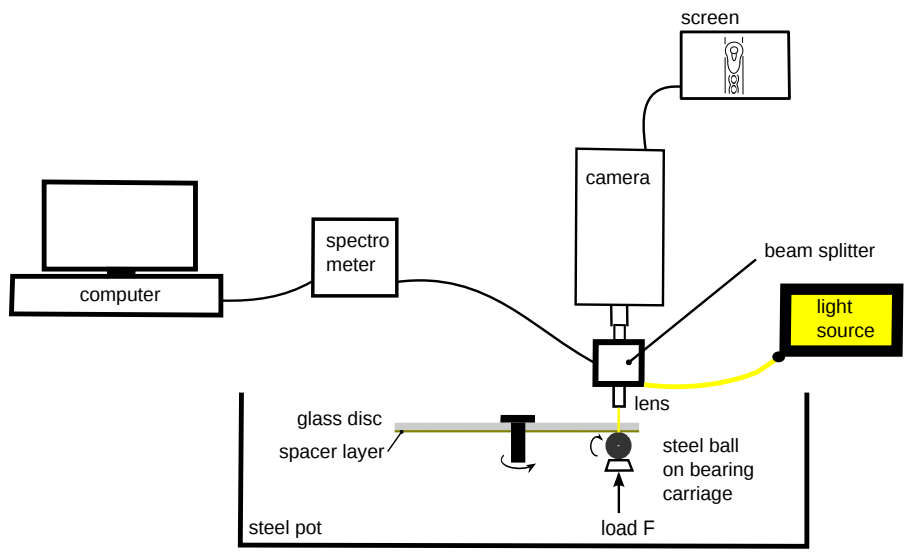

Figure 2.3: Experimental setup. 
2.3 Results

\begin{tabular}{|ll||ll|}
\hline parameter set up & {$[$ unit $]$} & nominal condition & variation \\
\hline radius of ball $(R)$ & $\mathrm{m}$ & $9.525 \cdot 10^{-3}$ & \\
rolling velocity & $\mathrm{mm} / \mathrm{s}$ & 5 to 40 & \\
loading force $(F)$ & $\mathrm{N}$ & 20 & 5,30 \\
\hline lens magnification & $\times$ & 5 & $2.5,10$ \\
high speed camera & $\mathrm{fps}$ & 300 & 60,100 \\
\hline lubricant & & $\mathrm{HVI} 60$ & 25,60 \\
temperature & ${ }^{\circ} \mathrm{C}$ & 40 & $44.7,10.2$ \\
dynamic viscosity [47] & $10^{-3} \mathrm{~Pa} \cdot \mathrm{s}$ & 21.6 & $2.25,1.97$ \\
viscosity pressure coefficient & $10^{-8} \mathrm{~Pa}^{-1}$ & 2.13 & \\
reduced modulus of elasticity $\left(E^{\prime}\right)$ & $10^{11} \mathrm{~N} / \mathrm{m}^{2}$ & 1.11 & \\
\hline
\end{tabular}

Table 2.1: Nominal test conditions for interferometry measurements

At the nominal conditions of $F=20 \mathrm{~N}$ the Hertzian dry contact parameters are $p_{H}=0.509 \mathrm{GPa}$ and the Hertzian contact radius $a=0.137 \mathrm{~mm}$. During the experiments, the central film thickness is in the order of 5 to $30 \mathrm{~nm}$.

\subsection{Results}

\subsubsection{Flow pattern state I}

Differences in the shape of the flooded region, the size of the cavitation bubble and the oil patterns on the downstream track can be observed when the rolling velocity changes. In figure 2.4 images from a flow pattern state I are shown, with the velocity increasing from (a) to (d). The oil-air meniscus around the flooded region narrows and elongates further downstream. Furthermore, it can be seen that the cavitation bubble length increases.

To study the cavitation bubble length, experiments have been performed in which the rolling velocity, the oil temperature and the load were varied. First, the dependence on the velocity and oil temperature (viscosity) was investigated, at a fixed load of $20 \mathrm{~N}$. The velocities were kept low and 3 temperatures were considered. Next, 3 different loads were considered at fixed temperature for different velocities. The bubble length $(l)$ is defined as the distance from the utmost downstream point on the Hertzian contact circle to the tip of the bubble, see figure 2.5. This is different from the approach used by Stadler et al. [28], who defined the length as the distance from the center of the contact zone to the tip of the bubble. However since the cavitation bubble cannot be present in the high pressure region of the contact zone, and cavitation takes place at pressures at vapour pressure and below, a different approach is chosen here. Because it takes some time to develop a steady cavitation bubble, meaning that the bubble length is not growing anymore, each test speed was maintained for at least 20 minutes before the length was measured. 


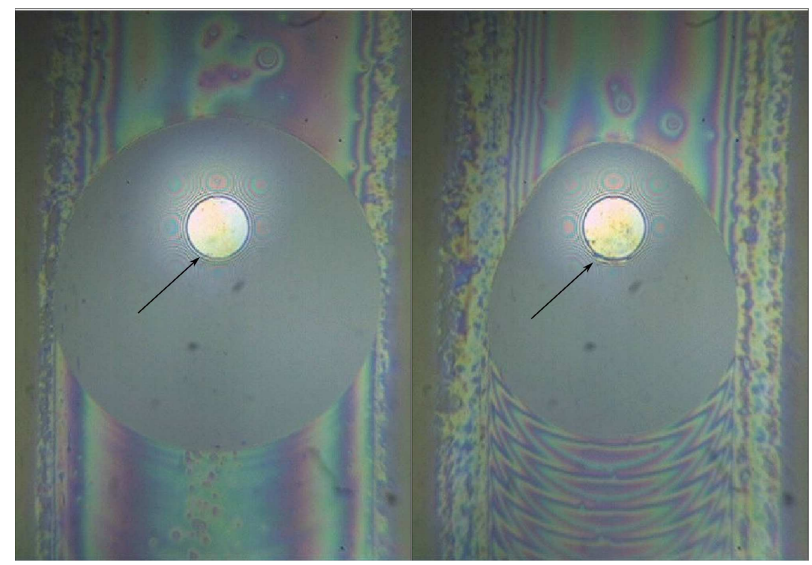

(a)

(b)

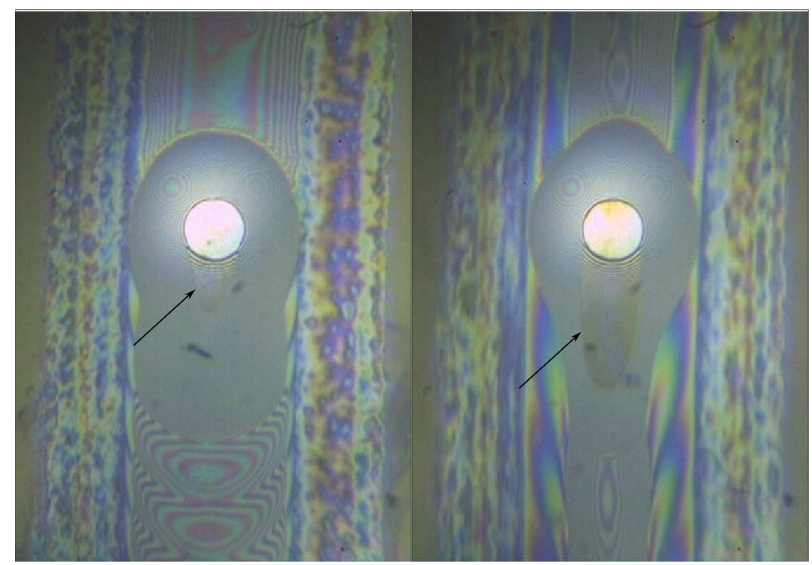

(c)

(d)

Figure 2.4: Optical interferometry images of an EHL contact at low speed. Flow patterns change with increased velocity from (a) to (d), $T=40{ }^{\circ} \mathrm{C}(2.5 \times)$. The velocities vary from approximately $2 \mathrm{~mm} / \mathrm{s}$ to $30 \mathrm{~mm} / \mathrm{s}$. 


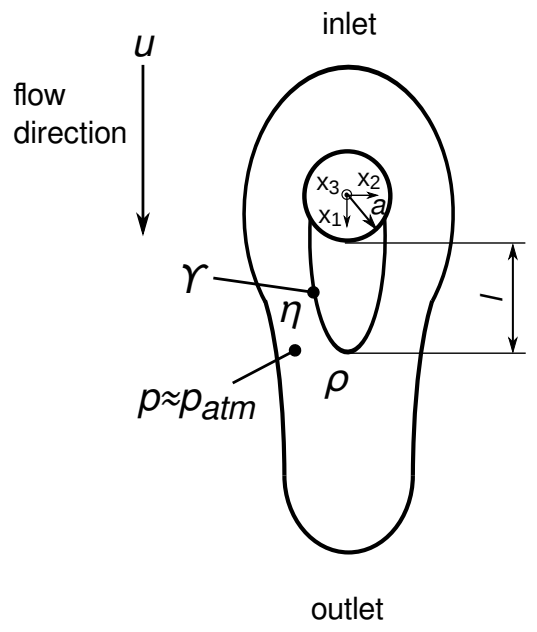

Figure 2.5: Flow around/through the contact with the definition of the cavitation bubble length 1 .

\section{Cavitation bubble length}

The results plotted in figure 2.6 (left) show for each temperature a linear dependence of the bubble length on the rolling velocity, with the steepest curve for the highest viscosity. So, for the same conditions, the length decreases with a decreasing viscosity.
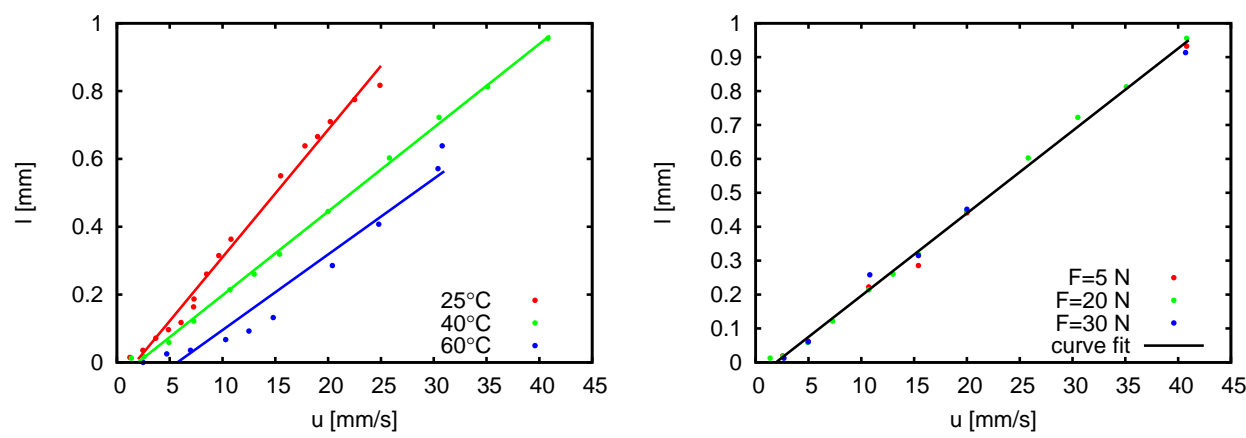

Figure 2.6: Cavitation bubble length versus velocity, temperature and load. Varied velocity and temperature and $F=20 \mathrm{~N}$ (left), varied velocity and loading at $T=40^{\circ} \mathrm{C}$ (right).

The dependence of the length on the load (Hertzian contact radius) is shown in figure 2.6 (right). For $\mathrm{T}=40^{\circ} \mathrm{C}$, the bubble length is measured as a function of the rolling velocity for $\mathrm{F}=5 \mathrm{~N}, 20 \mathrm{~N}$ and $30 \mathrm{~N}$. This implies a Hertzian contact radius of $a=0.086$ $\mathrm{mm}, a=0.137 \mathrm{~mm}$ and $a=0.157 \mathrm{~mm}$ respectively. In the considered low velocity region 
the results show that the bubble length appears to be independent of the load. This is illustrated in more detail by the images shown in figure 2.7.

Because the diameter of the Hertzian contact region increases with increasing load, the contact in the images has been positioned such that the exit of the Hertzian contact occurs at the same location. The tip location of the bubble is then clearly located at the same position. Note that the bubble length is only a $2 \mathrm{D}$ measurement although the cavitation bubble actually is a $3 \mathrm{D}$ phenomenon.

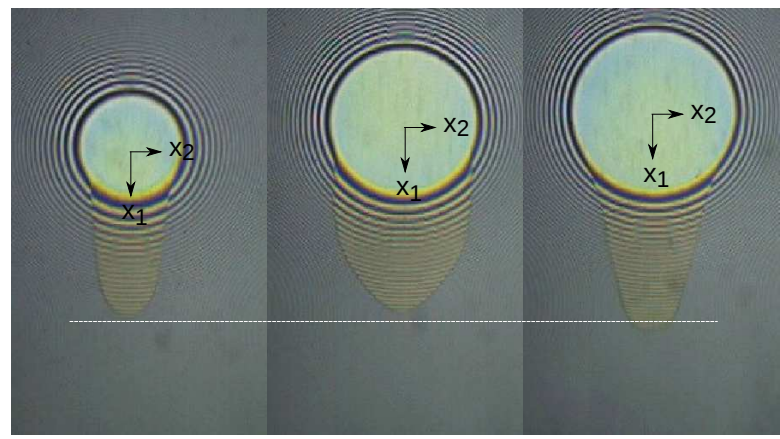

Figure 2.7: Cavitation bubble length for $5 \mathrm{~N}$ (left), $20 \mathrm{~N}$ (middle) and $30 \mathrm{~N}$ (left) and $u=11 \mathrm{~mm} / \mathrm{s}(10 \times$ lens $), T=40^{\circ} \mathrm{C}$.

\section{Bubble stability}

When a contact and the track have been completely wetted before, immediately after the start of rolling a cavitation bubble appears at the outlet side, see section 2.3.3. The bubble length gradually develops with time until a steady shape is attained.

'Stability' tests were performed for various velocities and different amounts of lubricant. In each test, a contact was kept rolling at the same velocity for more than 2 hours, while having a state I flow pattern.

The first test was performed with ample lubricant, the reservoir in the steel pot is filled with HVI60 oil at $40{ }^{\circ} \mathrm{C}$. A rolling velocity of $16.5 \mathrm{~mm} / \mathrm{s}$ and a loading force of $20 \mathrm{~N}$ was used. After 20 minutes, in this case equivalent to approximately 80 disc- and 320 ball revolutions, the cavitation bubble has a length of approximately 2-3 times the Hertzian contact radius.

The second test was performed with a minute amount of oil at $40^{\circ} \mathrm{C}$ and during the test no extra oil was added. A rolling velocity of $7 \mathrm{~mm} / \mathrm{s}$ and a loading force of $20 \mathrm{~N}$ were used. After 20 minutes, in this case equivalent to approximately 34 disc- and 136 ball revolutions the cavitation bubble has a length of approximately the Hertzian contact radius.

Stadler et al. [28], performed experiments with a reciprocating contact. However, in the experiment a constant speed was maintained during a significant part of the motion in each direction as stated to attain a steady state bubble for a short period. The rolling 
velocities considered were $0.02,0.05$ and $0.1 \mathrm{~m} / \mathrm{s}$. The subsequent theoretical/numerical analysis in [28] was carried out assuming a steady state contact. Stadler et al. observed that 'After a short time, the early stage of a cavity would just break through the oil meniscus and an atmospheric pressure can be assumed'. Here however, unlike Stadler [28. claimed, we observe that the cavitation bubble does not break up, it remains in place for the entire duration of the tests. It is safe to say that after 20 minutes of steady rolling the bubble length remains constant.

So, for a state I situation and using both a limited as well as a large amount of lubricant, a stable cavitation bubble is seen fixed at the outlet side of the contact. The bubble length is larger for a higher rolling velocity. For high velocities the bubble could even be very long and influence the inlet of the next contact in a real application e.g. a bearing. Figure 2.8 shows an image of a cavitation bubble present at the outlet side, after more than 20 minutes of steady rolling, for a rolling velocity of $98 \mathrm{~mm} / \mathrm{s}$ for the case of ample lubricant at $\mathrm{T}=40^{\circ} \mathrm{C}$, and a loading force of $20 \mathrm{~N}$. To capture the large bubble length a smaller magnification $2.5 \times$ lens was used. The extent of the complete cavitation bubble shown in the image is more than ' 5 contact area diameters' as is indicated by the white dashed line for clarity.

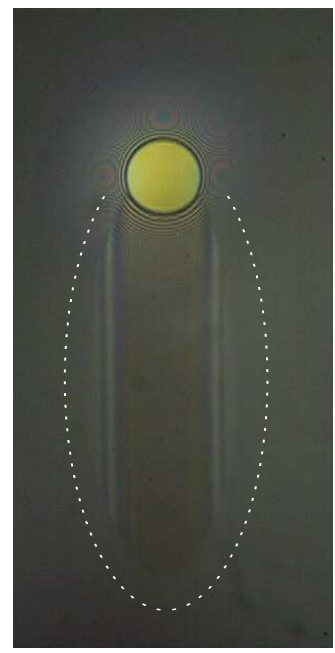

Figure 2.8: Optical interferometry images of an amply lubricated contact $T=40^{\circ} \mathrm{C} u=98$ $\mathrm{mm} / \mathrm{s} F=20 \mathrm{~N}(2.5 \times$ lens $)$.

Summarizing, at high rolling velocities and using enough lubricant a stable cavitation bubble is present at the outlet of the contact. It can have a length exceeding many times the contact diameter, depending on the rolling velocity and lubricant viscosity. Note that a flow pattern in this case can be easily mistaken for a state II pattern when a lens is used with a large magnification, which focusses at the contact area only, and one only observes a small region around the contact. 


\subsubsection{Transition between flow pattern states}

The transitions between the flow patterns of state I and state II are reversible by changing the velocity. The transition depends on the amount of lubricant supplied to the contact, the lubricant viscosity, the surface tension, and the rolling velocity. The amount of lubricant supply depends on the shape and size of the flooded region and the amount of lubricant left behind on the tracks of both the ball and the disc after overrolling. Jacod [32] explains this as replenishment, which is divided into 'out-of-contact' and 'in-contact' reflow.
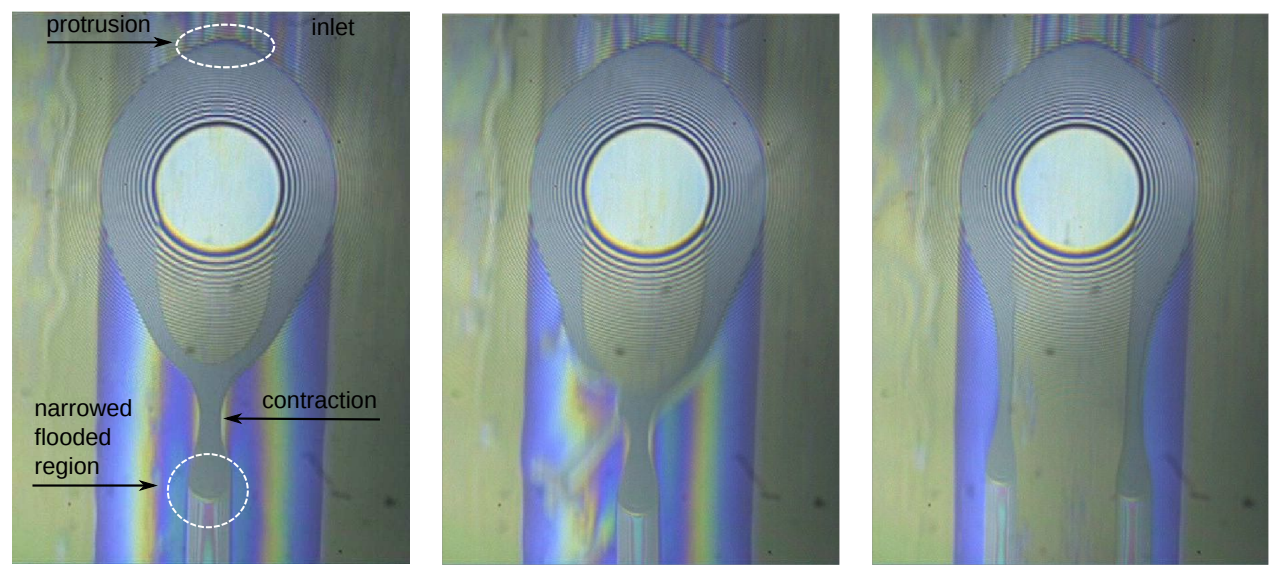

Figure 2.9: Optical interferometry images: transition of state I (left) to II (right), (5× lens).

The images in figure 2.9 show an example of the transition from flow pattern state I to state II. Going from left (state I) to right (state II) the velocity increases and at some point the cavitation bubble breaks. On the left-hand side of the centre image the bubble has opened and the transition initiates. The right image shows the state II flow pattern just after transition, in which the inlet is still supplied by a track formed in the outlet of a state I flow pattern. An extra protrusion is observed upstream to the convex shaped inlet meniscus, see for example the left image in figure 2.9. This extra protrusion is caused by a decreased lateral lubricant supply to the inlet of the flooded region due to a smaller width of the flooded region at the outlet. In the transition-velocity range, the quasi 'equilibrium' is delicate, a minor disturbance such as a dirt particle or surface irregularity on the ball or the disc can induce the transition from flow state I to state II. Reverse transition, from flow state II to I, in general occurs at lower velocities, i.e. there is a hysteresis effect due to the lubricant supply change at the inlet, having a two-track pattern of state II. 


\subsubsection{Starting up and film formation}

A most important and interesting topic is how a film actually starts to build up starting from zero speed, and which conditions affect the film formation process. Recordings were made during the start of rolling: the disc starts to rotate and the ball is taken along under pure rolling conditions. Two cases were examined:

1. Dry start: Before start-up a drop of oil is applied to the ball at a location just in front the clean and dry contact zone. Both ball and disc surfaces were thoroughly cleaned so that no residual oil is present.

2. Wet start: Start-up after the contact has been lubricated before, i.e. it has already been rolling for some time under steady state conditions, and a track exists on ball and disc.

The experiments were repeated several times for different temperatures and final velocities. As may be expected, it takes more time to form a stable film in case of a dry start than for a restart. For the dry start it takes at least one full disc rotation, and a number of ball rotations to form an evenly distributed 'quasi steady' oil track on both the ball and the disc. Eventually, both the wet and dry start conditions lead to the same results.

\section{Start-up from dry contact}

A drop of HVI60 is positioned on the ball in front of the contact. The contact load is set at $\mathrm{F}=20 \mathrm{~N}$ at a pot temperature of $\mathrm{T}=40{ }^{\circ} \mathrm{C}$ and thermal equilibrium is ensured for the setup. From stand still the rolling velocity rapidly increases to $u=7 \mathrm{~mm} / \mathrm{s}$. Figure 2.10 shows images extracted from a movie recorded during the first rotation of the disc. Each of the images corresponds to a different time in the experiment, image (a) before rolling has started, to image ( $\mathrm{t}$ ) taken at approximately about 30 seconds after the rolling has started, which corresponds to 1 disc revolution and 4 ball revolutions. The time interval between the images varies to show the stages of steady flow pattern formation.

The images in figure 2.10 can be described as follows:

(a): At $t=0$ : contact at rest, and no oil present in the contact or in its surroundings. The blue color is associated with the spacer layer thickness.

(b): Rolling: oil on the ball arrives at the inlet on the top from the left side.

(c) to (i): A flooded region is formed around the contact, starting at the inlet. Most of the lubricant is driven around the contact. Only a minute amount enters indicated by the change of color from blue to yellow at some locations in the contact region. The flooded region is not stable as there is no complete track on the ball and the disc yet. The oil mainly stays behind near the position on the ball where it was deposited, and on the disc where the ball and disc touched. It moves downstream and leaves the area close to the contact. 
Chapter 2. Aspects of Flow And CAvitation ARound an EHL COntact

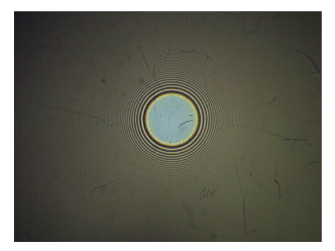

(a) $u=0 \mathrm{~mm} / \mathrm{s}, t=0 \mathrm{~s}$.

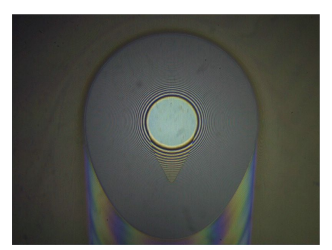

(e)

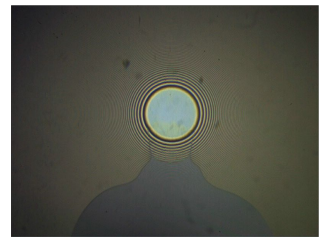

(i)

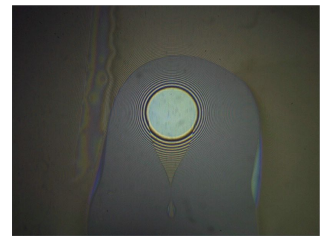

(m)

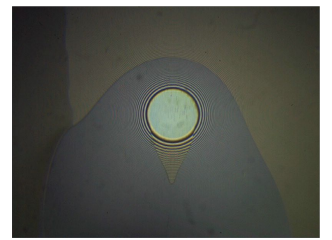

(q)

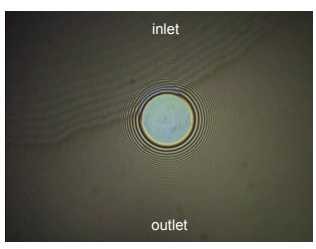

(b)

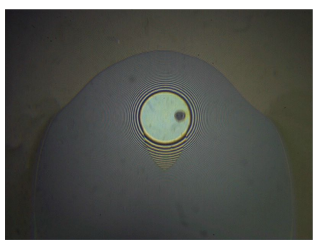

(f)

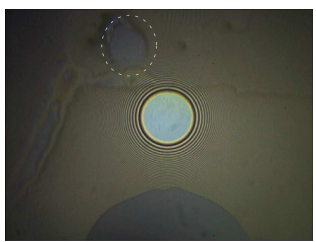

(j)

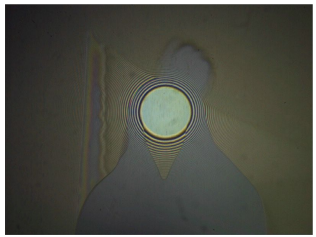

(n)

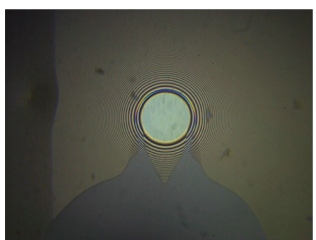

(r)

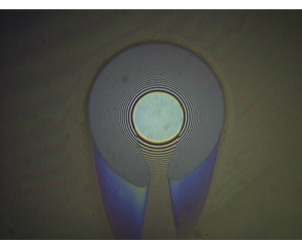

(c)

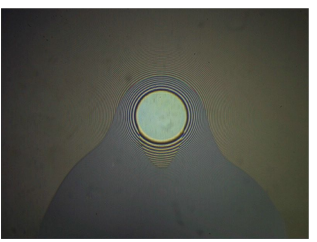

(g)

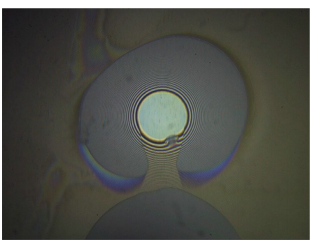

(k)

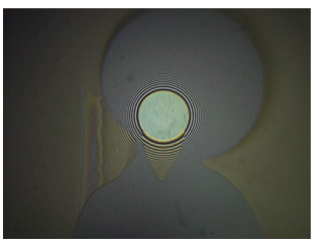

(o)

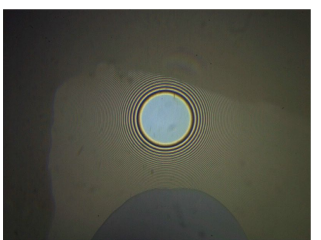

(s)

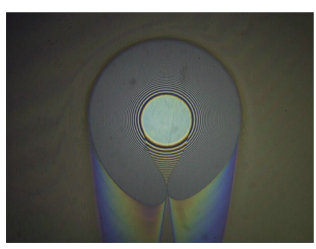

(d)

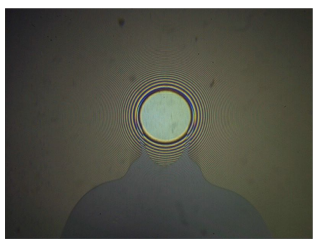

(h)

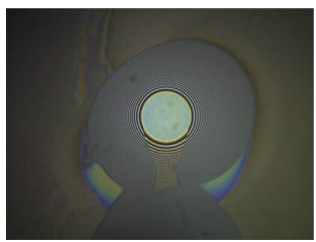

(I)

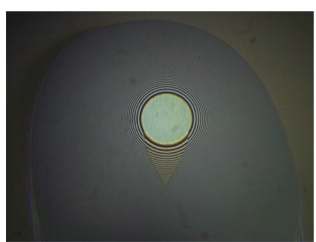

(p)

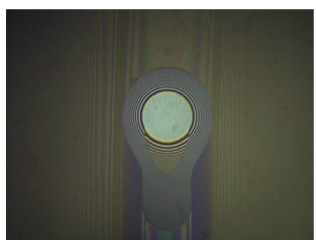

(t) $u=7 \mathrm{~mm} / \mathrm{s}, t \approx 30 \mathrm{~s}$.

Figure 2.10: Dry start to state I flow pattern $u=7 \mathrm{~mm} / \mathrm{s}, F=20 \mathrm{~N}, T=40^{\circ} \mathrm{C}$ (5× lens). 
(j): On top at the left side of the inlet a small drop of oil is trapped and travels towards the inlet side of the contact. This drop is probably left behind in a previous revolution of the ball. Furthermore, despite the moving surfaces of the ball and the disc, the previously unstable flooded region does not move relative to the contact anymore but remains trapped at the outlet side.

(k) to (s): Formation of a closed flooded region as can be seen in (c) to (i). The yellow coloring of the contact indicates more oil enters inside the contact. Oil left behind during the rolling process at the outlet side coagulates with oil supplied at the inlet side.

$(\mathrm{t})$ : An image of flow pattern state $\mathrm{I}$ is starting to take its stable form, after approximately 1 disc revolution and 4 ball revolutions.

\section{Restart}

In contrast to a dry start-up, for a previously lubricated contact, a stable flow pattern is formed much faster from the start of rolling, see the images in figure 2.11. During the start-up from rest, immediately a small cavitation bubble appears at the outlet side of the Hertzian contact region. This is due to a small pool of oil already present around the contact as well as a deposited track on ball and disc. The bubble further develops in time to a steady bubble.

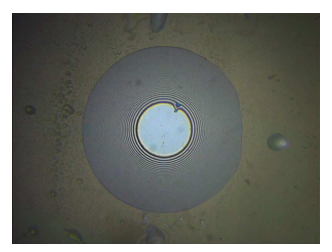

(a) $u=0 \mathrm{~mm} / \mathrm{s}, t=0 \mathrm{~s}$.

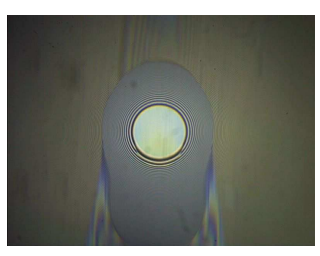

(b) $t=0.2 \mathrm{~s}$

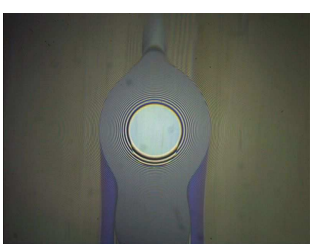

(c) $t=0.8 \mathrm{~s}$

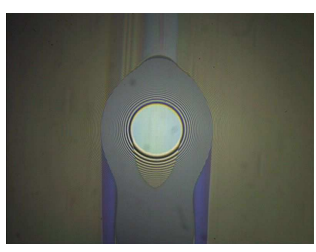

(d) $u=7 \mathrm{~mm} / \mathrm{s}, \quad t>20$ min.

Figure 2.11: Restart to state I flow pattern $u=7 \mathrm{~mm} / \mathrm{s}, F=20 \mathrm{~N}, T=40^{\circ} \mathrm{C}(5 \times$ lens). 


\subsubsection{Film breakdown}

The probability of local dry contact between the moving surfaces increases when the film thickness level decreases. This can lead to unwanted damage of the moving surfaces, and unexpected failure in engineering applications. Film breakdown is an important phenomenon to study. In particular more knowledge is needed about the physics of the transition between lubrication regimes (mixed lubrication).

Film breakdown occurs when the lubricant supply becomes too low, e.g. due to insufficient replenishment time between overrollings (higher speeds), decreasing lubricant viscosity (increasing temperature), dirt or foreign particles in the lubricant, surface roughness, and by abruptly stopping the motion.

In this section the influence of a sudden stop on a steady rolling contact is shown for a steady state I flow pattern.

After the disc has stopped abruptly, an island of oil, indicated by the yellow colored region in the Hertzian contact zone, is trapped inside the contact, see figure 2.12. This island slowly disappears by squeeze effects in time, Peiran et al. [48], i.e. the oil is leaked to the flooded region surrounding the Hertzian contact. This particular behaviour was studied previously in e.g. see [49, 50, 51] and [40] and references therein. Simultaneously, the flooded region around the contact becomes circular due to reflooding, Jacod [32], and is held together by the surface tension.

Figure 2.12 shows images taken after a sudden stop at a rolling velocity $u=8 \mathrm{~mm} / \mathrm{s}$, of a contact operating at room temperature with a load of $F=20 \mathrm{~N}$. In each image the dotted circle indicates a marker on the disc. This can be used to see the movement of the contact: the ball slightly reverses (inertia) after the sudden stop of the disc. Some additional marks are added to the images to emphasize certain phenomena.

After the disc has stopped, the cavitation bubble at the outlet side of the contact breaks up in one or more separate bubbles, decreasing in size when moving towards the outlet meniscus of the flooded region. Simultaneouly, reflow of oil in the region around the contact takes place, modifying the flooded region into a circular region.

The images in figure 2.12 can be described as follows:

(a): Steady state. A cavitation bubble is located at the outlet side of the contact.

(b): Sudden stop by halting the disc. The dark spot in the upper right quadrant of the contact is an impurity in the oil or on the ball or disc.

(c): The oil closes at the outlet side of the contact starting to drive the cavitation bubble out of the flooded region. The bubble reduces in width and at the tip a small separation bubble is to be formed. Note that the position of the contact relative to the disc has not changed, both the location of the impurity within the contact and the marker on the left are unchanged.

(d): The cavitation bubble narrows, the newly formed bubble at the tip grows and starts to move in the downstream direction. Both the location of the impurity in the contact and the marker are moved upstream, which means that the ball has slightly 
reversed. This is confirmed by the cavitation bubble that immediately has developed at the original inlet side of the contact.

(e): The cavitation bubble moves through the flooded region towards the meniscus on the outlet side. The marker has moved further upstream, and the cavitation bubble on the original inlet side of the contact grows.

(f): See the desription of (e). Oil trapped in the Hertzian contact zone is clearly visable as a yellow region, marked with the black dotted line.

(g) and (h): The ball is at rest, i.e. there is no further motion of the marker. The trapped oil is distributed over the contact region, and the redistribution of oil of the flooded region is clearly visable in the shape of the meniscus. The remainder of the cavitation bubble has almost reached the meniscus at the outlet side of the flooded region. The cavitation bubble at the original inlet side disappears.

(i) All cavitation bubbles have disappeared, the flooded region is almost circular shaped and the oil trapped in the Hertzian contact slowly spreads by squeeze effects. 
Chapter 2. Aspects of Flow And CAvitation ARound an EHL COntact

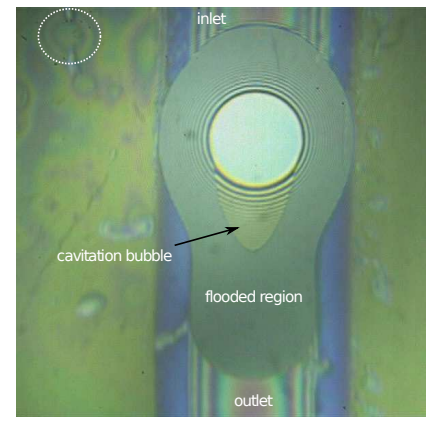

(a) $t<0$ : Steady rolling.

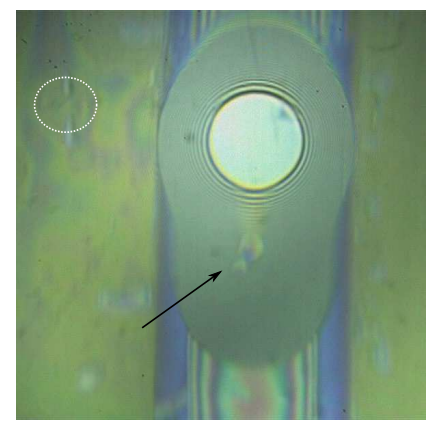

(d) $t=0.0067 \mathrm{sec}$.

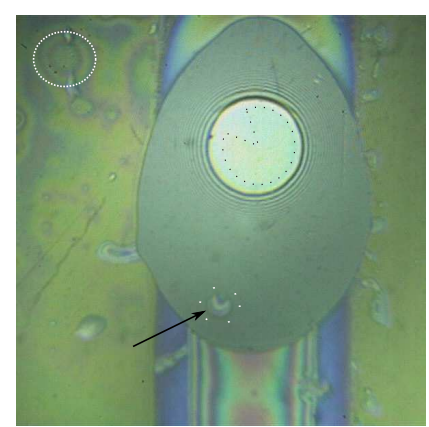

(g) $t=0.02 \mathrm{sec}$.

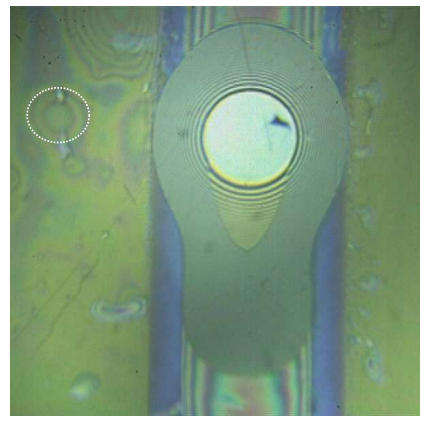

(b) $t=0$ : Sudden stop.

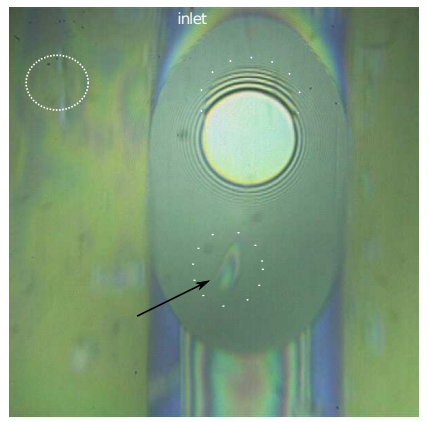

(e) $t=0.01 \mathrm{sec}$.

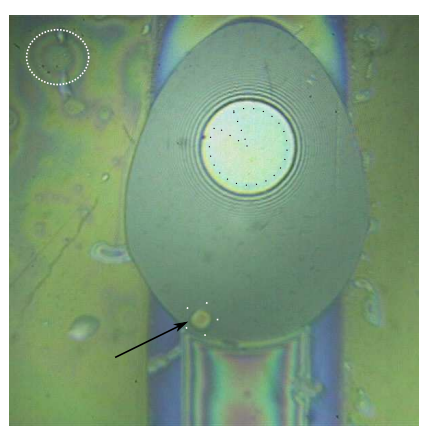

(h) $t=0.0367 \mathrm{sec}$.

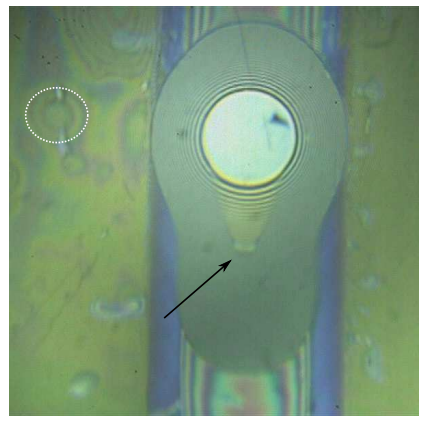

(c) $t=0.0033 \mathrm{sec}$

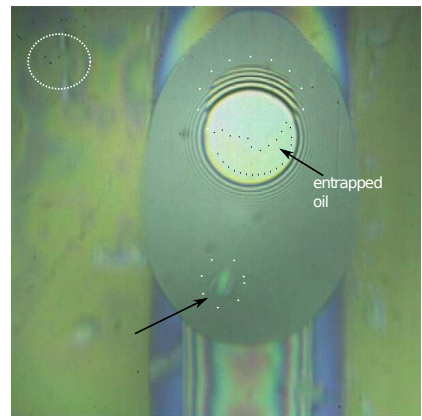

(f) $t=0.013 \mathrm{sec}$.

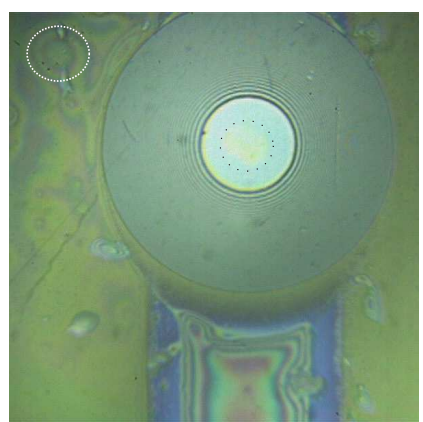

(i) $t=4.417 \mathrm{sec}$.

Figure 2.12: Sudden stop from state $I, u=8 \mathrm{~mm} / \mathrm{s}$ at $t=0, F=20 \mathrm{~N}, T=22{ }^{\circ} \mathrm{C}(5 \times$ lens), 300 fps. 


\subsection{Theoretical results}

\subsubsection{Dimensional analysis}

The experimental results of section 2.3.1 and the Buckingham Pi theorem [52, 53], can be used to describe the dimensionless length of the cavitation bubble, $l / a$, as a function of several dimensionless parameters.

As shown in appendix $A$, the physics of the cavitation bubble are defined by 6 variables: $u$, the velocity in the $x_{1}$-direction, $a$ the Hertzian contact radius, $\eta$ the dynamic lubricant viscosity, $\Delta p=p_{a t m}-p_{\text {cav }}$, and $\gamma$ the surface tension. The dimensionless parameters that can be formed are the Reynolds number, $\mathcal{R} e$, Cavitation number, $\mathcal{C} a$, and the Weber number, $\mathcal{W} e$. The functional relation for $l / a$ that fits the experimental results reads:

$$
\frac{l}{a}=\mathcal{C}_{1}\left(\mathcal{R} e^{-\frac{1}{2}}\left(\frac{\mathcal{C} a}{2}\right)^{-\frac{5}{4}} \mathcal{W} e^{-\frac{1}{2}}\right)+\mathcal{C}_{2}
$$

with $\mathcal{C}_{1}$ and $\mathcal{C}_{2}$ two constants.

In figure 2.13 the experimental values are substituted and plotted in the dimensionless form as found in equation (2.1). This figure shows that the experimental values agree very well with the relation found.

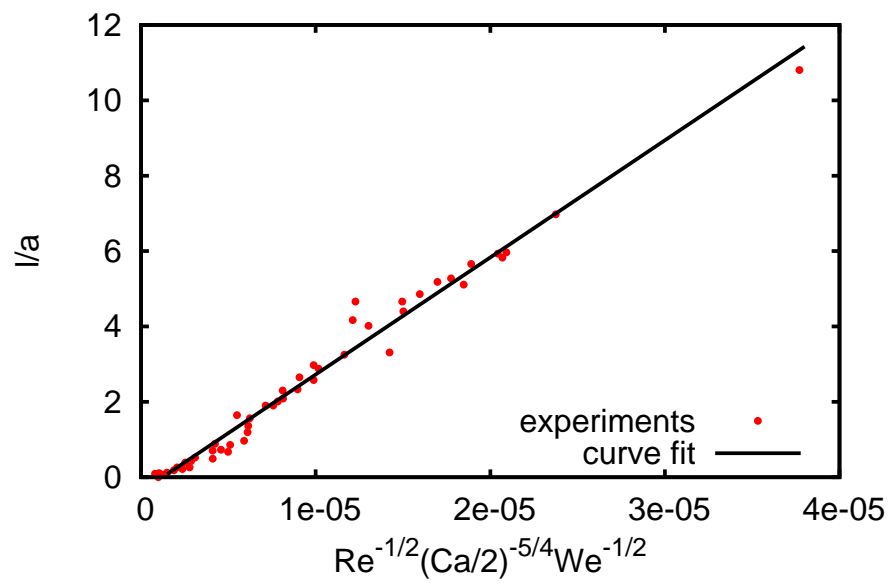

Figure 2.13: Dimensionless relation for the ratio of cavitation bubble length and Hertzian contact radius, versus the combination of the dimensionless numbers $\mathcal{R} e, \mathcal{C} a$ and $\mathcal{W} e$.

In the region considered, the cavitation number, $\mathcal{C} a$ has the highest value which is of order $\mathcal{O}\left(10^{5} \ldots 10^{8}\right)$, followed by the Reynolds number, $\mathcal{R} e$ which is of order $\mathcal{O}\left(10^{-3} \ldots 10^{-1}\right)$, and the Weber number, $\mathcal{W} e$ is of order $\mathcal{O}\left(10^{-6} \ldots 10^{-3}\right)$.

Relation (2.1) is relatively simple compared to the dimensionless cavity length equation found by Stadler et al. [28]. 


\subsubsection{Discussing the effects contributing to cavitation}

To investigate some aspects contributing to the formation of the cavitation bubble a preliminary theoretical study has been done using results of numerical computations with a modified EHL model. In the literature various cavitation modeling approaches have been taken, see e.g. Bayada and Chupin [54] and Bruyere et al. [55].
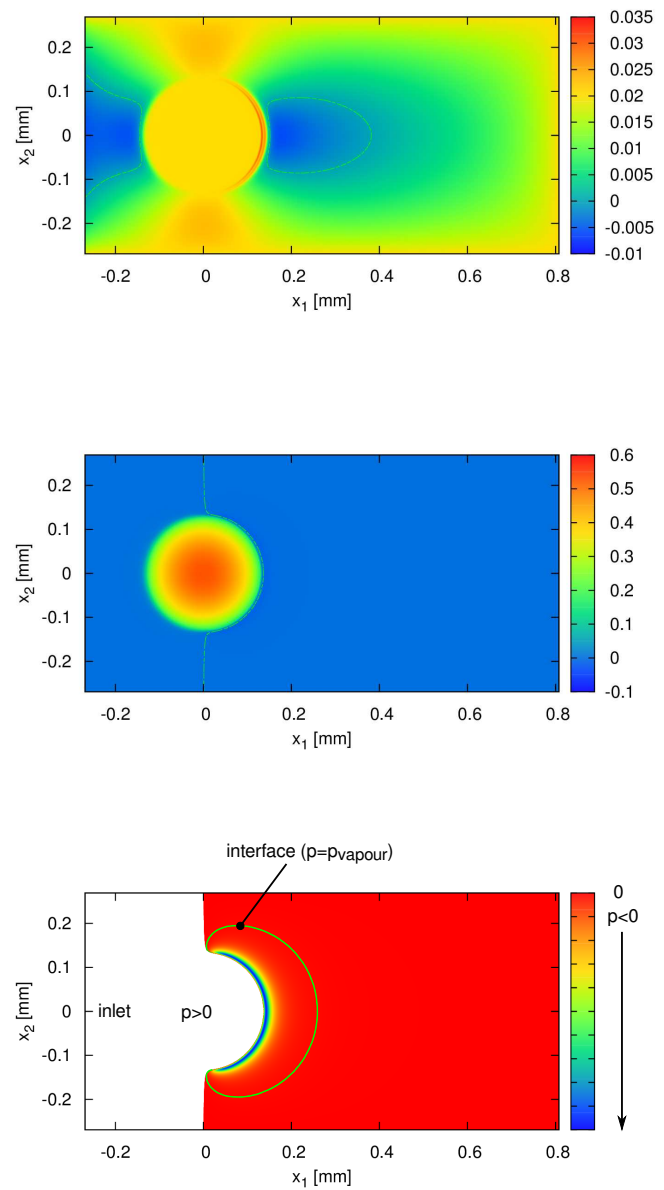

Figure 2.14: The lubricant velocity distribution, $u_{1}$, at $x_{3}=0.5 h$ (top), the pressure distribution (centre) and the pressure region with subambient pressure (bottom), for a rolling velocity of $0.02 \mathrm{~m} / \mathrm{s}$, a loading of $20 \mathrm{~N}$ and a temperature of $25^{\circ} \mathrm{C}$. 
The model equations are shown in appendix $\mathrm{B}$. The cavitation restriction on the pressure is removed and a Neumann pressure boundary condition is imposed at the outlet boundary of the computational domain, i.e. the pressure gradient with respect to the $x_{1}$ direction is zero at the outlet. To mimic oil-vapour behaviour, an elementary two phase model is used incorporated in the pressure-density relation. The density of the oil (vapour) strongly decreases in case of pressures below atmospheric pressure, see van Emden [56] for more details. Note that surface tension effects are still not accounted for in the used model.

The conditions considered are a rolling velocity of $0.02 \mathrm{~m} / \mathrm{s}$, a loading of $20 \mathrm{~N}$ and a temperature of $25^{\circ} \mathrm{C}$. A computational domain is used with $x_{1} \in[-2 a, 6 a]$ and $x_{2} \in$ $[-2 a, 2 a]$. The numerical method uses a $2^{n d}$ order accurate finite difference approximation on a uniform grid. The equations are solved using a multigrid algorithm, see Venner and Lubrecht [2], with $3073 \times 6145$ grid points on the finest grid level. In a post-processing step, from the pressure and film thickness solution the vertical velociy $u_{3}$ was obtained by integration of the continuity equation over $x_{3} \in\left[0, h\left(x_{1}, x_{2}\right)\right]$, for more details see van Emden [56]. This was done on a grid with 101 grid points across the film thickness. This calculation of $u_{3}$ allows us to investigate the complete velocity field, the shear stresses and show streamlines between the ball and the disc.

The lubricant velocity profile, $u_{1}$, at $x_{3}=0.5 h$ and the pressure distribution, $p\left(x_{1}, x_{2}\right)$, are shown in figure 2.14 together with the figure showing the negative relative pressure region as predicted by the modified EHL model. A cavitation bubble is predicted but its length is much smaller than the bubble length observed in the experiments. The numerical calculation yields a length ratio of $l / a \approx 0.9$ whereas the experiments yield a value of $l / a \approx 5$. A potential explanation for the discrepancy in bubble length between the experimental- and numerical results is given at the end of this section.

In figure 2.15 some streamlines are shown, colored by the local pressure. One can now follow an oil volume (particle) traveling along the streamline marked as (1), which lies in the plane $x_{2}=0$.

We now follow a particle along a streamline. The pressure, gap height and velocity component $u_{1}$ experienced by the volume of oil following streamline (1) (figure 2.15), are shown in figure 2.16 with important regions and condition changes marked by the capital letters $A$ to $E$, different regions that can be identified are characterized as follows:

A: A low viscous oil particle located in the flooded region between the ball and disc is trapped inside the rolling contact region at the inlet side. The pressure starts to build up and the velocity $u_{1}$ equals the ball and disc velocity, it is approximately uniform over the film thickness.

A-B: The volume is pulled through the contact region from the inlet side towards the center, by the rolling movement of ball and disc. During this passage the volume is subjected to an increasing pressure up to the maximal value reached in B. Consequently, the oil viscosity increases as well, such that the oil volume behaves as a solid layer with an approximately constant thickness in the $x_{1}$ direction. The velocity distribution $u_{1}$ from $\mathrm{A}$ to $\mathrm{B}$ equals the ball and disc velocity and is uniform 
over the film thickness.

B-C: The pressure in the volume decreases and so does the oil viscosity. The velocity distribution $u_{1}$ remains uniform as the case in $\mathrm{A}-\mathrm{B}$, and the film thickness for $x_{2}=0$ in the $x_{1}$ direction remains constant until it has reached $\mathrm{C}$. Just before it arrives $\mathrm{C}$ the pressure in the volume quickly increases to a local maximum, the pressure spike, and consequently the viscosity as well.

C-D: When the volume travels from $C$ to $D$ the pressure quickly drops, and consequently the oil viscosity too. At $C$ the gap narrows and in $D$ the minimal film thickness is reached. In the narrowed gap C-D the velocity $u_{1}$ is maximal, it is non-uniform in the $x_{3}$-direction. At $x_{3}=0$ and $x_{3}=h$ the velocity equals the disc and ball velocity respectively. In between the velocity increases to high values, upto 1.5 times the rolling velocity, owing to mass conservation. This implies that the fluid is actually ejected from the contact.

D-E: From $D$ to $E$ the gap widens and the pressure to which the volume is subjected further decreases, together with the viscosity. The deformed contact region approximately ends at $\mathrm{E}$. Near by $\mathrm{D}$ the velocity $u_{1}$ is still as high as experienced in the converging gap, then it decreases to a value still higher than the disc and ball velocity. The highly viscous 'solid' layer upstream the volume, pushes the much lower viscous volume towards the outlet side.

$\mathrm{E}$ : When the volume passes $\mathrm{E}$ the pressure becomes negative, reaching values below the vapour pressure. The velocity $u_{1}$ has decreased compared to the velocity in the narrowed gap, still in the film it is a bit higher than the velocity of the ball and the disc. Further downstream the velocity rapidly decreases, even to negative values, and recirculation takes place, inside the negative pressure region.

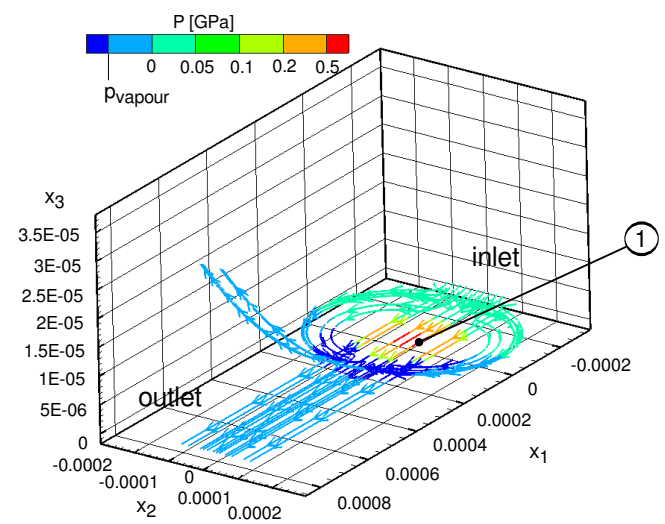

Figure 2.15: Streamlines with pressures, for a rolling velocity of $0.02 \mathrm{~m} / \mathrm{s}$, a loading of $20 \mathrm{~N}$ and a temperature of $25^{\circ} \mathrm{C}$. 

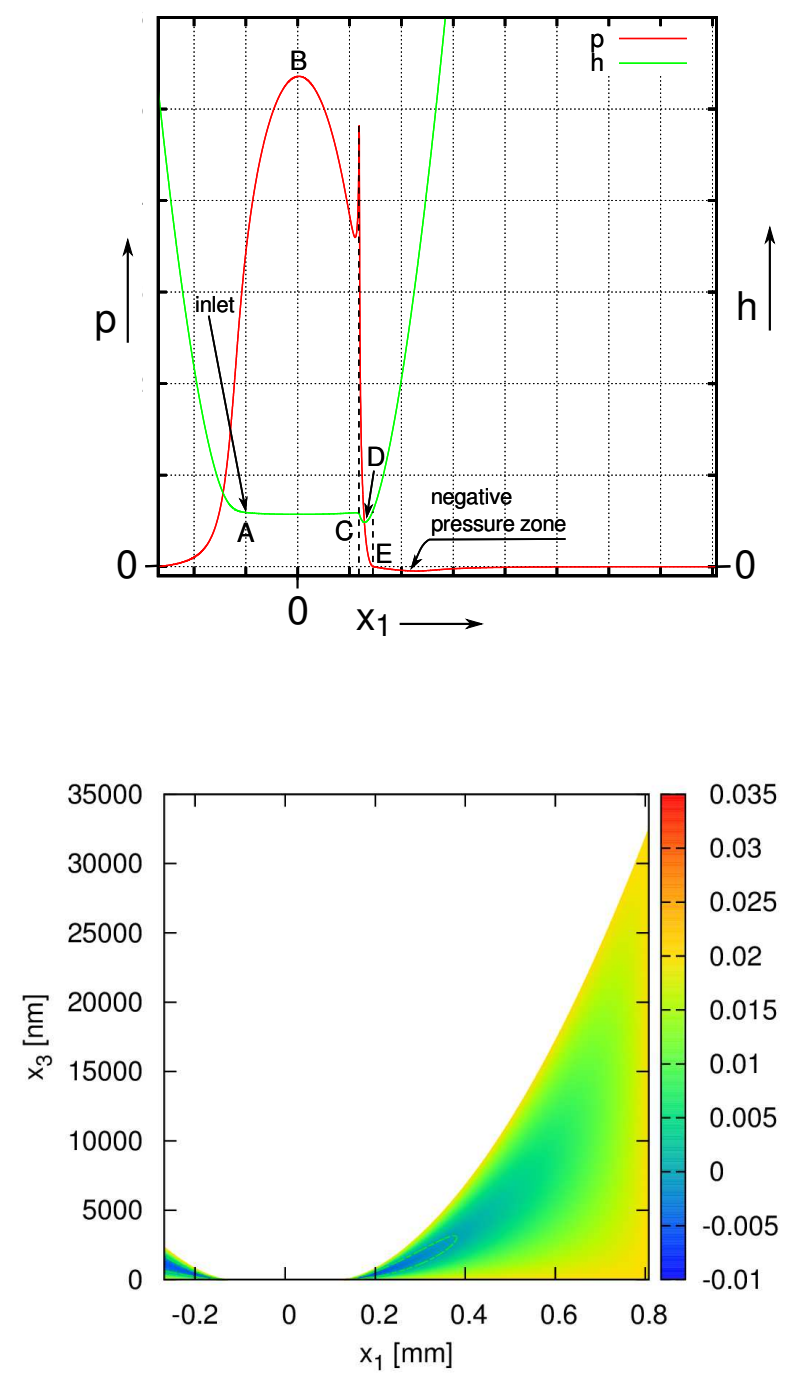

Figure 2.16: Generic sketch of pressure and film distribution (top). The lubricant velocity distribution $u_{1}$ (bottom), for $x_{2}=0$ and a rolling velocity of $0.02 \mathrm{~m} / \mathrm{s}$, a loading of 20 $\mathrm{N}$ and a temperature of $25^{\circ} \mathrm{C}$.

With equation (2.2), the shear stress components can be calculated.

$$
\tau_{i j}=\eta\left(\frac{\partial u_{i}}{\partial x_{j}}+\frac{\partial u_{j}}{\partial x_{i}}\right) \quad i \neq j
$$


The highest values of shear stress are found for $\tau_{13}\left( \pm \mathrm{O}\left(4.4 \cdot 10^{-4}\right) \mathrm{GPa}\right)$, followed by $\tau_{23}$ and $\tau_{12}$. The shear stress components $\tau_{12}$ and $\tau_{23}$ are zero in the plane $x_{2}=0$. The shear stress component $\tau_{13}$ is zero for $x_{3}=0.5 \mathrm{~h}$. In figure 2.17 the shear stress distribution $\tau_{13}$ is plotted together with some streamlines for the outlet region in the plane $x_{2}=0$.
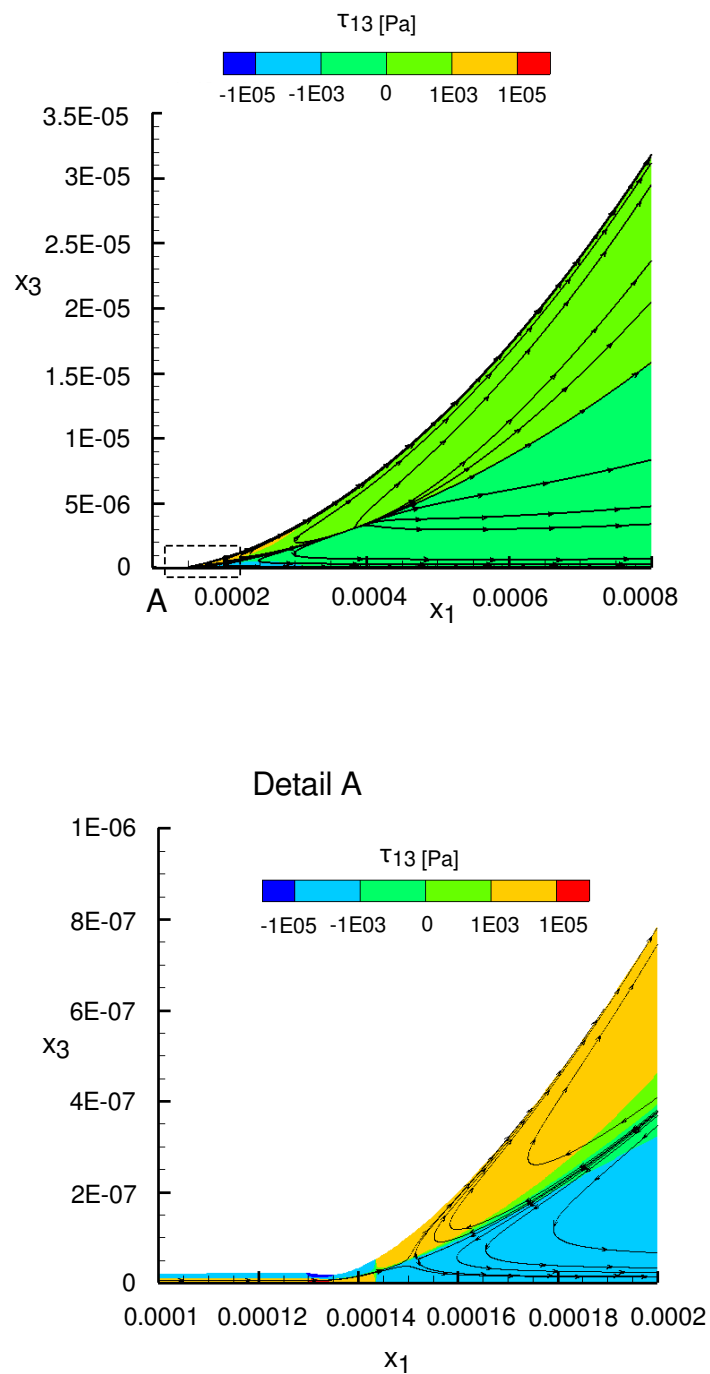

Figure 2.17: Shear stress $\tau_{13}$ with streamlines at the outlet side in $x_{2}=0$, for a rolling velocity of $0.02 \mathrm{~m} / \mathrm{s}$, a loading of $20 \mathrm{~N}$ and a temperature of $25^{\circ} \mathrm{C}$. 
Kottke et al. [57] and Padrino et al. [58] use a cavitation criterion referred to as, 'Principal Normal Stress Cavitation Criterion' (PNSCC), to indicate the likely regions for cavitation to occur. The principal stesses, in an incompressible Newtonian fluid are calculated by determination of the eigenvalues of the stress tensor. Then the highest eigenvalue is compared to the cavitation pressure, usually taken equal to the vapour pressure. The maximum tension theory states that the lubricant will cavitate under the condition that when the cavitation pressure added to the maximum of the 3 principal stresses must be larger than 0 .

In our calculation, only the pressures are used as a measure. However, since the maximum shear stresses are high, cavitation may well be induced by negative pressures as well as by shear stresses. This may explain why the bubble length is much longer in reality than predicted by the numerical method.

\subsection{Conclusion}

Two steady flow pattern states are observed in experiments using an optical interferometry apparatus for an oil lubricated ball-and-disc configuration during steady rolling. The appearing state depends on the rolling speed and the lubricant supply conditions. In this paper the state was studied in which the flooded region envelops the entire contact area. Inside the flooded area on the outlet side of the Hertzian contact region a cavitation bubble is present. The cavitation bubble length grows with the rolling velocity and increased (square root) lubricant viscosity and was observed to be independent of the Hertzian contact radius (load) in the considered low velocity region. A function has been formulated relating the ratio of cavitation bubble length and Hertzian contact radius to a combination of the Reynolds, cavitation and Weber number. Numerical results show that the appearing maximal shear stresses are high. Cavitation may well be induced by both negative pressures (pressures below vapour pressure) as well as by shear stresses. The theoretical models predict much shorter bubbles than experiments show. Therefore more research on bubble formation and cavitation modeling is needed.

In case a surface is wetted before, the formation of a flow pattern will be accelerated compared to the case of starting from a dry situation. However, both types of start-up, dry or wetted, eventually lead to similar flow patterns.

Irrespective of the flow pattern, when the movement of the disc stops an island of oil is trapped inside the Hertzian contact region. The trapped oil in the contact slowly spreads by squeeze effects. The flooded region becomes circular shaped with the Hertzian contact region in its center due to surface tension of the oil. After a sudden stop the cavitation bubble at the outlet side of the contact (state I) breaks up in one or more smaller bubbles leaving the flooded region through the outlet meniscus. 


\section{Nomenclature}

\begin{tabular}{|c|c|}
\hline$F$ & loading force \\
\hline$R$ & radius of ball \\
\hline$E^{\prime}$ & reduced modulus of elasticity \\
\hline$E_{\text {ball }}, E_{\text {plate }}$ & modulus of elasticity of ball and plate respectively \\
\hline$\nu_{\text {ball }}, \nu_{\text {plate }}$ & Poisson's ratio of ball and plate respectively \\
\hline$a$ & Hertzian contact radius $a=\left(\frac{3 F R}{2 E^{\prime}}\right)^{\frac{1}{3}}$ \\
\hline$p_{H}$ & Hertzian contact pressure $p_{H}=\frac{3 F}{2 \pi a^{2}}$ \\
\hline$l$ & cavitation bubble length \\
\hline$T$ & temperature \\
\hline$t$ & time \\
\hline$u_{1}, u_{2}, u_{3}$ & lubricant velocities in $x_{1^{-}}, x_{2^{-}}, x_{3^{-}}$direction respectively \\
\hline$u$ & rolling velocity \\
\hline$u_{\text {ball }}, u_{\text {plate }}$ & velocity of ball and plate respectively \\
\hline$p$ & pressure \\
\hline$\eta$ & dynamic viscosity of lubricant \\
\hline$\eta_{0}$ & temperature dependent viscosity at atmospheric pressure \\
\hline$p_{0}$ & pressure constant \\
\hline$z$ & pressure viscosity index \\
\hline$\rho$ & density of lubricant \\
\hline$\rho_{0}$ & density of lubricant at atmospheric pressure \\
\hline$\gamma$ & surface tension of lubricant \\
\hline$p_{\text {cav }}$ & cavitation pressure of lubricant \\
\hline$p_{a t m}$ & atmospheric pressure \\
\hline$\Delta p$ & pressure difference $\Delta p=p_{a t m}-p_{c a v}$ \\
\hline$h$ & film thickness \\
\hline$h_{0}$ & mutual approach \\
\hline$f$ & undeformed geometry \\
\hline$d$ & elastic deformation \\
\hline$\tau$ & shear stress \\
\hline $\mathcal{R} e$ & dimensionless Reynolds number \\
\hline $\mathcal{C} a$ & dimensionless cavitation number \\
\hline $\mathcal{W} e$ & dimensionless Weber number \\
\hline
\end{tabular}




\section{Appendix A: Dimensional analysis}

The Buckingham Pi theorem [52, 53], is used for a dimensional analysis. With 7 dimensional parameters involved, see figure [2.5 and 3 primary dimensions $[\mathrm{m}],[\mathrm{kg}]$ and $[\mathrm{s}], 4$ $\Pi$-groups can be found. The physics of the cavitation bubble can be described as:

$$
l=\mathcal{F}(u, a, \eta, \rho, \Delta p, \gamma)
$$

with $u$ the velocity in the $x_{1}$-direction, $a$ the Hertzian contact radius, $\eta$ the dynamic lubricant viscosity, $\Delta p=p_{a t m}-p_{c a v}$, and $\gamma$ the surface tension. Note that the Hertzian contact radius, $a$, is a result of the loading force $F$, the ball radius $R$ and the reduced modulus of elasticity $E^{\prime}$. Although the latter three parameters are left out of this analysis, their influence appears in $a$.

The velocity, the Hertzian contact radius and oil viscosity in equation (2.3) are selected as repeating parameters. Application of the Buckingham $\mathrm{Pi}$ theorem then yields the following П-groups, or non-dimensional parameters.

The first $\Pi$-group reads:

$$
\Pi_{1}=\frac{l}{a}
$$

The second $\Pi$-group reads:

$$
\Pi_{2}=\frac{\rho u a}{\eta}=\mathcal{R} e
$$

$\Pi_{2}$ is the Reynolds number based on the contact radius. It represents the ratio of inertia forces to viscous forces in the flow around the contact.

The third П-group reads:

$$
\Pi_{3}=\frac{a \Delta p}{u \eta}=\frac{1}{2} \mathcal{C} a \mathcal{R} e
$$

$\Pi_{3}$ is a combination of the cavitation number, $\mathcal{C} a$, and the Reynolds number. This combination gives the ratio of pressure forces to viscous forces. The cavitation number is defined as:

$$
\mathcal{C} a=\frac{\Delta p}{\frac{1}{2} \rho u^{2}}
$$

and represents the ratio of pressure forces to inertia forces.

Finally, the fourth $\Pi$-group reads:

$$
\Pi_{4}=\frac{\gamma}{u \eta}=\frac{\mathcal{R} e}{\mathcal{W} e}
$$

Again a combination of known dimensionless parameters can be recognized, the Reynolds number and the Weber number. This combination gives the ratio of surface tension force and viscous force. The Weber number is defined as:

$$
\mathcal{W} e=\frac{\rho u^{2} a}{\gamma}
$$


and represents the ratio of inertial forces to surface tension forces.

Having determined all non-dimensional groups, the functional relation for equation (2.3) now reads:

$$
\frac{l}{a}=\mathcal{F}\left(\mathcal{R} e, \frac{1}{2} \mathcal{C} a \mathcal{R} e, \frac{\mathcal{R} e}{\mathcal{W} e}\right)
$$

During the experiments 3 parameters are varied, the velocity $u$, the dynamic viscosity $\eta$ and the load which is expressed in the contact radius $a$.

When the ratio of cavitation bubble length and Hertzian contact radius is plotted versus the ratio of the squared viscosity multiplied by the velocity and Hertzian contact radius the graphs in figure 2.6 can be combined, and a linear dependence of $\frac{l}{a}$ and $C \frac{u \sqrt{\eta}}{a}$ can be recognized, see figure 2.18 .

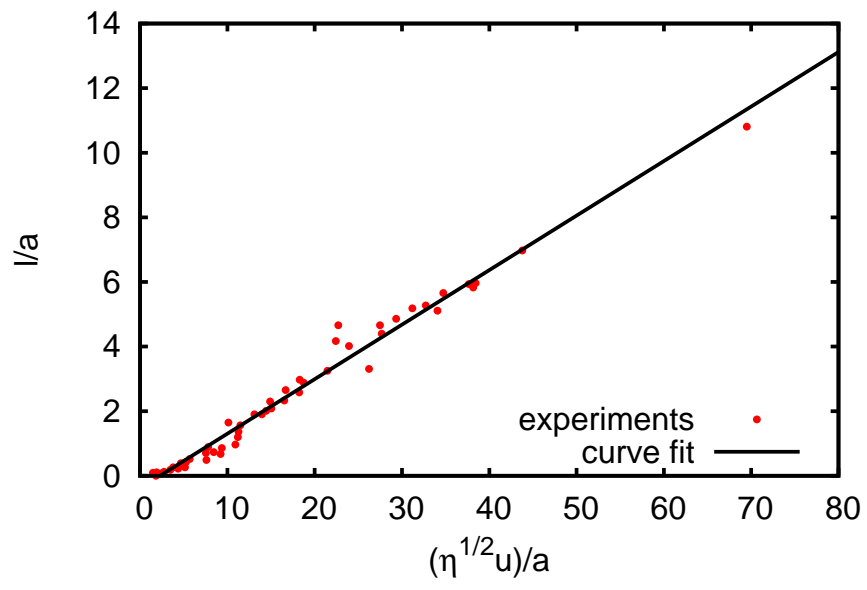

Figure 2.18: Ratio of cavitation and Hertzian contact radius, versus the combination of velocity, viscosity and Hertzian contact radius.

The function $\mathcal{F}$ in equation (2.8) can be determined by using the experimental results. Constant values for the oil density, the surface tension and the pressure drop can be assumed. These assumptions are allowed since these values hardly change in the considered temperature- and velocity regime. This leaves the velocity $u$, the viscosity $\eta$ and the contact radius $a$ as variables. The dimensionless relations can now be substituted by the simplified dimensionfull relations:

$$
\begin{aligned}
\frac{\rho u a}{\eta} & \rightarrow \frac{u a}{\eta} \\
\frac{a \Delta p}{u \eta} & \rightarrow \frac{a}{u \eta} \\
\frac{\gamma}{u \eta} & \rightarrow \frac{1}{u \eta}
\end{aligned}
$$


By determing the exponents $b, c$ and $d$ of:

$$
\left(\frac{u a}{\eta}\right)^{b}\left(\frac{a}{u \eta}\right)^{c}\left(\frac{1}{u \eta}\right)^{d}=\eta^{\frac{1}{2}} u^{1} a^{-1}
$$

the associated functional relation is found,

$$
\frac{l}{a}=\mathcal{C}_{1}\left(\mathcal{R} e^{\frac{1}{4}}\left(\frac{1}{2} \mathcal{C} a \mathcal{R} e\right)^{-\frac{5}{4}}\left(\frac{\mathcal{R} e}{\mathcal{W} e}\right)^{\frac{1}{2}}\right)+\mathcal{C}_{2}
$$

with $\mathcal{C}_{1}$ and $\mathcal{C}_{2}$ two constants. Equation 2.10 can be rewritten into:

$$
\frac{l}{a}=\mathcal{C}_{1}\left(\mathcal{R} e^{-\frac{1}{2}}\left(\frac{\mathcal{C} a}{2}\right)^{-\frac{5}{4}} \mathcal{W} e^{-\frac{1}{2}}\right)+\mathcal{C}_{2}
$$




\section{Appendix B: Model equations}

A standard EHL model is employed, with 3 model equations (2.12), (2.16) and (2.17) and 2 constitutive relations (2.18) and (2.20) describing the material properties of the lubricant. The cavitation restriction on the pressure, which is usually applied in EHLmodeling, is removed. This means that negative values for the gauge pressure are allowed.

The film thickness equation:

$$
h\left(x_{1}, x_{2}\right)=h_{0}+f\left(x_{1}, x_{2}\right)+d\left(x_{1}, x_{2}\right)
$$

$f\left(x_{1}, x_{2}\right)$ is the undeformed geometry of the circular contacting surfaces:

$$
f\left(x_{1}, x_{2}\right)=\frac{x_{1}^{2}}{2 R}+\frac{x_{2}^{2}}{2 R}
$$

The elastic deformation $d\left(x_{1}, x_{2}\right)$ in (2.12) reads:

$$
d\left(x_{1}, x_{2}\right)=\frac{2}{\pi E^{\prime}} \iint_{S} \frac{p\left(x_{1}^{\prime}, x_{2}^{\prime}\right) d x_{1}^{\prime} d x_{2}^{\prime}}{\sqrt{\left(x_{1}-x_{1}^{\prime}\right)^{2}+\left(x_{2}-x_{2}^{\prime}\right)^{2}}}
$$

where, $E^{\prime}$ is the reduced modulus of elasticity:

$$
\frac{2}{E^{\prime}}=\frac{\left(1-\nu_{\text {ball }}^{2}\right)}{E_{\text {ball }}}+\frac{\left(1-\nu_{\text {plate }}^{2}\right)}{E_{\text {plate }}}
$$

The force balance equation reads:

$$
\iint_{S} p\left(x_{1}, x_{2}\right) d x_{1} d x_{2}=F \quad \text { for which } \quad x_{1}, x_{2} \in[-\infty, \infty]
$$

$F$ is a loading in the $x_{3}$-direction. The force balance equation determines the value of $h_{0}$, the mutual approach, in equation (2.12).

The Reynolds equation reads:

$$
\frac{\partial}{\partial x_{1}}\left(\frac{\rho h^{3}}{\eta} \frac{\partial p}{\partial x_{1}}\right)+\frac{\partial}{\partial x_{2}}\left(\frac{\rho h^{3}}{\eta} \frac{\partial p}{\partial x_{2}}\right)-6\left(u_{\text {ball }}+u_{\text {plate }}\right) \frac{\partial(\rho h)}{\partial x_{1}}=0
$$

with $\rho$ is the fluid density.

The viscosity-pressure behaviour of the lubricant is described by Roelands relation, 59]:

$$
\eta(p)=\eta_{0} e^{\left(\left(\ln \left(\eta_{0}\right)+9.67\right)\left(-1+\left(1+\frac{p}{p_{0}}\right)^{z}\right)\right)}
$$

With $\eta_{0}$ the temperature dependent viscosity at atmospheric pressure, $z$ the pressure viscosity index, $0.5 \leq z \leq 0.7$, and $p_{0}$ a constant $p_{0}=1.98 \cdot 10^{8} \mathrm{~Pa}$. 
A 2-phase model employed to describe density-pressure behaviour of the lubricant:

$$
\begin{array}{ll}
\rho(p)=\rho_{0} \frac{\left(5.9 \cdot 10^{8}+1.34 \cdot p\right)}{\left(5.9 \cdot 10^{8}+p\right)} & p>0 \\
\rho(p)=\rho_{0}\left(1.0+\operatorname{erf}\left(30 \cdot \frac{p}{p_{H}}\right)\right. & p \leq 0
\end{array}
$$

with $p$ the gauge pressure (in $\mathrm{Pa}$ ) and $\rho_{0}$ the density of the lubricant at atmospheric pressure. For HVI60 at room temperature $\rho_{0}=888 \mathrm{~kg} / \mathrm{m}^{3}$. For more details about the 2-phase model, see van Emden et al. [56]. 



\section{Chapter 3}

\section{A CHALlEnge TO CAVitation MODELING IN THE OUTLET FLOW OF AN EHL CONTACT}

This paper is a numerical study on the prediction of a cavitation bubble in the wake of an elasto-hydrodynamically lubricated ball-on-plate contact as observed in experiments at low velocity. A standard EHL-model is coupled with an elementary 2-phase pressure-density model, which yields a strong density decrease for sub-atmospheric pressures. A cavitation bubble can indeed be predicted, but its length is highly underpredicted when compared with available experimental results. Accurate prediction appears to call for more advanced fluid modeling, e.g. the physics of cavitation and aspects of 3D 2-phase flow.

The work in this chapter has been published as: E. van Emden, C.H. Venner and G.E. Morales-Espejel, Tribology International 102 (2016) 275-286.

DOI: http: //dx. doi.org/10.1016/j. triboint.2016.05.039

\subsection{Introduction}

The ability to form an enduring lubricant film in elasto-hydrodynamic contacts depends significantly on the flow of lubricant around the contact. In the seventies Pemberton and Cameron [26] identified two different steady flow pattern states to occur during rolling.

The first state appears at sufficient lubricant supply. It is characterized by a flooded region that envelopes the entire Hertzian contact region, and the outside meniscus of the flooded region is closed. Figure 3.1 shows an optical interferometry image of a flow pattern I situation. At the contact's outlet side a cavitation bubble exists, which elongates with increasing velocity, see Chiu [27] and Stadler et al. [28]. Based on experimental observations on a reciprocating contact and a numerical parametric study assuming a steady state contact, Stadler and coworkers developed an empirical equation for the length of the bubble. Stadler et al. found that the lubricant viscosity, the entrainment velocity, the cavitation pressure, and the geometry of the contact determine the dimensionless bubble length. They state that the cavitation bubble in a normal unidirectional rolling contact does not persist: after a short time, the bubble breaks through the oil meniscus, 
leading to an open downstream wake in which atmospheric pressure can be assumed. The rolling velocities considered were $0.02,0.05$ and $0.1 \mathrm{~m} / \mathrm{s}$.

The present authors [60] performed experiments under steady state conditions and pure rolling. Contrary to Stadler et al. [28], it was demonstrated that the cavitation bubble can persist in time depending on velocity and lubricant supply. It remained in place for the entire duration of the pure rolling tests. They formulated a function, based on experiments in the low velocity regime, relating the ratio of cavitation bubble length to Hertzian contact radius to a combination of the Reynolds, cavitation and Weber numbers. These dimensionless numbers incorperate the relevant physical aspects of the problem. The Reynolds number (based on the contact radius) represents the ratio of inertia forces to viscous forces in the flow around the contact. The cavitation number represents the ratio of pressure forces to inertia forces, and the ratio of inertial forces to surface tension forces is represented by the Weber number. For more details about the formulated function see [60].

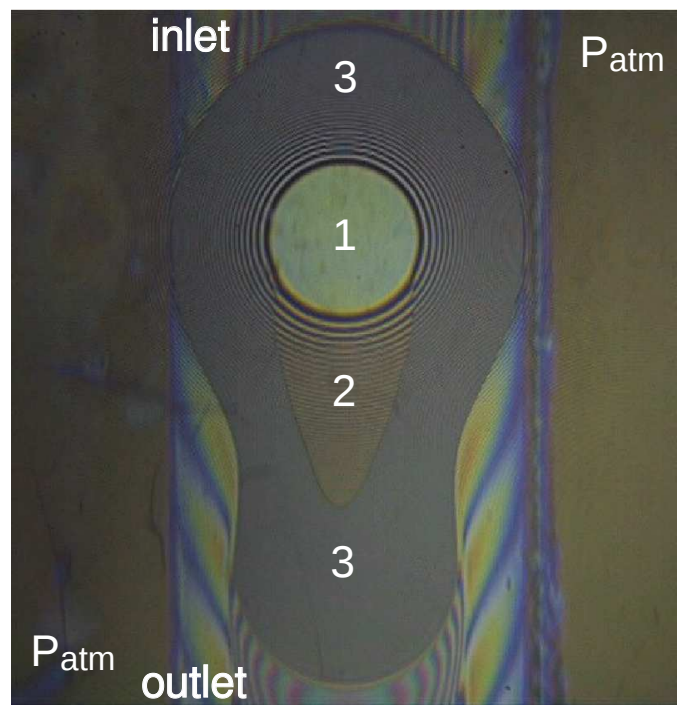

Figure 3.1: Optical interferometry image of flow pattern I, [60].

The pressure zones are marked as:

1: High pressure zone with positive gauge pressures and $p_{\max } \approx$ Hertzian pressure.

2: Cavitation bubble with negative gauge pressures $p \leq p_{\text {vap }}$.

3: The flooded region with both positive and negative gauge pressures ( $\left.p_{v a p}<p<p_{\max }\right)$.

When the rolling velocity is increased, the second flow pattern state appears. A concave-shaped inlet meniscus and an open downstream wake is typical for this state. State II has a butterfly shaped flooded region for starved situations, see Pemberton and Cameron [26]. Chiu [27] shows that the transition point between States I and II depends on the oil viscosity and the rolling velocity. In the case of increasing starvation, the inlet 
meniscus of the flooded region touches the Hertzian contact region, inside the Hertzian contact region significant variations in film thickness are observed leading to a reduced central- and minimal film thicknesses. Starved contacts have been studied extensively by Wedeven et al. [20] Cann et al. [22], Chevalier et al. [29] and Damiens et al. [45, 46]. In this paper the focus is on state I with a cavitation bubble in the wake.

The presence of cavitation bubbles in a configuration of multiple contacts in a real bearing has been confirmed by Chennaoui [43] using optical interferometry measurements on a model rolling bearing with a sapphire bearing ring. The cavitation bubbles were observed to extend even to the inlet zone of the following contact region with significant effect on the inflow and film thickness. This justifies further investigation of the effects of this bubble, particularly its length prediction.

Since the vapour pressure of lubricant oil is below atmospheric pressure, the bubble is associated with negative gauge pressures in the flow field. In standard EHL models for fully flooded conditions, the pressures are restricted to positive gauge pressures, using the so-called cavitation limit, see e.g. [2, 61, 62]: no negative gauge pressures are allowed, and consequently no cavitation bubble can be predicted based on a criterion of vapour pressure only.

Joseph [63], Kottke et al. [57] and Padrino et al. [58] use the 'Principal Normal Stress Cavitation Criterion' (PNSCC), to indicate the likely regions for cavitation to occur. The principal stesses in a fluid are calculated using the eigenvalues of the local stress tensor. The highest eigenvalue is compared to the cavitation pressure, usually taken equal to the vapour pressure. The maximum tension theory states that the lubricant will cavitate when the sum of the cavitation pressure and the maximum principal stress is larger than 0 .

Various approaches have been proposed in lubrication studies to model cavitation, see e.g. Bayada and Chupin [54] and Bruyere et al. [55]. In hydrodynamic lubrication it is common to distinguish two approaches. In the first approach, two different areas appear in the contact domain: a cavitation region and a liquid film region. For example, both Jacobsson, Floberg and Olsson [64] (the JFO model), and Elrod-Adams [65], use a switch function in the Reynolds equation to suppress the Poiseuille flow terms for density values smaller than the cavitation density, i.e. the Poiseuille flow terms of the Reynolds equation are omitted in the cavitation region. For both models the pressure in the cavitated area is constant and never below the vapour pressure.

In the second approach a generalized flow equation is satisfied for the entire contact domain with a 2-phase model for the density-pressure relation and possibly also an adjusment to the viscosity-pressure relation. For example, Van Odyck and Venner [66] (and see also Van Odyck [67]) and Bayada and Chupin [54] use a compressible cavitation model based upon the isentropic assumption. In the case of Van Odyck and Venner [66] the cavitation model is combined with both the Reynolds equation and the Stokes equations. It is applied to the flow in a gap with a fixed rigid upper part and a lower part moving with a constant velocity along the $x_{1}$-direction (prescribed 1 -dimensional geometry).

The 2-phase models of Bayada-Chupin and Van Odyck-Venner both consider 3 density regimes with a continuous transition, one of pure liquid, one of pure vapour and a mixture of liquid and vapour. For the pure liquid regime, the liquid is either incompressible (Van 
Odyck-Venner) or compressible, e.g. the pressure-density relation of Dowson-Higginson [10] is used to determine the fluid density. In the pure vapour regime the pressure is considered constant and never below the vapour pressure. Bayada and Chupin consider a void fraction $(\tilde{\alpha})$, i.e. the ratio of the vapour volume to the total volume in the mixture regime. The speed of sound in the mixture regime, $c_{f}=\sqrt{\frac{d \rho}{d p}}$, varies with the density $\rho(\tilde{\alpha})$ and it is calculated by using the relation employed by van Wijngaarden [68]. Van Odyck takes a simpler approach in which a single, minimum speed of sound in the mixture is used to determine a constant value for the density-pressure gradient of the mixture. By introducing the assumption that the liquid density is much larger than the vapour density in the relation by van Wijngaarden, they find the minimum speed of sound at a void fraction equal to $\tilde{\alpha}=\frac{1}{2}$, for more details and the derivation see [67]. At both ends of the mixture region, the pressure-density relation is modified to prevent a discontinuity in the slope of the relation. It is mentioned that the value of the density-pressure gradient strongly influences the numerical convergence properties.

A comparison of the density-pressure behaviour for various cavitation models, the model of Bayada and Chupin [54], the JFO model [64], the Elrod-Adams [65], and the model of Van Odyck-Venner [66], is shown in figure 3.2. for more details see [54].

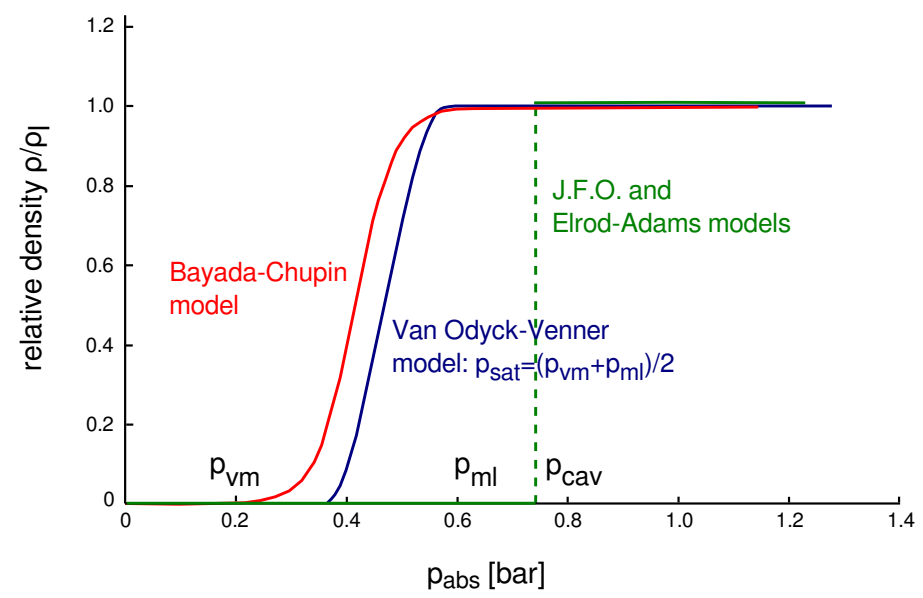

Figure 3.2: Density-pressure relations, see also Bayada and Chupin, figure 2 of [54].

It can be seen that for the JFO and the Elrod-Adams models the pressure is constant in the cavitated region. For the compressible model of Van Odyck-Venner [66], the density decreases with decreasing pressure to the vapour density and then the density remains constant at vapour density for decreasing pressures.

In this paper it is investigated to which extent 2-phase models as [66] and [54] can predict the size of the cavitation bubble behind an EHL contact. For this purpose, a representative generic 2-phase model has been constructed, which contains compressibility of the fluid in the high pressure range with transition to vapour pressure in the low 
pressure range. The slope of transition is variable in the model. Furthermore, to allow sub-atmospheric pressures, the cavitation condition forcing the gauge pressures to remain positive [30, 62, 61], is removed from the standard EHL model.

\subsection{Model}

\subsubsection{Equations}
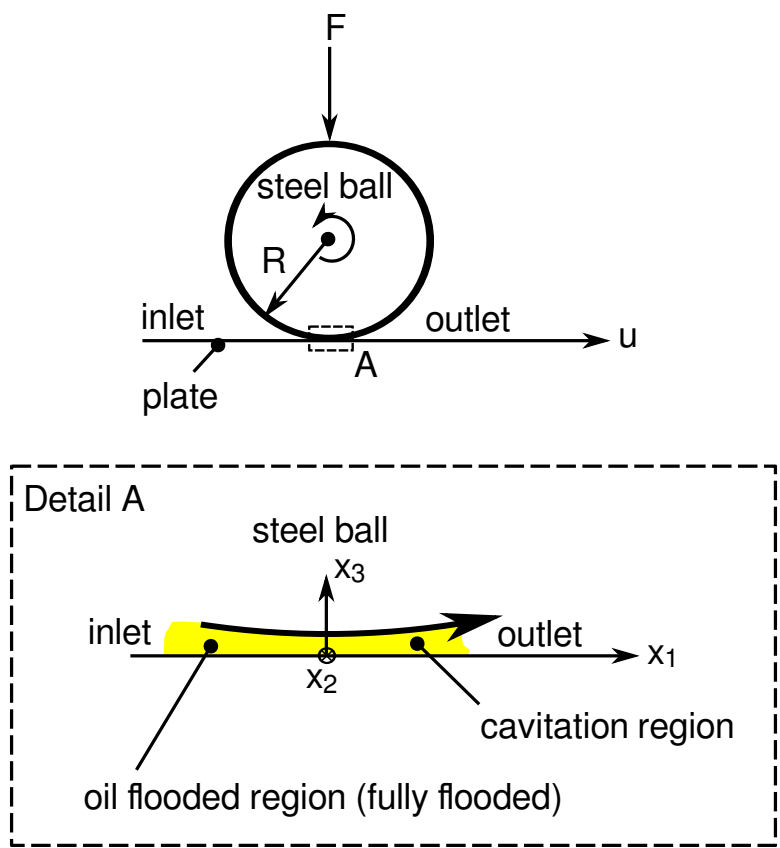

Figure 3.3: Generic sketch of problem setup.

A standard Elasto Hydrodynamic Lubrication (EHL) model is used for the case of a circular contact. Let $x_{1}$ be in the rolling direction and $x_{3}$ be the direction of the film thickness, see figure 3.3 .

The flow behaviour of the thin liquid film is described by the The Reynolds equation:

$$
\frac{\partial}{\partial x_{1}}\left(\frac{\rho h^{3}}{\eta} \frac{\partial p}{\partial x_{1}}\right)+\frac{\partial}{\partial x_{2}}\left(\frac{\rho h^{3}}{\eta} \frac{\partial p}{\partial x_{2}}\right)-6 u_{s} \frac{\partial(\rho h)}{\partial x_{1}}=0
$$

with $u_{s}$ the sum velocity of the ball and the plate, respectively, in the $x_{1}$-direction.

The gap height $h\left(x_{1}, x_{2}\right)$ in the $x_{3}$-direction is supposed to be filled with lubricant, and it depends on the local pressures, the mutual approach and on the geometry of the 
contacting surfaces:

$$
h\left(x_{1}, x_{2}\right)=h_{0}+f\left(x_{1}, x_{2}\right)+d\left(x_{1}, x_{2}\right)
$$

Where $f\left(x_{1}, x_{2}\right)$ is the undeformed geometry:

$$
f\left(x_{1}, x_{2}\right)=\frac{x_{1}^{2}}{2 R}+\frac{x_{2}^{2}}{2 R},
$$

$d\left(x_{1}, x_{2}\right)$ is the elastic deformation, which reads:

$$
d\left(x_{1}, x_{2}\right)=\frac{2}{\pi E^{\prime}} \iint_{S} \frac{p\left(x_{1}^{\prime}, x_{2}^{\prime}\right) d x_{1}^{\prime} d x_{2}^{\prime}}{\sqrt{\left(x_{1}-x_{1}^{\prime}\right)^{2}+\left(x_{2}-x_{2}^{\prime}\right)^{2}}}
$$

with, $p$ the pressure and $E^{\prime}$ is the reduced modulus of elasticity.

The pressure integral in the normal direction must equal the applied load $F_{3}$. The force balance equation reads:

$$
\iint_{S} p\left(x_{1}, x_{2}\right) d x_{1} d x_{2}=F_{3} \quad \text { for which } \quad x_{1}, x_{2} \in[-\infty, \infty]
$$

The force balance equation determines the value of $h_{0}$, in equation (3.2).

\section{Velocity Profiles}

The Reynolds equation is obtained from Navier Stokes by invoking the 'Lubrication assumption'. From the resulting reduced momentum equations the lubricant velocity profiles in the $x_{1}$ - and $x_{2}$-directions are analytically given as:

$$
\begin{aligned}
& u_{1}\left(x_{1}, x_{2}, x_{3}\right)=\frac{1}{2 \eta}\left(x_{3}^{2}-h x_{3}\right) \frac{\partial p}{\partial x_{1}}+u_{1_{h}} \frac{x_{3}}{h}+u_{1_{0}} \frac{h-x_{3}}{h} \\
& u_{2}\left(x_{1}, x_{2}, x_{3}\right)=\frac{1}{2 \eta}\left(x_{3}^{2}-h x_{3}\right) \frac{\partial p}{\partial x_{2}}+u_{2_{h}} \frac{x_{3}}{h}+u_{2_{0}} \frac{h-x_{3}}{h}
\end{aligned}
$$

To complete the flow field one can now use the equation of continuity:

$$
\frac{\partial\left(\rho u_{1}\right)}{\partial x_{1}}+\frac{\partial\left(\rho u_{2}\right)}{\partial x_{2}}+\frac{\partial\left(\rho u_{3}\right)}{\partial x_{3}}=0
$$

to obtain $u_{3}$. From the lubrication assumption it followed that $p=p\left(x_{1}, x_{2}\right)$, so also $\rho$ is independent of $x_{3}, \rho=\rho\left(x_{1}, x_{2}\right)$. Rewriting equation (3.8) then leads to:

$$
\frac{\partial u_{3}}{\partial x_{3}}=-\left(\frac{\partial u_{1}}{\partial x_{1}}+\frac{u_{1}}{\rho} \frac{\partial \rho}{\partial x_{1}}+\frac{\partial u_{2}}{\partial x_{2}}+\frac{u_{2}}{\rho} \frac{\partial \rho}{\partial x_{2}}\right)
$$

Integration of equation (3.9) with respect to $x_{3}$ yields

$$
u_{3}=u_{3_{0}}-\int_{0}^{x_{3}}\left(\frac{\partial u_{1}}{\partial x_{1}}+\frac{u_{1}}{\rho} \frac{\partial \rho}{\partial x_{1}}+\frac{\partial u_{2}}{\partial x_{2}}+\frac{u_{2}}{\rho} \frac{\partial \rho}{\partial x_{2}}\right) d x_{3}, \quad x_{3} \in\left[0, h\left(x_{1}, x_{2}\right)\right]
$$


with $u_{1_{0}}=u_{1_{h}}=u, u_{2_{0}}=u_{2_{h}}=0, \eta=\eta\left(x_{1}, x_{2}\right)$ and $h=h\left(x_{1}, x_{2}\right)$. Using the equations for the velocities (3.6) and (3.7), and their partial derivatives, the integral of equation 3.10 yields:

$$
\begin{aligned}
u_{3}\left(x_{1}, x_{2}, x_{3}\right)= & u_{3_{0}} \\
& -\left(\frac{1}{2 \eta}\left(\frac{\partial^{2} p}{\partial x_{1}^{2}}+\frac{1}{\rho} \frac{\partial \rho}{\partial x_{1}} \frac{\partial p}{\partial x_{1}}+\frac{\partial^{2} p}{\partial x_{2}^{2}}+\frac{1}{\rho} \frac{\partial \rho}{\partial x_{2}} \frac{\partial p}{\partial x_{2}}\right)\left(\frac{1}{3} x_{3}^{3}-\frac{h}{2} x_{3}^{2}\right)\right) \\
& +\frac{1}{2 \eta}\left(\frac{\partial h}{\partial x_{1}} \frac{\partial p}{\partial x_{1}}+\frac{\partial h}{\partial x_{2}} \frac{\partial p}{\partial x_{2}}\right) \frac{x_{3}^{2}}{2}-\frac{u_{1_{0}}+u_{1_{h}}}{2 \rho} \frac{\partial \rho}{\partial x_{1}} x_{3}
\end{aligned}
$$

When the solution $p, h$ of the Reynolds equation is known equation (3.11) can be used to visualize the flow in the film by a posteriori computing $u_{3}$ and, the stress components.

\section{Stress Tensor and Principal Stresses}

The local stress tensor is given by:

$$
\begin{gathered}
\sigma_{i j}=-p \delta_{i j}+\tau_{i j} \\
\tau_{i j}=\eta\left(\frac{\partial u_{i}}{\partial x_{j}}+\frac{\partial u_{j}}{\partial x_{i}}\right)-\frac{2}{3} \eta \delta_{i j} \frac{\partial u_{k}}{\partial x_{k}}
\end{gathered}
$$

with $\delta_{i j}$ the Kronecker delta:

$$
\delta_{i j}= \begin{cases}0 & \text { if } i \neq j \\ 1 & \text { if } i=j\end{cases}
$$

When the (local) stress tensors are known, the three principal stresses can be calculated by using the eigenvalues of $\sigma_{i j}$, as follows:

$$
\operatorname{det}\left|\sigma_{i j}-\lambda \delta_{i j}\right|=0
$$

with $\lambda$ the eigenvalues, which are the principal stresses $\sigma_{1}, \sigma_{2}$ and $\sigma_{3}$ defined such that:

$$
\sigma_{1}>\sigma_{2}>\sigma_{3}
$$

\subsubsection{Constitutive Equations}

Two constitutive relations for the lubricant are needed to close the model: $\eta(p)$ and $\rho(p)$.

\section{Viscosity-Pressure Relation}

Pure rolling conditions are applied, and high temperature gradients do not appear because there is no slip. Therefore, the problem is considered isothermal, and the pressuredependent viscosity relation proposed by Roelands [59] is employed, which is valid up to pressures of approximately $1 \mathrm{GPa}$ [62]:

$$
\eta(p)=\eta_{0} e^{\left(\left(\ln \left(\eta_{0}\right)+9.67\right)\left(-1+\left(1+\frac{p}{p_{0}}\right)^{z}\right)\right)}
$$


where $\eta_{0}$ is the temperature dependent viscosity at atmospheric pressure, and $z$ is the pressure viscosity index calculated according to:

$$
z=\frac{\alpha p_{0}}{\ln \left(\eta_{0}\right)+9.67}
$$

with $p_{0}$ a constant with a value $p_{0}=1.98 \cdot 10^{8} \mathrm{~Pa}$, and $\alpha$ the pressure-viscosity coefficient, which depends on the lubricant and temperature.

The specifics of the viscosity-pressure behaviour are the topics of a continuous fundamental discussion, see Bair and Kottke [69]. For instance, an alternative relation based on free volume theory is the Doolittle equation, in which the volume variation depending on the pressure is determined with the Tait equation, see Bair et al. [69, 70, 71].

Since we look at the aspects of the outlet flow, where the pressures are relatively low, the exact specifics are not expected to significantly affect the results and the simpler Roelands equation is used. Besides, even the overall maximum pressure is well below 1 $\mathrm{GPa}$, and well in the range in which the error made using Roelands' equation will be quite limited, especially as also no sliding occurs.

\section{Cavitation Modeling via the Pressure-Density Relation}

The standard EHL model only accounts for cavitation, by forcing the gauge pressure to remain positive, see for example Popovici [30], Wijnant [62] and Venner [61]:

$$
p\left(x_{1}, x_{2}\right) \geq 0 \quad \forall\left(x_{1}, x_{2}\right) \in S
$$

In the present work this so-called cavitation condition is removed and sub-atmospheric pressures are allowed.

The pressure-density relation used in most EHL models is the empirical DowsonHigginson relation:

$$
\rho(p)=\rho_{0} \frac{\left(5.9 \cdot 10^{8}+\mathcal{A} \cdot p\right)}{\left(5.9 \cdot 10^{8}+p\right)}
$$

with $\mathcal{A}=1.34, p$ the gauge pressure (in $\mathrm{Pa}$ ) and $\rho_{0}$ the density of the lubricant at atmospheric pressure. The equation is intended for mineral oils at pressures in the liquid phase well above atmospheric pressure. An alternative density-pressure compressibility relation is proposed by Jacobson-Vinet [72]. For this relation, the lubricant compressibility increases for higher pressures but for low pressures the compressibility approximates the Dowson-Higginson relation.

When the Dowson-Higginson relation is applied to sub-atmospheric pressures it predicts a small decrease of oil density as shown by the red line in figure 3.4 but it has no real physical relevance as to account for the transition to vapour.

This can be rectified by using a 2-phase model. Here, the Dowson-Higginson relation is used for gauge pressures larger than a predefined pressure limit $\left(p_{\text {lim }}\right)$ and an additional relation yielding a faster density decrease is used for pressures less than the predefined 


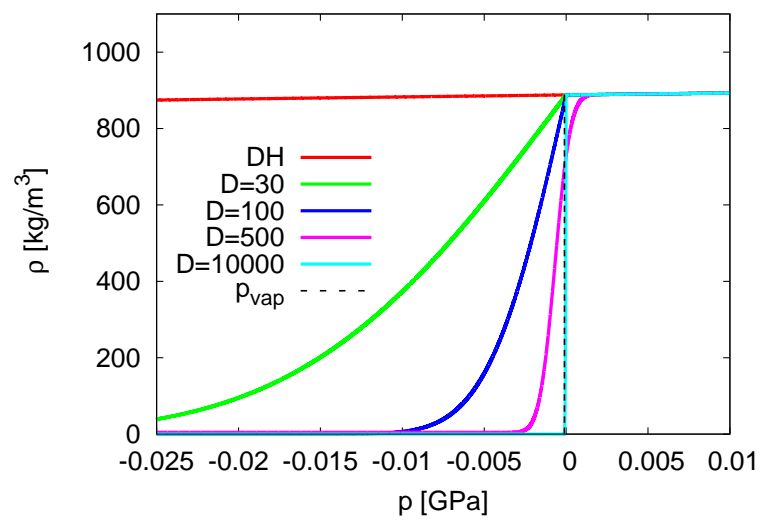

Figure 3.4: Gauge pressure-density relations for the low pressure region, Dowson-Higginson $(D H)$ and the present model using different values for $\mathcal{D}$.

dimensionless pressure limit. A generic form which captures a gradual smooth transition with variable slope is obtained by using (3.20):

$$
\rho(p)=\rho_{0}\left(\mathcal{B}+\mathcal{C} \cdot \operatorname{erf}\left(\frac{\mathcal{D}}{p_{\text {ref }}} \cdot p+\mathcal{E}\right)\right) \quad p \leq p_{\text {lim }}
$$

with the constants $\mathcal{B}, \mathcal{C}, \mathcal{D}$ and $\mathcal{E}$. The reference pressure $p_{\text {ref }}$ equals the Hertzian contact pressure $p_{h}$. D determines the steepness of the transition. Three different values of $\mathcal{D}$ are employed: $\mathcal{D}=30, \mathcal{D}=100$ and $\mathcal{D}=500$, see figure 3.4. For the two lower values of $\mathcal{D}$ the pressure limit is chosen as $p_{\text {lim }}=0$, and only the lower half of the error function is used so that $\mathcal{B}=\mathcal{C}=1$ and $\mathcal{E}=0$. For $\mathcal{D}=500$ the complete error function is used, with $\mathcal{B}=0.5$ and the values of $\mathcal{C}$ and $\mathcal{E}$ are chosen to ensure a smooth transition to the Dowson-Higginson relation at the pressure limit of $p_{\text {lim }}=0.0035 \cdot p_{\text {ref }}$.

Note that since the EHL model assumes that the pressure is independent of $x_{3}$, this also applies to the density. So when a cavitation region is predicted, the density is the density of the mixture, i.e. when the pressure is below vapour pressure, cavitation occurs, but since the model assumes a constant density over the film thickness, it is not possible to pinpoint the exact location in the $x_{3}$-direction of the bubble across the film thickness.

\subsection{Numerical Calculations}

\subsubsection{Computational Method}

For the numerical solution of the equations, the changes to the EHL model have been implemented in the multigrid approach developed by Venner and Lubrecht [2, 61]. The method uses a $2^{\text {nd }}$ order accurate upstream finite difference approximation on a uniform 
grid. Multigrid methods are used to solve the equation for the gap height, the Reynolds equation and the force balance equation. Dirichlet boundary conditions, forcing the pressures to be zero at the outlet boundary of the computational domain affect the cavitation bubble length. Therefore, instead of a Dirichlet boundary condition, a Neumann pressure boundary condition is imposed at the outlet boundary of the computational domain. This boundary condition forces the pressure derivative with respect to $x_{1}$ to be zero, see also Van Odyck [67].

\subsubsection{Input Parameters}

\begin{tabular}{|ll||l|}
\hline parameter set up & {$[$ unit ] } & condition \\
\hline radius of ball $(R)$ & $\mathrm{m}$ & $9.525 \cdot 10^{-3}$ \\
rolling velocity $(u)$ & $\mathrm{m} / \mathrm{s}$ & $0.01-1.0$ \\
loading force $(F)$ & $\mathrm{N}$ & 20 \\
\hline lubricant & & $\mathrm{HVI60}$ \\
temperature & ${ }^{\circ} \mathrm{C}$ & 25 \\
dynamic viscosity [47] & $10^{-3} \mathrm{~Pa} \cdot \mathrm{s}$ & 44.7 \\
viscosity pressure coefficient & $10^{-8} \mathrm{~Pa}^{-1}$ & 2.25 \\
vapour pressure $\left(p_{\text {vap }}\right)$ & $\mathrm{Pa}(\mathrm{abs})$ & 0.5 \\
density at room temperature $\left(\rho_{0}\right)$ & $\mathrm{kg} / \mathrm{m}^{3}$ & 888 \\
reduced modulus of elasticity $\left(E^{\prime}\right)$ & $10^{11} \mathrm{~N} / \mathrm{m}^{2}$ & 1.17 \\
\hline
\end{tabular}

Table 3.1: Conditions for numerical calculations.

The input parameters for the calculations and the characteristic data of the employed oil are given in table 3.1 . Calculations are done with 3 variants of the pressure-density relation given in relation (3.20) and the standard Dowson-Higginson relation (3.19). Gauge pressures less or equal to $-1.012995 \cdot 10^{-4}(=0.5 \mathrm{~Pa}$ above absolute zero pressure $)$ are considered to predict oil vapour, 'the cavitated region'.

\subsubsection{Computational Details}

The calculations are performed on a domain of $x_{1} \in[-2 a, 6 a]$ and $x_{2} \in[-2 a, 2 a]$, with $a$ the Hertzian contact radius. A total of 7 grid levels in a multigrid W-cycle are used to solve the film thickness equation, with $6145 \times 3073$ grid points on the finest grid level. The computational domain together with the employed boundary conditions are shown in figure 3.5. The centre of the ball is located above the origin.

The system is solved to a numerical error far below the discretization error. In appendix A some results are shown to demonstrate grid convergence. The effect of the size of the in $x_{1}$-direction on the solution is shown in appendix $\mathrm{B}$. Increasing the steepness of the pressure-density relation in the 2-phase model also increases the necessary grid refinement 
computational domain:

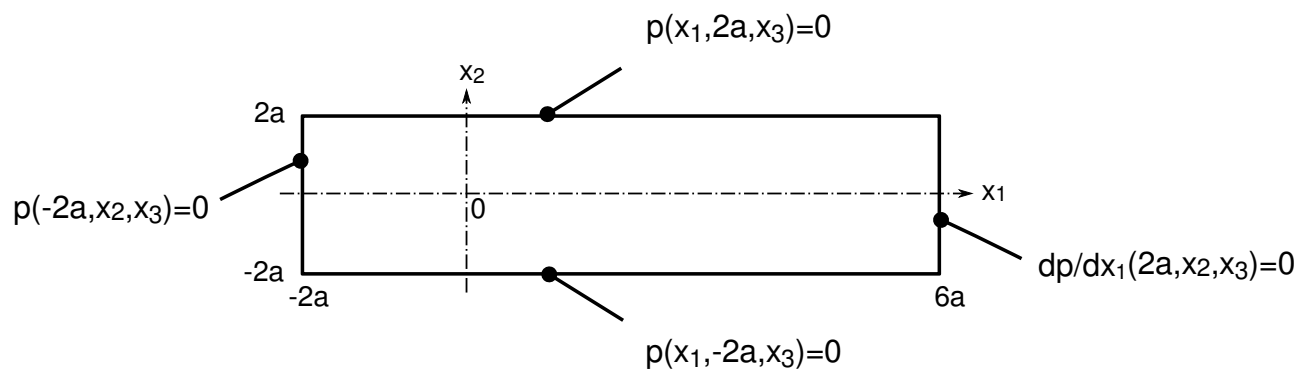

Figure 3.5: Generic sketch of the used computational domain with the employed boundary conditions.

in order to obtain converged results. The domain size chosen in the rolling direction $\left(x_{1}\right)$ is based on the results shown in appendix $B$.

In a post-processing step, the velocities and stresses are calculated on a 3-dimensional grid with 101 points across the film thickness.

\subsection{Results}

\subsubsection{Typical Solution for Pressure and Film Thickness}

To study the effect of the 2-phase model on the pressure- and film thickness distribution inside the contact region, the contact results are compared with the original EHL results, see figure 3.6. This figure shows the pressure and film thickness distribution in the contact region obtained with the original $E H L$ model and the present model using $\mathcal{D}=500$, for the conditions listed in table 3.1 at a rolling velocity of $1 \mathrm{~m} / \mathrm{s}$. The differences between these models inside the contact region are very small. The minimal film thickness found with the original EHL model and the present model $(\mathcal{D}=500)$ is $162.0 \mathrm{~nm}$ and 162.2 $\mathrm{nm}$, respectively. This is an effect of the changed pressure distribution due to the subatmosheric pressure region at the outlet. The pressures must balance with the loading $F_{3}$ causing a change in $h_{0}=-0.849$ to $h_{0}=-0.853$ for original EHL model and the 2-phase model $(\mathcal{D}=500)$, respectively. The maximum pressure in the contact center, which is $0.533 \mathrm{GPa}$ when the original EHL model is applied, is increased by a marginal $1 \mathrm{MPa}$ when using the present model with $\mathcal{D}=500$. The pressure spike near the outlet found for the original EHL model is located a little closer to the contact center, see figure 3.7. 

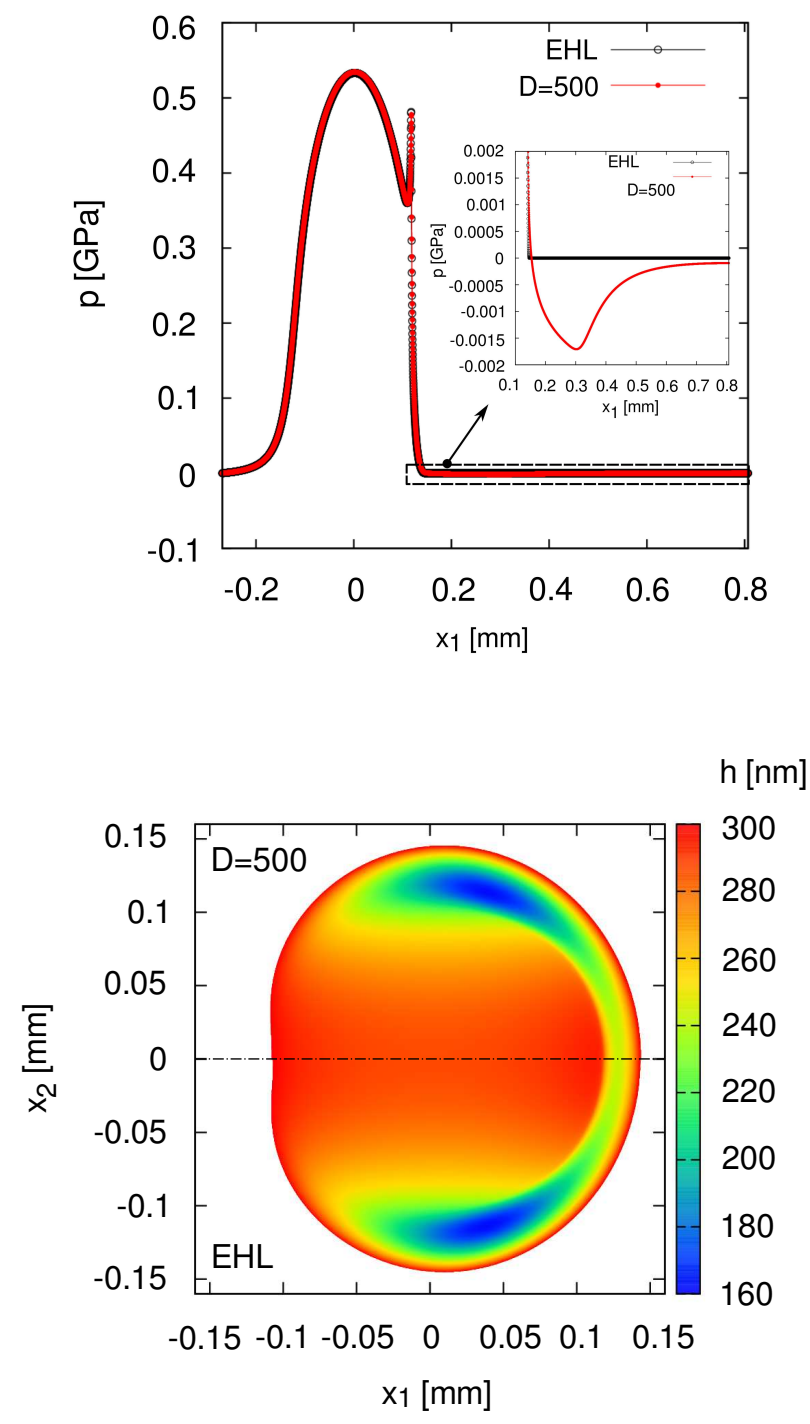

Figure 3.6: Results obtained with the modified EHL problem with density-pressure relations according to Dowson-Higginson and a 2-phase model $(\mathcal{D}=500), u=1 \mathrm{~m} / \mathrm{s}$. The contact pressure $p\left(x_{1}\right)$ in the numerical domain (top), and film thickness in the contact zone $h\left(x_{1}, x_{2}\right)$ (bottom). 


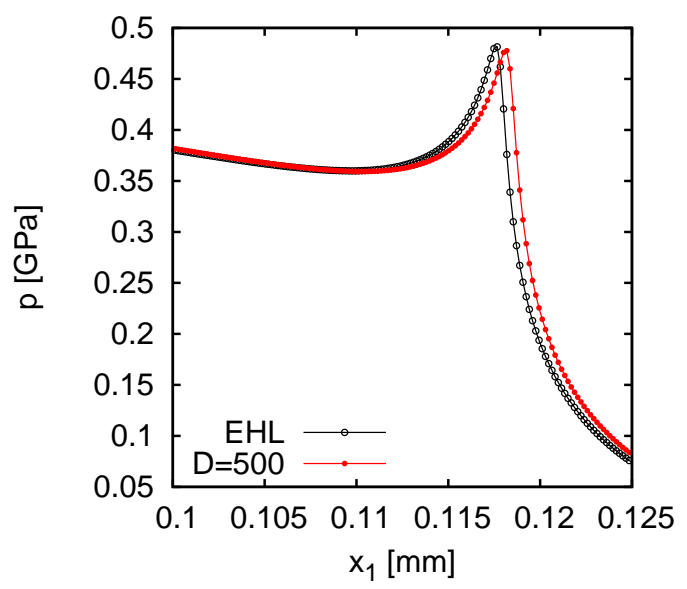

Figure 3.7: Pressure distribution near by the pressure spike, using the original EHL model and the present model $\mathcal{D}=500, u=1 \mathrm{~m} / \mathrm{s}$

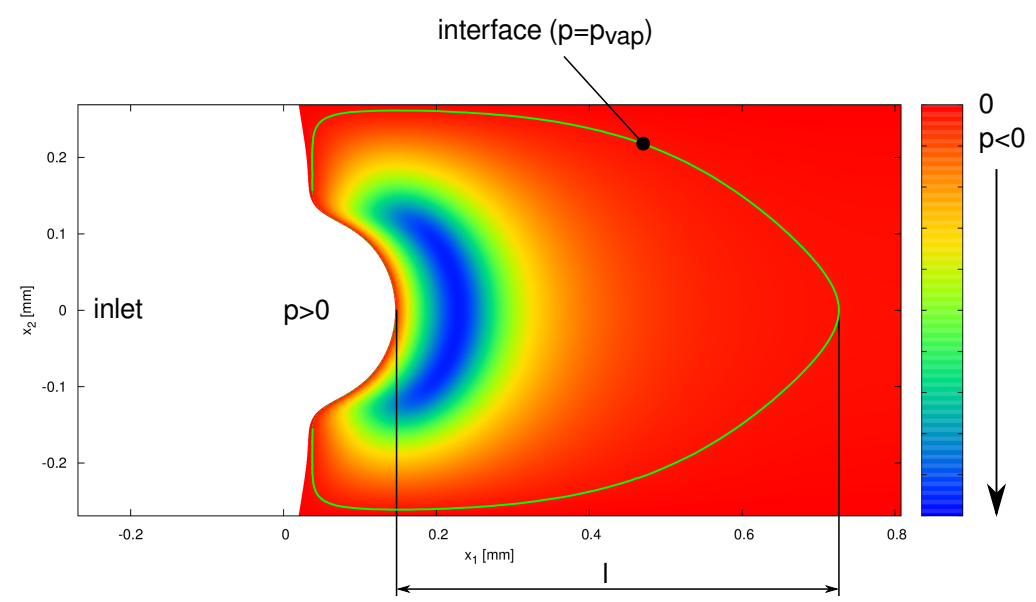

Figure 3.8: Pressure distribution region with negative gauge pressures, using a 2-phase model, $u=1 \mathrm{~m} / \mathrm{s}$ 
The result obtained with the present model predicts a sub-atmospheric pressure zone at the outlet side. The gauge minimum pressure is in the order of $\mathrm{O}\left(-10^{6}\right) \mathrm{Pa}$, as will be discussed in section 3.4 .2 . This result is not physical (too low), as the atmospheric pressure is in the order of $\mathrm{O}\left(10^{5}\right) \mathrm{Pa}$.

In figure 3.8 the negative gauge pressures are shown using the present model $(\mathcal{D}=500)$. The liquid-vapour interface is indicated with a line for which $p=p_{v a p}$. This line envelops the cavitation bubble according to the definition of the liquid-vapour interface. The predicted bubble length is approximately $4.3 \times a$, when defined as the distance between the $x_{1}$-coordinate on the $x_{2}=0$ line for which the gauge pressure $p=p_{v a p}$, and the Hertzian contact radius $a$.

\subsubsection{Minimal Pressure- and Density Results}

To study the influence of the density-pressure steepness of the 2-phase cavitation model on the minimum values for pressure and density, results for different values of $\mathcal{D}$ and Dowson-Higginson are shown in figure 3.9. For the larger values of $\mathcal{D}$, only the high velocity results are shown due to difficulties of converging to a numerical solution having an error far below the discretization error. Van Odyck coped with simular problems by using a modified iteration process [67].

The plot at the top in figure 3.9 shows that the minimum pressures are increased when $\mathcal{D}$ increases in equation (3.20). Not shown here, the same happens when the pressure limit $\left(p_{\text {lim }}\right)$ is increased to a higher value. Larger values of $\mathcal{D}$ give better results and the lines are roughly independent of velocity. Although still a region of unphysical negative gauge pressures is found, the values obtained with $\mathcal{D}=500$ are one order of magnitude closer to the absolute zero pressure than those obtained with the Dowson-Higginson relation.

The plot at the bottom of figure 3.9 shows that the minimum density decreases for increasing $\mathcal{D}$. It is expected that for $\mathcal{D}=\mathrm{O}\left(10^{4}\right)$ all pressure values are physical and the minimum density tends to zero. However, such a value for $\mathcal{D}$ leads to very high computational requirements (mesh densities and computational times) and difficulties to obtain a converged solution. However, even though such a value would be more realistic, the value of $\mathcal{D}$ has only little effect on the bubble length as will be shown next. 

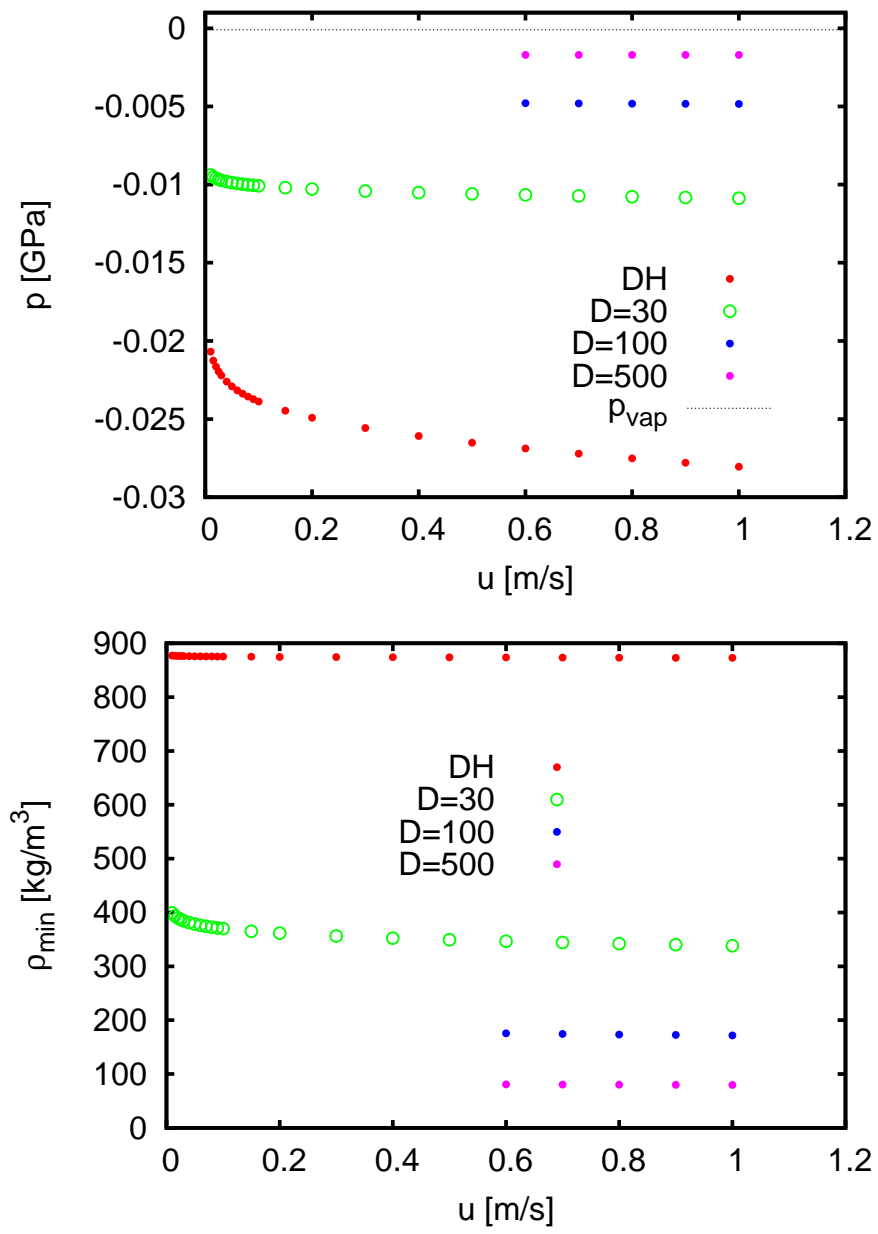

Figure 3.9: Results of gauge pressure minima

(top) and density minima (bottom), versus the velocity and pressure-density relation. 


\subsubsection{Cavitation Bubble Length}

In figure 3.10 the ratio of cavitation bubble length to Hertzian contact radius $a$ is plotted as a function of the rolling velocity for the numerical results of different values of $\mathcal{D}$, and for the standard pressure density relation according to Dowson-Higginson, together with the experimental results from reference [60].

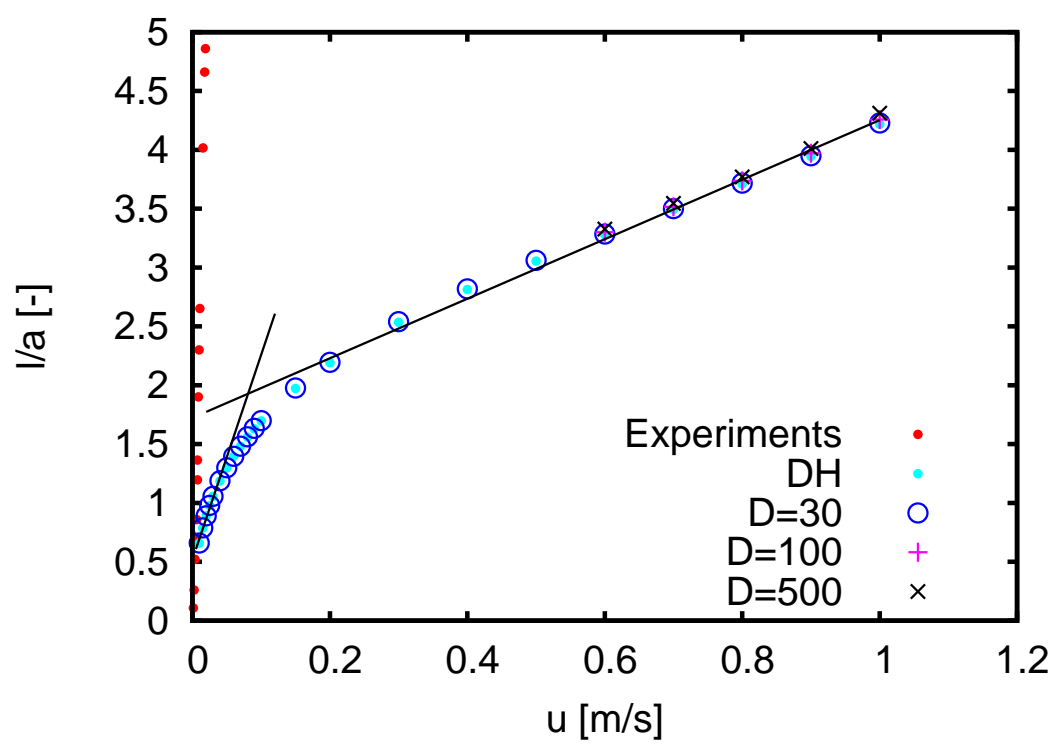

Figure 3.10: Numerical- and experimental [60] results of the ratio of cavitation bubble length to Hertzian contact radius, versus the rolling velocity.

From the numerical results in figures 3.9 and 3.10 it can be concluded that although the steepness $(\mathcal{D})$ of the 2-phase model has a large effect on the pressure minimum and on the minimum density, the effect on the cavitation bubble length is only minor.

The calculations are performed in the complete velocity regime with both the DowsonHigginson and the 2-phase model with $\mathcal{D}=30$. Note that there is no significant difference between the numerical results obtained with the 2-phase model and those obtained with the Dowson-Higginson relation. It appears that the numerical results of $l / a$ with respect to $u$ first follow a linear trend in the low velocity regime and around $u=0.04 \mathrm{~m} / \mathrm{s}$. This gradually changes to a linear trend with a decreased slope in the high velocity regime (starting approximately at $u=0.15 \mathrm{~m} / \mathrm{s}$ ). 


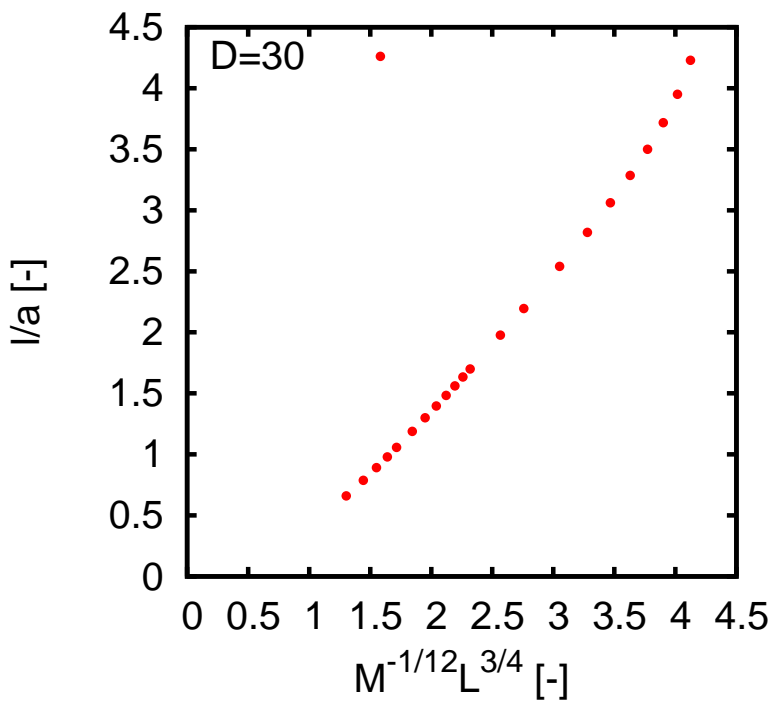

Figure 3.11: Dimensionless relation for the ratio of cavitation bubble length to Hertzian contact radius, versus the combination of Moes parameters $M$ and $L$ for elastic piezoviscous regime [61]. Numerical results for $\mathcal{D}=30$.

The observed behaviour in the numerical results seems to suggest a relation between film thickness and bubble length. Venner [61] used numerical solutions (EHL model) to develop a relation to predict the dimensionless Moes film thickness parameter $H^{M}$ with the Moes parameters $M$ and $L$ [73], for the elastic-piezoviscous regime: $H_{\text {elastic-piezoviscous }}^{M}=1.25 M^{-\frac{1}{12}} L^{\frac{3}{4}}$. The values for $M$ vary from $70.3 \leq M \leq 2222.8$ and the values for $L$ vary between $2.5 \leq L \leq 7.9$. In figure 3.11 the numerical results for $l / a$ using $\mathcal{D}=30$ are plotted as a function of this relation $1.25 M^{-\frac{1}{12}} L^{\frac{3}{4}}$. The figure shows that the results for the length ratio also scale linearly with the dimensionless film thickness parameter $1.25 M^{-\frac{1}{12}} L^{\frac{3}{4}}$. This means that relation (3.21) follows for the numerically predicted cavitation bubble length $l$ :

$$
l \propto h_{c}\left(\frac{3 F_{3}}{2}\right)^{\frac{1}{3}}\left(\frac{E^{\prime}}{R}\right)^{\frac{1}{6}}\left(\eta_{0} u_{s}\right)^{-\frac{1}{2}}
$$

with the ball radius $R$, reduced modulus of elasticity $E^{\prime}$, lubricant viscosity $\eta_{0}$, the loading $F_{3}$, the sum velocity $u_{s}$ and the central film thickness $h_{c}$. 


\section{Comparison of Numerical- to Experimental Results}

In figure 3.10 the ratio of cavitation bubble length to Hertzian contact radius $a$ is plotted as a function of the rolling velocity for both the numerical results and the experimental results [60]. Experimental results of the authors [60] in the high velocity regime at room temperature are not available because the cavitation bubble length becomes larger than the used experimental setup is able to visualize.

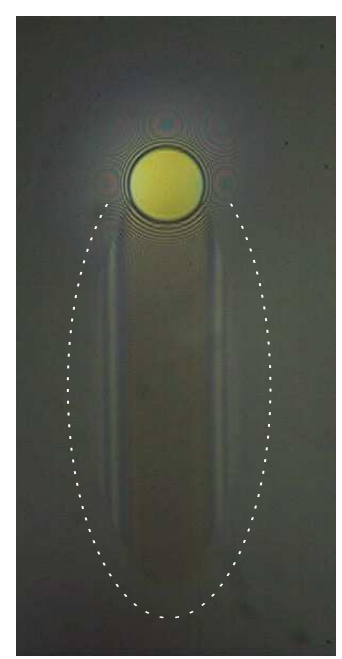

Figure 3.12: Optical interferometry image [60] of a lubricated contact $\mathrm{HVI} 60, \mathrm{~T}=40^{\circ} \mathrm{C}$ $u=98 \mathrm{~mm} / \mathrm{s} F=20 \mathrm{~N}(2.5 \times$ lens $)$.

However, in figure 3.12 an optical interferometry image [60] of a lubricated contact with a cavitation bubble present at the outlet side of the contact is shown for a rolling velocity of $u=98 \mathrm{~mm} / \mathrm{s}$, at a higher temperature of $T=40^{\circ} \mathrm{C}$ and a loading of $F=20 \mathrm{~N}$. As shown in figure 3.12 the cavitation bubble length is very large, more than $l / a>10$. The image gives an indication of the large cavitation bubble lengths encountered at higher velocities, and ample lubricant supply.

In the experiments a linear dependence of $l / a$ on the rolling velocity was observed. In this low velocity regime up to $0.04 \mathrm{~m} / \mathrm{s}$, a linear dependency of $l / a$ on the rolling velocity is also observed for the numerical results, see figure 3.10. However, the predicted lengths are much shorter than the lengths found in the experiments. For example, in the numerical calculations, a length ratio of $l / a \approx 4$ is predicted for a rolling velocity of $u \approx 0.9 \mathrm{~m} / \mathrm{s}$ whereas in the experiments [60] the same value was already found for a velocity of $u \approx 0.015 \mathrm{~m} / \mathrm{s}$. Near the contact, the predicted bubble width is larger than observed in the experiments [60].

The results in figures 3.93 .10 and 3.12 imply that for an even steeper pressure-density relation that predicts physical values for the pressure minima, the cavitation bubble length will still be underpredicted. 


\subsubsection{Velocity Distribution}

For the example with the 2-phase model $(\mathcal{D}=30)$ and a rolling velocity of $0.015 \mathrm{~m} / \mathrm{s}$ the velocity distribution of $u_{1}$ and $u_{3}$ are given in the symmetry plane $x_{2}=0$, for which $u_{2}=0$, see figures 3.13 and 3.14 respectively.

Figure 3.13 shows that the lubricant velocity $u_{1}$ is negative in the cavitated zone and slightly downstream in the area around the line $x_{3}=0.5 \mathrm{~h}$. This indicates a reverse flow, as is confirmed by the vector-plot of the velocity field shown in detail A of figure 3.13 .

Figure 3.14 shows that up to at least $x_{1}=0.5 \mathrm{~mm}$ the velocity $u_{3}$ has negative values for a large part across the film thickness, which means that the fluid tends to flow towards the plate.
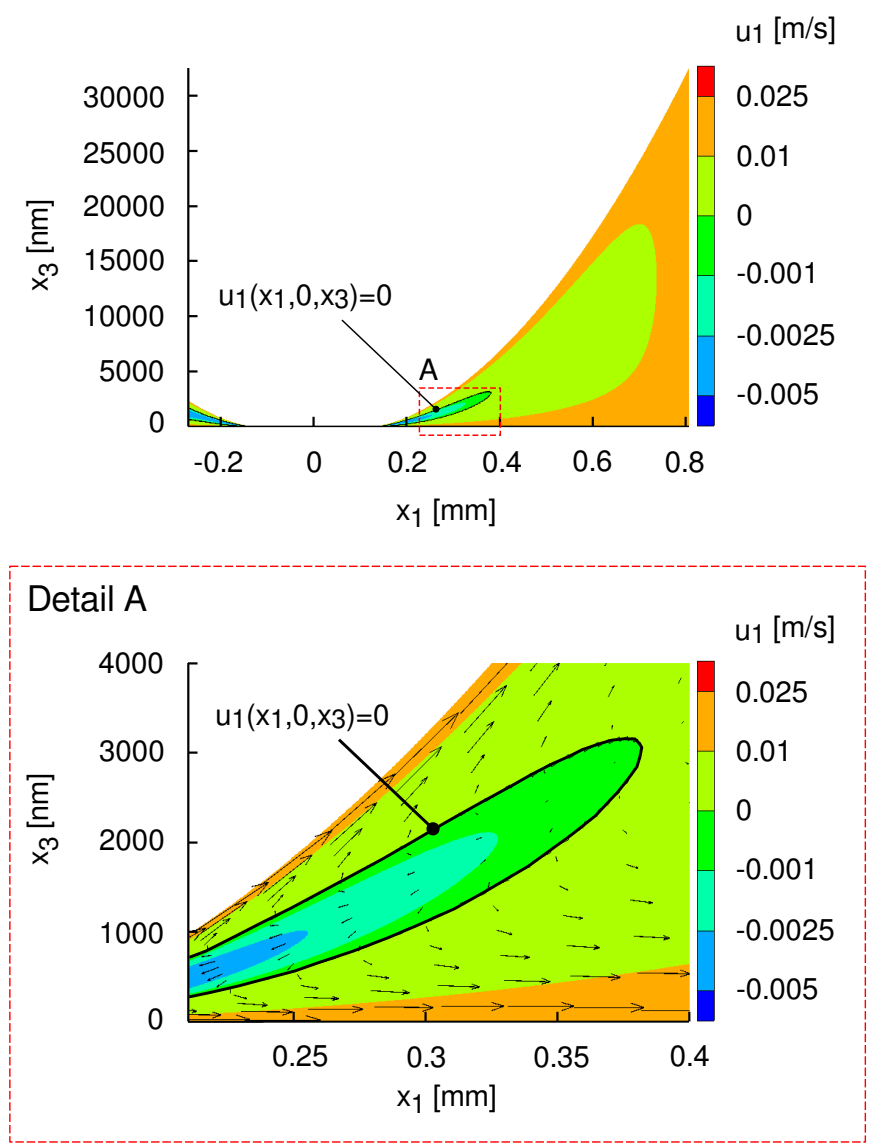

Figure 3.13: Velocity distribution in the plane $x_{2}=0$ for $u=0.015 \mathrm{~m} / \mathrm{s}$ and a 2-phase model with $\mathcal{D}=30$. Distributions of $u_{1}$ with detail $A$ showing the vector-plot of the velocity field. 

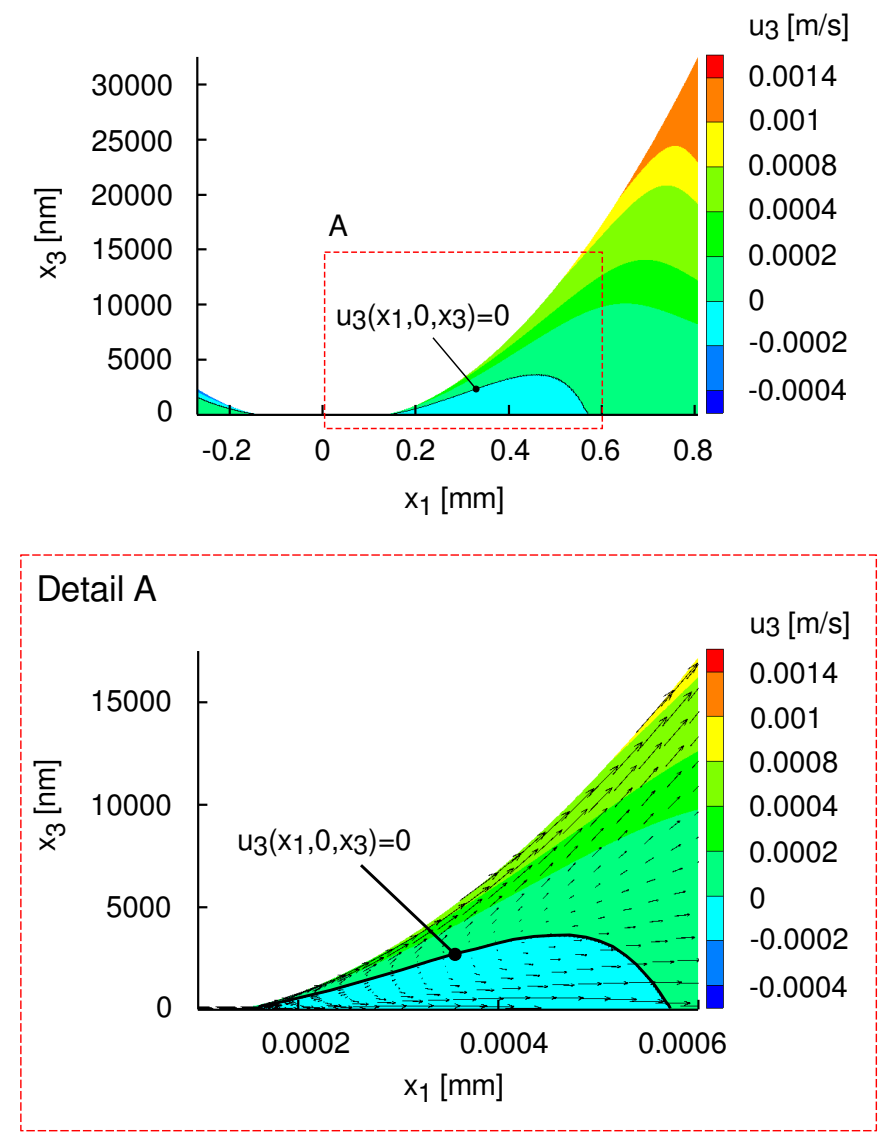

Figure 3.14: Velocity distribution in the plane $x_{2}=0$ for $u=0.015 \mathrm{~m} / \mathrm{s}$ and a 2-phase model with $\mathcal{D}=30$. Distributions of $u_{3}$ with detail $A$ showing the vector-plot of the velocity field.

In figures 3.15 and 3.16 the distribution of the velocity components $u_{1}, u_{2}$ and $u_{3}$ respectively are shown for $x_{3}=0.5 \mathrm{~h}$ (film midplane). Again, the velocity in the $x_{1}$ direction shows a reverse flow region within the cavitated zone. As expected, the velocity $u_{2}=0$ at $x_{2}=0$. The results for $u_{2}$ show that the flow envelopes the cavitation bubble, and it tends to return to the $x_{2}=0$-axis downstream the contact, enclosing the bubble. 


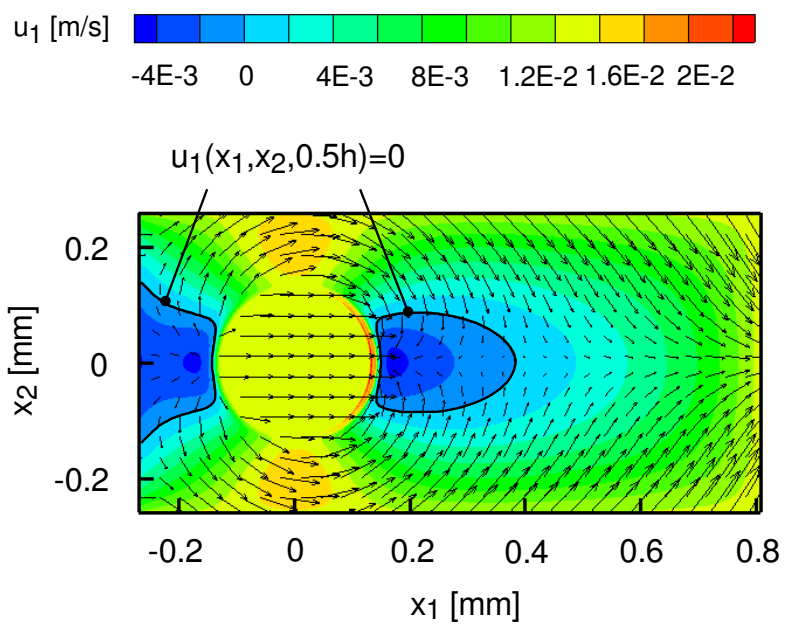

$\mathrm{u}_{2}[\mathrm{~m} / \mathrm{s}]$

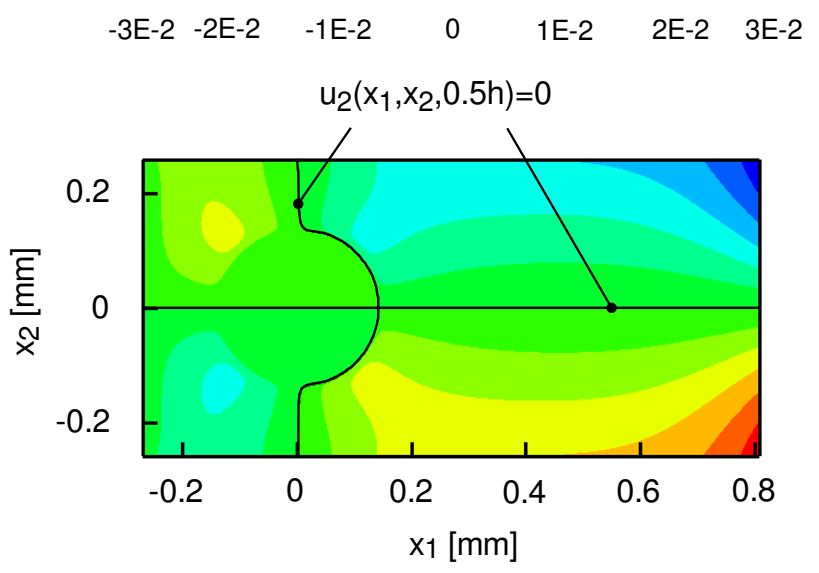

Figure 3.15: Velocity distribution in the plane $x_{3}=0.5 h$ for $u=0.015 \mathrm{~m} / \mathrm{s}$ and a 2-phase model with $\mathcal{D}=30$. Distributions of $u_{1}$ with the vector-plot of the velocity field (top) and $u_{2}$ (bottom). 

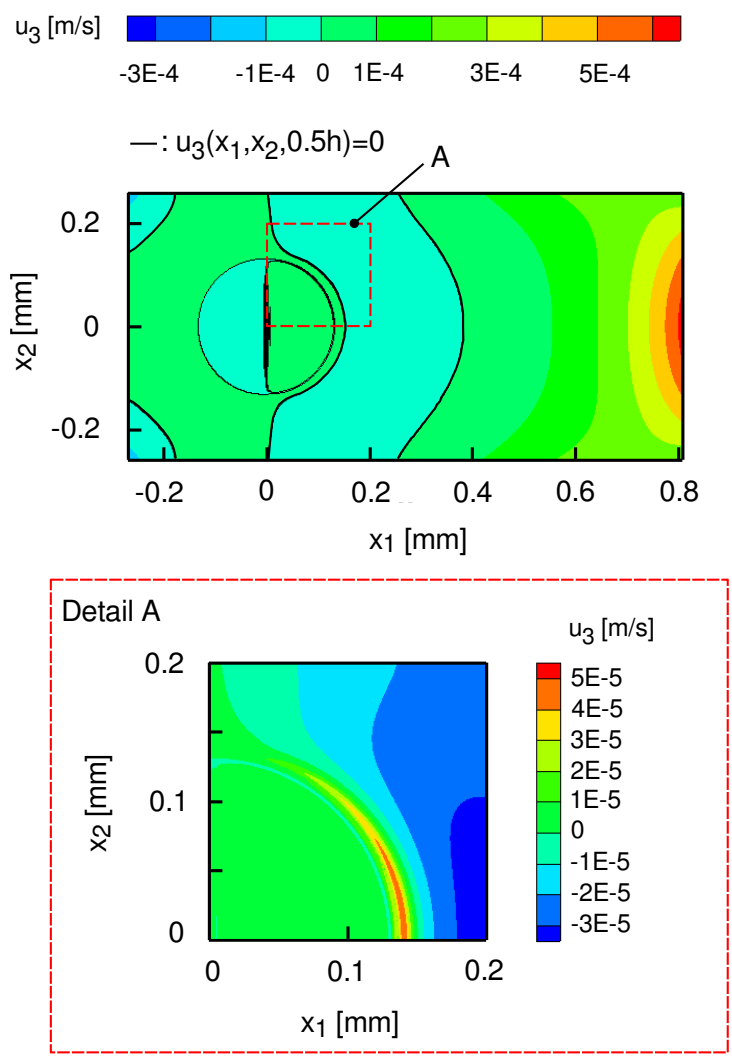

Figure 3.16: Velocity distribution of $u_{3}$ in the plane $x_{3}=0.5 h$ for $u=0.015 \mathrm{~m} / \mathrm{s}$ and a 2-phase model with $\mathcal{D}=30$. 


\subsubsection{Cavitation Criterion Based on Principal Stresses}

Alternatively, the cavitation bubble length can also be predicted using a different cavitation criterion based on the principal stress state calculated according to equation (3.14), see Joseph [63]. This criterion reads:

$$
p_{v a p}>-\sigma_{1}
$$

with $\sigma_{1}$ the maximum principal stress.

The predicted bubble length is now defined as the distance between the $x_{1}$-coordinate on the $x_{2}=0$ line at $x_{3}=0.5 h$ for which equation (3.22) applies, and the Hertzian contact radius $a$.

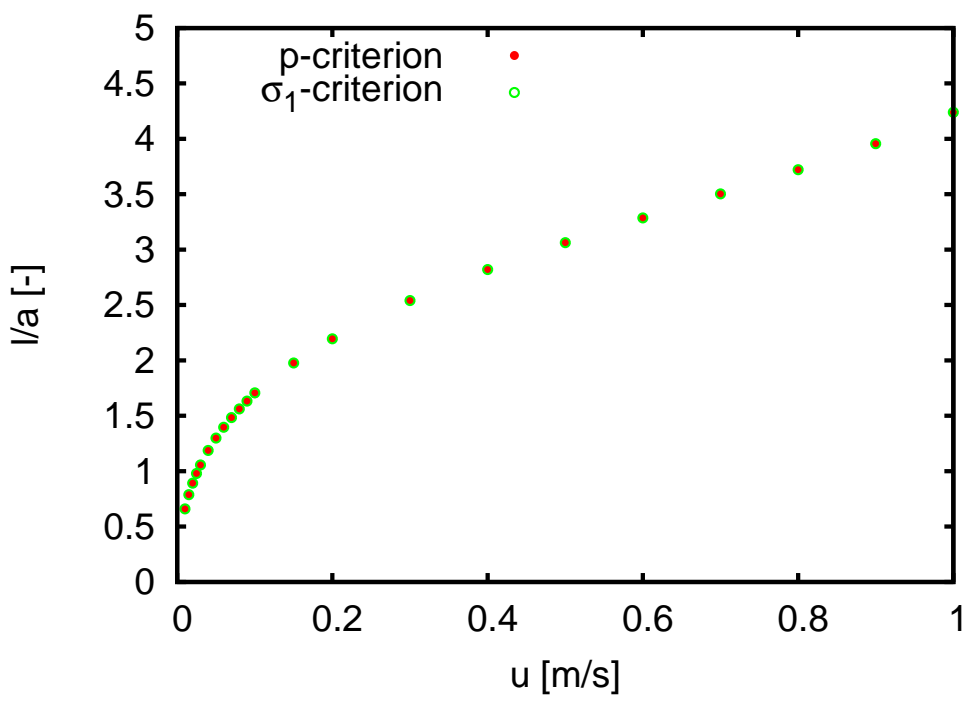

Figure 3.17: Numerical results of the ratio of cavitation bubble length to Hertzian contact radius versus the rolling velocity, based on gauge pressure- and principal stress criterion. Results for $\mathcal{D}=30$.

In figure 3.17 the numerical results for $l / a$ versus rolling velocity $u$ obtained with the 2-phase model and $\mathcal{D}=30$ are presented for both criteria. The criterion based on the principal stresses is indicated with $\sigma_{1}$ and original criterion is indicated with $p$. No significant differences in the results are observed between both criteria.

Only minor differences can be observed in the $x_{3}$-direction over the film thickness. For the negative gauge pressure criterion the bubble is constant over the thickness since the pressure is constant over $x_{3}$. This does not apply to the principal stresses because the deviatoric part in the stress tensor depends on $x_{3}$. This can be seen in figure 3.18 which shows the principal stress distribution $\sigma_{1}$. In this example the 2-phase model with $\mathcal{D}=30$ is used and the rolling velocity is $0.015 \mathrm{~m} / \mathrm{s}$. The cavitated area is indicated by 


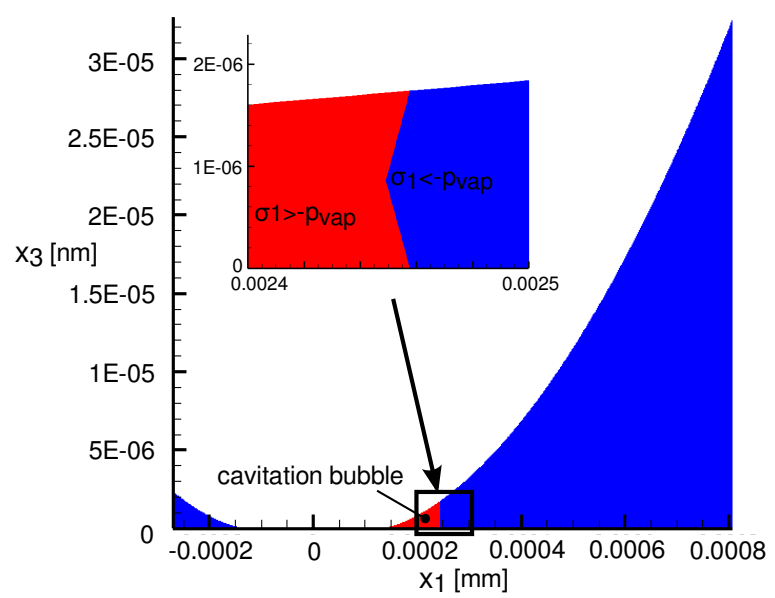

Figure 3.18: Cavitation region based on principal stress criterion. 2-phase model with $\mathcal{D}=30$ and $u=0.015 \mathrm{~m} / \mathrm{s}, x_{2}=0$.

the region for which $\sigma_{1}>-p_{v a p}$. On the surfaces of the ball and the plate the cavitated length is slightly longer. Figure 3.19 (top) shows the principal stress distribution, $\sigma_{1}$, for this example at $x_{3}=0.5 \mathrm{~h}$. The cavitated zone is indicated by the region for which $\sigma_{1}>-p_{v a p}$, the region has a darker colour and it is located inside the interface line. In figure 3.19 (bottom), the pressure distribution for this case is shown. The cavitation region, based on the pressure criterion, is indicated by the region for which $p<p_{\text {vap }}$. It can be seen that both criteria also lead to approximately the same cavitation bubble shape.

Again, the results presented here imply that for an even steeper pressure-density relation that predicts physical values for the pressure minima, the cavitation bubble length will still be underpredicted regardless of the used cavitation criterion. This indicates that the EHL-model coupled with a type of 2-phase pressure density relation as defined is obviously not able to accurately predict the cavitation bubble length. This suggests a lack of essential physics included in the model, e.g. surface tension effects, pressure- and density gradients across the film thickness and other 3D-effects such as the influence of the liquid lubricant flow around the contact and cavitation bubble. 
$\sigma_{1}$

-5E08 -4E08 -3E08-2E08-1.5E08 -1E08 -5E07 $\mid \sigma_{1}>-p_{\text {vap }}$
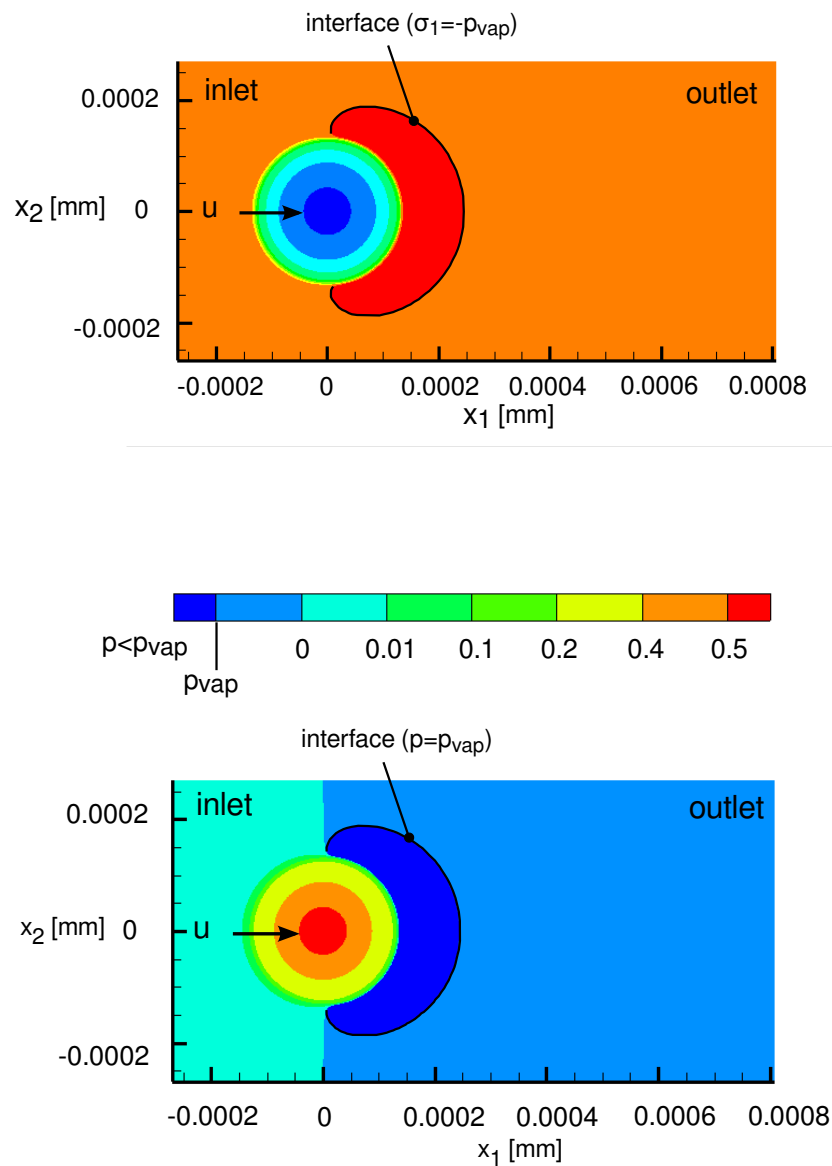

Figure 3.19: Cavitation region based on principal stress criterion (top) and based on the pressure criterion (bottom). 2-phase model with $\mathcal{D}=30$ and $u=0.015 \mathrm{~m} / \mathrm{s}, x_{3}=0.5 h$ (top). 


\subsection{Conclusion}

In this paper the possibility to numerically predict a cavitation bubble at the outlet side of an elasto-hydrodynamic contact has been investigated. A standard EHL model has been coupled with an elementary 2-phase model, which adds a pressure-density relation that yields a faster density decrease than the Dowson-Higginson relation for negative gauge pressures.

A cavitation bubble at the outlet side of an EHL contact can be predicted, but the pressure minima in the bubble have values that are not physical (too low). This can be improved by increasing the steepness $(\mathcal{D})$ of the pressure-density relation in the 2-phase model, which causes the gauge pressure minima to become less negative. However, the steepness of the pressure-density relation in the 2-phase model does not significantly affect the cavitation bubble length prediction.

It can be concluded that the numerical calculations highly underpredict the cavitation bubble length when compared to low velocity experiments [60. This also applies when different cavitation criteria are compared, i.e. the pressure- and the principal stress criterion. The numerically predicted bubble length based on the pressure criterion and the principal stress criterion $\left(\sigma_{1}\right)$ is not significantly different. Furthermore, the predicted bubble width near the contact is larger than observed in the experiments [60].

The computed cavitation bubble lengths relative to Hertzian contact radius show a linear dependence in the low-velocity regime and gradually switch towards a different linear trend in the high-velocity regime (with a lower slope). Experimental results in [60] also show a linear trend in the low velocity regime, but the slope is much larger than in the simulations.

The numerical results found for the ratio of the cavitation bubble length to the Hertzian contact radius scale linearly with the combination of Moes parameters $M$ and $L$ for elasticpiezoviscous regime [61], and thereby it is proportional to the dimensionless Moes film thickness parameter $H^{M}$.

It has been shown that it is not possible to predict correct values for the cavitation bubble length when using a standard EHL model together with the modifications presented in this paper and using a 2-phase density-pressure model for cavitation modeling. The cavitation lengths are strongly underpredicted, suggesting a lack of essential physics included in the model. In the prediction of the film thickness inside the contact a Reynolds based model is accurate and full Navier-Stokes solutions are not necessarily needed. However, in the outlet region more advanced models are needed that fully capture the 3D aspects of a 2-phase flow. Furthermore, it can be beneficial to include the effect of surface tension.

The results of this study are an invitation to exploit full 3D 2-phase flow CFD models which allow modeling of a $3 \mathrm{D}$ cavitation region to analyse the flow in the wake of rolling EHL point contacts in order to better understand the phenomenon of cavitation bubble formation and its length. 
Nomenclature

\begin{tabular}{|c|c|}
\hline$F_{3}$ & loading force in the $x_{3}-$ direction \\
\hline$R$ & radius of ball \\
\hline$E^{\prime}$ & reduced modulus of elasticity $\frac{2}{E^{\prime}}=\frac{1-\nu_{\text {ball }}^{2}}{E_{\text {ball }}}+\frac{1-\nu_{\text {plate }}^{2}}{E_{\text {plate }}}$ \\
\hline$E_{\text {ball }}, E_{\text {plate }}$ & modulus of elasticity of ball and plate respectively \\
\hline$\nu_{\text {ball }}, \nu_{\text {plate }}$ & Poisson's ratio of ball to plate respectively \\
\hline$a$ & Hertzian contact radius $a=\left(\frac{3 F_{3} R}{2 E^{\prime}}\right)^{\frac{1}{3}}$ \\
\hline $\begin{array}{l}p_{H} \\
l\end{array}$ & $\begin{array}{l}\text { Hertzian contact pressure } p_{H}=\frac{3 F_{3}}{2 \pi a^{2}} \\
\text { cavitation bubble length }\end{array}$ \\
\hline$T$ & temperature \\
\hline$u_{1}, u_{2}, u_{3}$ & lubricant velocities in $x_{1^{-}}, x_{2^{-}}, x_{3^{-}}$- direction respectively \\
\hline$u$ & rolling velocity \\
\hline$u_{1_{0}}, u_{2_{0}}, u_{3_{0}}$ & velocity of plate in $x_{1^{-}}, x_{2^{-}}, x_{3^{-}}$direction respectively \\
\hline$u_{1_{h}}, u_{2_{h}}, u_{3_{h}}$ & velocity of ball in $x_{1^{-}}, x_{2^{-}}, x_{3^{-}}$- direction respectively \\
\hline$u_{s}$ & sum velocity $u_{s}=u_{1_{0}}+u_{1_{h}}$ \\
\hline$p$ & gauge pressure: the pressure relative to the atmospheric pressure \\
\hline$p_{a b s}$ & absolute pressure \\
\hline$p_{\text {atm }}$ & atmospheric pressure \\
\hline$p_{v a p}$ & vapour pressure of lubricant \\
\hline$p_{\text {lim }}$ & pressure limit, a relation switch in the 2-phase model \\
\hline$\eta$ & dynamic viscosity of lubricant \\
\hline$\eta_{0}$ & temperature dependent viscosity at atmospheric pressure \\
\hline$p_{0}$ & pressure constant \\
\hline$z$ & pressure viscosity index \\
\hline$\rho$ & density of lubricant \\
\hline$\rho_{0}$ & density of lubricant at atmospheric pressure \\
\hline$\tilde{\alpha}$ & void fraction \\
\hline $\mathcal{A}, \mathcal{B}, \mathcal{C}, \mathcal{D}, \mathcal{E}$ & constants in pressure-density relations \\
\hline$h$ & film thickness \\
\hline$h_{c}$ & central film thickness \\
\hline$h_{0}$ & mutual approach \\
\hline$f$ & undeformed geometry \\
\hline$d$ & elastic deformation \\
\hline$\sigma_{i j}$ & stress tensor \\
\hline$\tau_{i j}$ & shear stress tensor \\
\hline$\delta_{i j}$ & Kronecker delta \\
\hline$\sigma_{1}, \sigma_{2}, \sigma_{3}$ & principal stresses \\
\hline
\end{tabular}


Chapter 3. A Challenge to Cavitation modeling in the outlet Flow

\begin{tabular}{|ll|}
\hline \multicolumn{1}{|c|}{ Nomenclature continued } \\
$M$ & dimensionless Moes parameter $M=\frac{F_{3}}{E^{\prime} R^{2}}\left(\frac{E^{\prime} R}{\eta_{0} u_{s}}\right)^{\frac{3}{4}}$ \\
$L$ & dimensionless Moes parameter $L=\alpha E^{\prime}\left(\frac{E^{\prime} R}{\eta_{0} u_{s}}\right)^{-\frac{1}{4}}$ \\
$H^{M}$ & dimensionless Moes film thickness parameter $H^{M}=\frac{h_{c}}{R}\left(\frac{E^{\prime} R}{\eta_{0} u_{s}}\right)^{\frac{1}{2}}$ \\
$\alpha$ & pressure-viscosity coefficient \\
\hline
\end{tabular}




\section{Appendix A: Grid Convergence Test}

A convergence test is done with the EHL-multigrid code for which: the pressure restriction is omitted, a Neumann (zero-gradient) pressure boundary condition applied at the outlet boundary and a 2-phase model is used. The constants in the relation used for the 2-phase model are defined as: $\mathcal{B}=\mathcal{C}=1, \mathcal{D}=100, \mathcal{E}=0$ and the limit pressure is $p_{\text {lim }}=0$.

The convergency calculations are performed on a domain of $x_{1} \in[-2 a, 6 a]$ and $x_{2} \in$ $[-2 a, 2 a]$. The finest grid levels applied are respectively with $2049 \times 1025,3073 \times 1537$, $4097 \times 2049,6145 \times 3073$ and $8193 \times 4097$ grid points. The calculations are performed at $25{ }^{\circ} \mathrm{C}$, according to the input parameters given in 3.1 and a rolling velocity of $1 \mathrm{~m} / \mathrm{s}$. The cavitation bubble length is used as a measure for grid convergence, and the results are given in figure 3.20 . The size of the marked mesh is used for the calculations throughout this study.

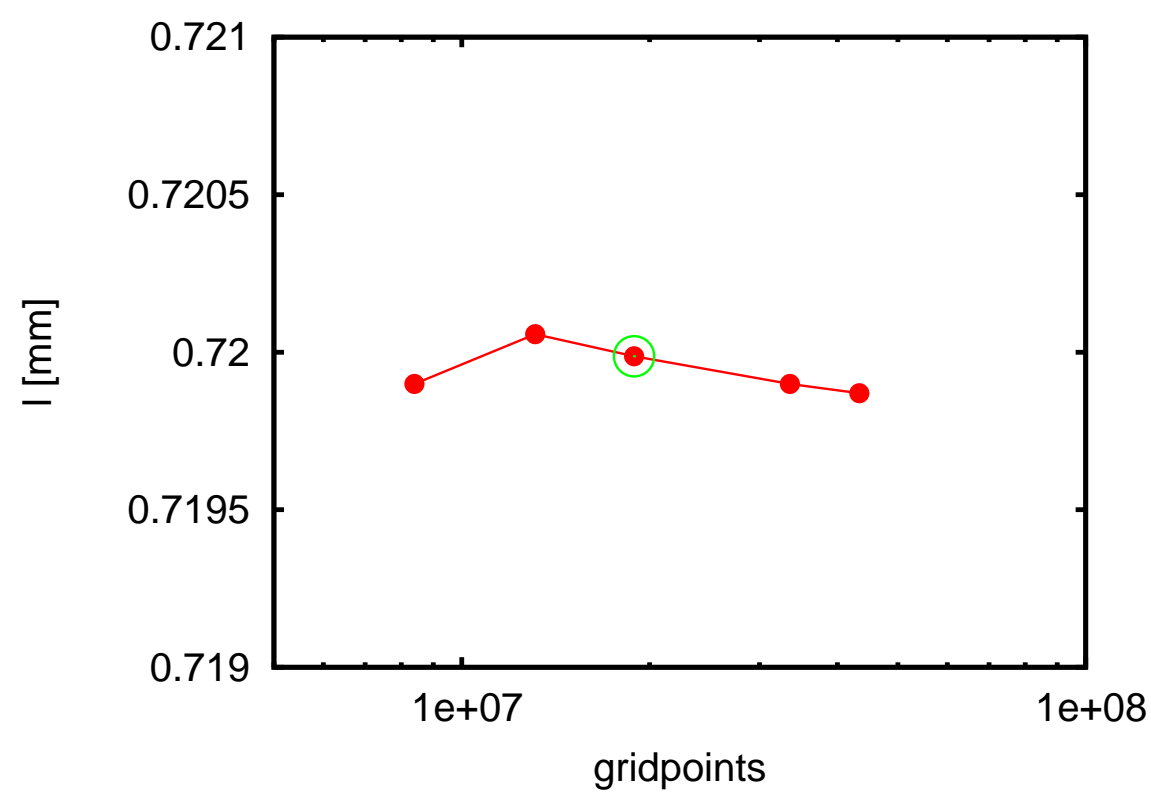

Figure 3.20: Cavitation bubble length versus mesh size. 
Chapter 3. A Challenge to Cavitation modeling in the outlet Flow

\section{Appendix B: Domain size Test}

A domain size test in the rolling direction ( $x_{1}$-direction) is done with the EHL-multigrid code for which: the pressure restriction is omitted, a Neumann (zero-gradient) pressure boundary condition applied at the outlet boundary and a 2-phase model is used. The constants in the relation used for the 2-phase model are defined as: $\mathcal{B}=\mathcal{C}=1, \mathcal{D}=100$, $\mathcal{E}=0$ and the limit pressure is $p_{\text {lim }}=0$.

The size of the tested domains are: $x_{1} \in[-2 a, 2 a], x_{1} \in[-2 a, 3 a], x_{1} \in[-2 a, 4 a]$, $x_{1} \in[-2 a, 5 a], x_{1} \in[-2 a, 6 a]$ and $x_{1} \in[-2 a, 7 a]$ and $x_{2} \in[-2 a, 2 a]$. The finest grid levels applied are respectively with $3073 \times 3073,3841 \times 3073,4609 \times 3073,5377 \times 3073$, $6145 \times 3073$ and $6913 \times 3073$ grid points. The calculations are performed at $25{ }^{\circ} \mathrm{C}$, according to the input parameters given in 3.1 and a rolling velocity of $1 \mathrm{~m} / \mathrm{s}$. Capturing of the total cavitation bubble length is used as a measure for the required domain size, and the results are plotted in figure 3.21. The domain size of the mesh used for the calculations throughout this study is $x_{1} \in[-2 a, 6 a]$ and $x_{2} \in[-2 a, 2 a]$ with $6145 \times 3073$ grid points on the finest level.

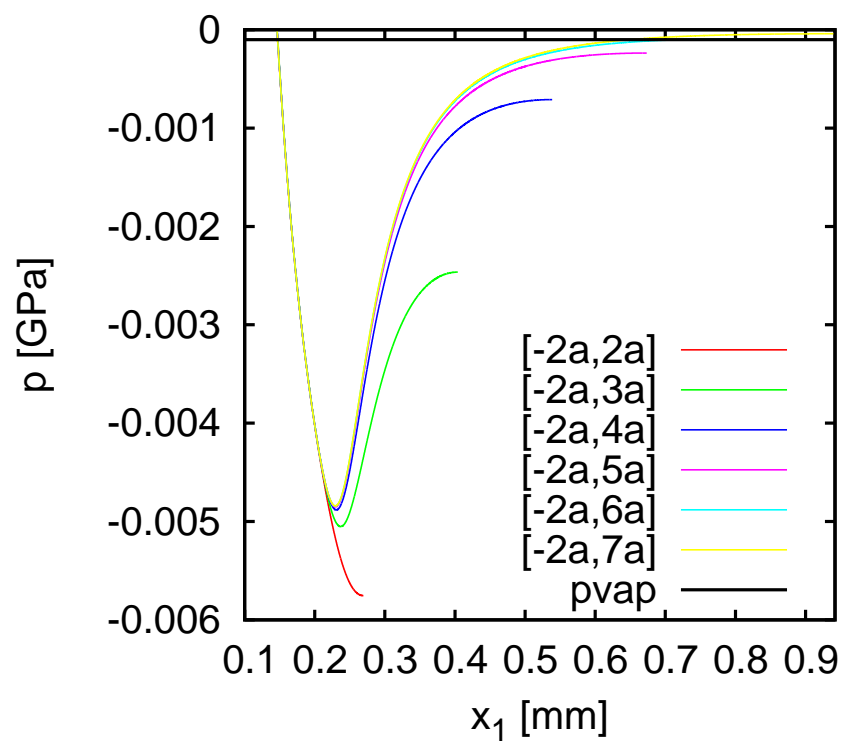

Figure 3.21: The effect of domain size in $x_{1}$-direction on the pressure distribution in the negative pressure zone. 


\section{Chapter 4}

\section{INVESTIGATION INTO THE VISCOELASTIC BEHAVIOUR OF A THIN LUBRICANT LAYER IN AN EHL CONTACT}

Inside a loaded EHL contact, even for low viscous lubricants, the pressure flow is virtually absent. Based on this knowledge, this paper explores to what extent EHL contact behaviour can be modeled using a simpler model in which the flow equation is replaced by an oedometric viscoelastic layer equation. Results for fully flooded-and mixed-lubricated conditions under pure rolling and squeeze conditions are presented and compared with results obtained with a standard Reynolds-based EHL-model. Although there are still discrepancies, the proposed model is shown to be able to predict characteristic behaviour of an EHL contact under fully-flooded and mixed-lubricated conditions remarkably well. This encourages further investigation.

The work in this chapter has been published as: E. van Emden, C.H. Venner and G.E. Morales-Espejel, Tribology International 111 (2017) 197-210.

DOI: http://dx. doi.org/10.1016/j.triboint.2017.03.014

\subsection{Introduction}

Once oil is trapped in a loaded rolling EHL contact it is subjected to high pressures. This strongly increases the viscosity of the oil, such that it behaves as a 'solid' layer that is transported from the inlet side towards the outlet of the contact, see also [60, 56]. This is clearly visible in the velocity distribution and-vectors plotted in figure 4.1 In this case the Reynolds equation was used to describe the lubricant flow in a pure-rolling situation. There is very little pressure driven flow inside the contact, it is mainly boundary driven transport. The velocity in the layer approximately equals the ball- and disc- velocity in almost the entire contact region. This is also observed by Hartinger et al. [74], who modeled an EHL line contact with CFD, using the full Navier-Stokes equations to describe the lubricant flow. 

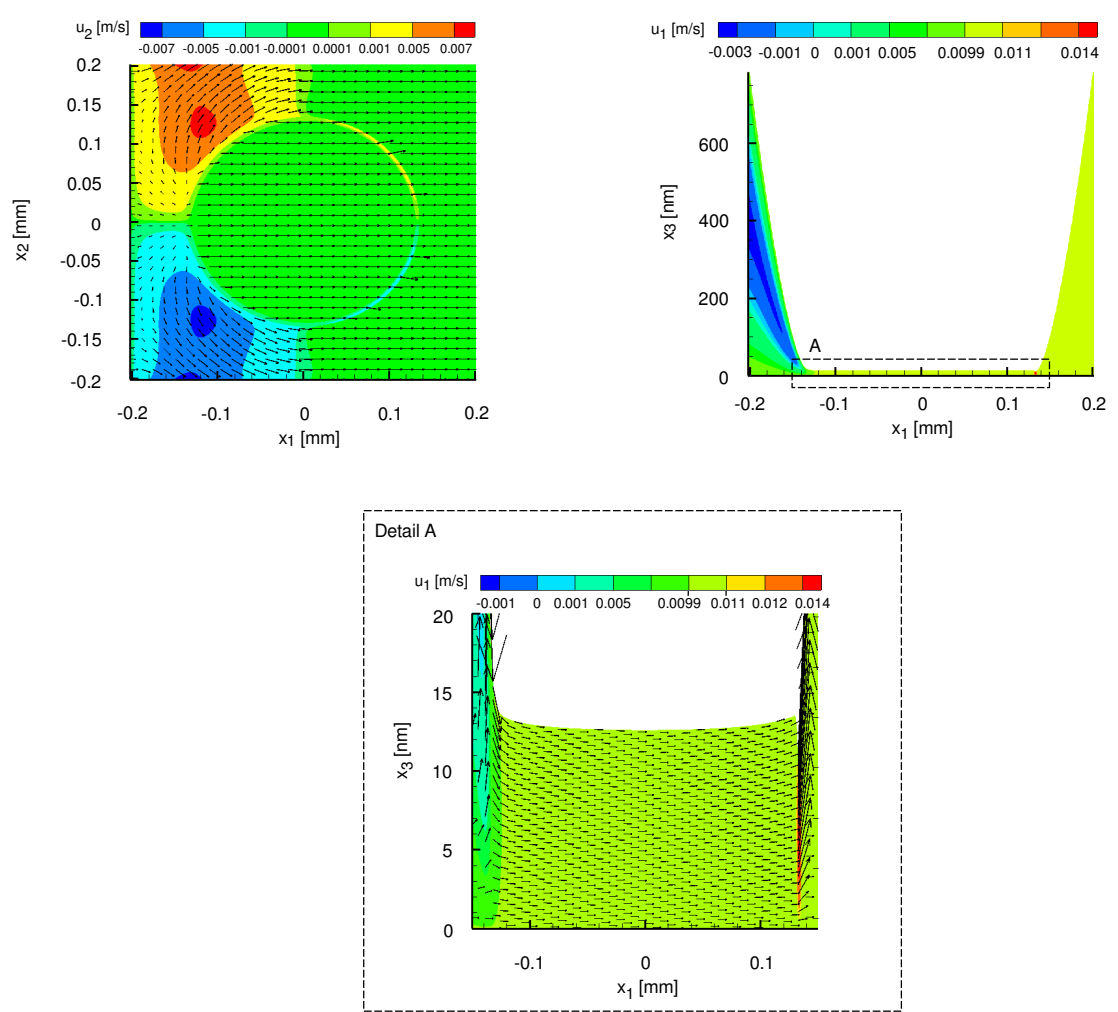

Figure 4.1: Velocity distributions obtained with a standard Reynolds-based EHL-model, $u=0.01 \mathrm{~m} / \mathrm{s}, F_{3}=20 \mathrm{~N}$ and $T=25{ }^{\circ} \mathrm{C}$. The equations are solved using a multigrid algorithm, see Venner and Lubrecht [2], employing 7-level multigrid W-cycles with $1025 \times$ 1025 grid points on the finest grid level.

In the highly loaded contact region the oil behaves stiffer than the ball and disc, which causes a deformation of the ball and disc. In a point contact the oil film has a horse-shoe shaped zone having side lobes with minimum film thickness towards the outlet, i.e. it has a smaller film thickness compared to the central film thickness. With sufficient lubricant, the amount of oil trapped inside the contact increases with increasing rolling velocity such that both the minimum and central film thickness increase.

In EHL literature, studies can be found concerning the prediction of friction with viscoelastic constitutive relations. Tevaarwerk and Johnson [75], proposed a constitutive relation to describe the shear behaviour of lubricating oil films at high pressure. The relation stems from the behaviour of a linear spring with shear modulus $G$ and a nonlinear damper connected in series, which is referred to as a non-linear Maxwell model.

Auslender [76], Trifa [77] together with Sidoroff et al. [78], analysed an oedometric 
elastic squeeze model for a confined layer between two bodies. An 'oedometric' model describes the behaviour of a thin elastic layer and follows from the Navier-Cauchy equations by invoking the thin layer assumption $(h / L \ll 1)$. This is analogous to the derivation of the Reynolds equation by applying the same assumption $(h / L \ll 1)$ to the Navier Stokes equations. Characteristic for the oedometric model is that there are no displacements in the lateral directions $x_{1}$ and $x_{2}$, only in the layer thickness direction $\left(x_{3}\right)$, i.e. there is no flow of material sideways. With this model, Trifa et al. [79] analysed squeeze of thin films for a sphere-plane contact under imposed harmonic vertical displacement.

Inspired by the observations concerning the 'solid' layer behaviour of the lubricant inside the contact zone, this paper investigates the possibility to model the behaviour of a thin oil film in the contact zone of a rolling ball on a disc by a viscoelastic oedometric squeeze model. This model is based on the purely elastic oedometric model of Auslender and coworkers [76, 77, 78], but with viscoelastic behaviour obtained by connecting a pressure- and strain- dependent oedometric spring in parallel with a pressure-dependent viscous damper. The resulting model is a dry contact model with a viscoelastic oedometric layer between the ball and the disc. A bottom-up approach is followed, starting from the dry contact equations for which the layer thickness is zero inside the contact, see Venner [61] and Wijnant [62], and adding the layer to the gap height equation. This model may open many possibilities for mixed lubrication modeling in pure rolling as it allows a 'natural' transition to dry contact. It can also be used to study effects of layers with local characteristics, and the design optimization and analysis of soft layers, e.g. polymer coatings, see Pujari [80] and Nagendra [81].

\subsection{Viscoelastic layer model}

Consider the situation of a model ball-on-disc contact as used in experiments sketched in figure 4.2 (top). A ball with radius $R$ is pressed with a normal force $F_{3}$ in the $x_{3}$-direction against a disc. Pure rolling is assumed in the $x_{1}$-direction. In between the sufaces a thin layer of oil is present, its thickness is allowed to vanish. We focus on the region in which the ball and disc are elastically deformed, i.e. the contact zone.

To model this situation and predict the layer thickness, the elastic deformation of the ball and disc, and the pressure distribution inside the contact zone, a new viscoelastic layer model is proposed. This model consists of three equations: a gap equation for a circular contact, a layer equation and a force balance equation. The gap equation together with the force balance equation describe the dry contact situation, and yields the solution presented by Hertz [3], see also Wijnant [62] and Venner [61].

The layer equation describes the 'lubricant' behaviour in the contact region. Instead of using a fluid-based approach (such as the Reynolds equation) we take a solid-based approach with a viscoelastic layer. It is chosen to model the layer with multiple viscoelastic elements acting in the layer thickness direction $\left(x_{3}\right)$, see figure 4.2 (bottom). The idea originates from a Kelvin-Voigt element, see for example Young and Lovell [82]. It is assumed that the layer moves with a uniform velocity through the contact region, where the velocity is equal to that of the ball and the disc under pure rolling conditions. 


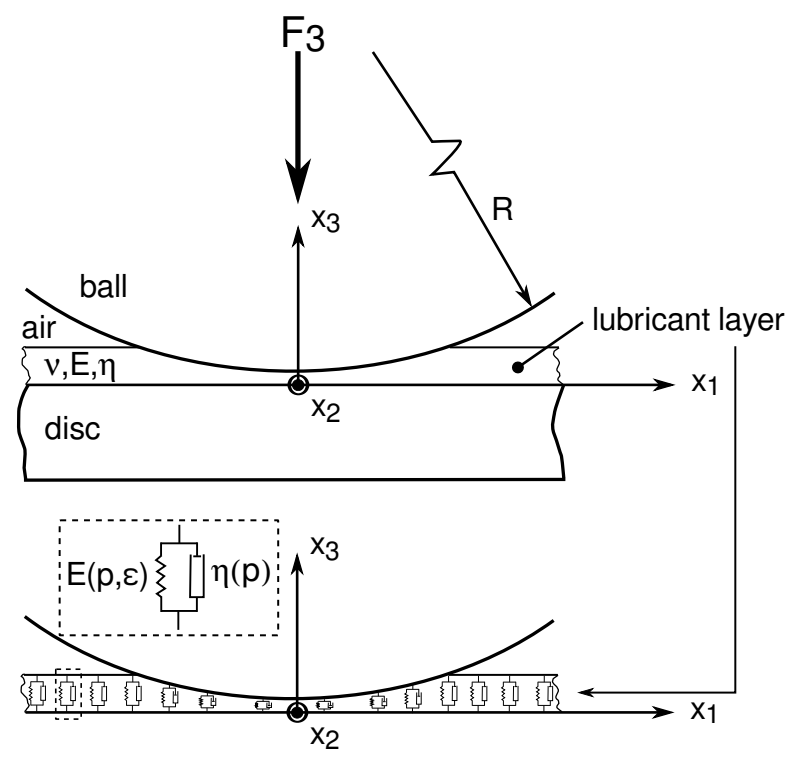

Figure 4.2: Generic sketch of a confined viscoelastic layer between a bal and a disc.

An element consists of a spring parallel to a damper. The damper has a pressure dependent dynamic viscosity. The modulus of elasticity of the spring is oedometric and depends on the local pressure and strain of the layer.

The elements are distributed over the $\left(x_{1}, x_{2}\right)$-domain, and allow no instantaneous deformation: the deformation depends on the modulus of elasticity of the spring, the dynamic viscosity of the damper and the loading time. After releasing the pressure, the strain recovers similarly in time to zero.

This model is much simpler and allows local absence of layer. Therefore it is possible to create conditions that mimic local mixed lubricated contacts, i.e. partial contact due to lubricant layers with dry spots present in the contact region.

\subsubsection{Model equations}

The three model equations, the gap equation for a circular contact, the layer equation and the force balance equation, will now be described in more detail.

The gap height consists of the geometry of the contacting surfaces, the pressuredependent deformation of the ball and disc, the viscoelastic layer thickness and the mutual approach. Therefore, the gap height equation reads:

$$
h\left(x_{1}, x_{2}, t\right)=h_{0}(t)+f\left(x_{1}, x_{2}\right)+w\left(x_{1}, x_{2}, t\right)-l\left(x_{1}, x_{2}, t\right)
$$


with $f\left(x_{1}, x_{2}\right)$ the undeformed geometry:

$$
f\left(x_{1}, x_{2}\right)=\frac{x_{1}^{2}}{2 R}+\frac{x_{2}^{2}}{2 R}
$$

The term $w\left(x_{1}, x_{2}, t\right)$ is the elastic deformation of the ball and disc which is modeled by the elastic half space expression, see Johnson [83]:

$$
w\left(x_{1}, x_{2}, t\right)=\frac{2}{\pi E^{\prime}} \iint_{S} \frac{p\left(x_{1}^{\prime}, x_{2}^{\prime}, t\right) d x_{1}^{\prime} d x_{2}^{\prime}}{\sqrt{\left(x_{1}-x_{1}^{\prime}\right)^{2}+\left(x_{2}-x_{2}^{\prime}\right)^{2}}}
$$

Here, $p\left(x_{1}^{\prime}, x_{2}^{\prime}, t\right)$ is the time-dependent local pressure and $E^{\prime}$ the reduced modulus of elasticity of the ball and disc.

The term $l\left(x_{1}, x_{2}, t\right)$ represents the viscoelastic layer thickness, which can be calculated using the strain $\varepsilon\left(x_{1}, x_{2}, t\right)$ and the initial layer thickness $l_{0}\left(x_{1}, x_{2}\right)$ :

$$
l\left(x_{1}, x_{2}, t\right)=l_{0}\left(x_{1}, x_{2}\right)\left(1-\varepsilon\left(x_{1}, x_{2}, t\right)\right)
$$

The initial layer thickness $l_{0}\left(x_{1}, x_{2}\right)$ can be interpreted as the initial undeformed lubricant layer. For more general information concerning strain relations see e.g. [82, 84].

The element strain $\varepsilon\left(x_{1}, x_{2}, t\right)$ follows from the ordinary differential equation at each location $\left(x_{1}, x_{2}\right)$, see Young and Lovell [82]:

$$
\eta \frac{\partial \varepsilon}{\partial t}+E \varepsilon=p
$$

with $E=E\left(E_{0}, p, \varepsilon\right)$ and $\eta=\eta(p)$ the modulus of elasticity and the dynamic viscosity of the layer, respectively. When the strain, from equation (4.4), is substituted in equation (4.5), the differential equation for the layer thickness is:

$$
-\frac{\eta}{l_{0}} \frac{\partial l}{\partial t}+E\left(1-\frac{l}{l_{0}}\right)=p
$$

More details about the layer material behaviour, represented by $\eta$ and $E$ are given in section 4.2.2

When neglecting system dynamics, e.g. inertia, the integral over the pressure in the normal direction must equal the applied load $F_{3}$, and the force balance equation reads:

$$
\iint_{S} p\left(x_{1}, x_{2}, t\right) d x_{1} d x_{2}=F_{3} \quad \text { for which } \quad x_{1}, x_{2} \in[-\infty, \infty]
$$

The value of $h_{0}(t)$, the mutual approach in equation (4.1), is determined by the force balance equation. 


\subsubsection{Layer material}

The oedometric value of the modulus of elasticity of the layer is determined according to:

$$
E_{o}=\frac{E_{\text {layer }}}{1-\left(\frac{2 \nu^{2}}{(1-\nu)}\right)}
$$

where $E_{\text {layer }}$ is the original modulus of elasticity and $\nu$ is Poisson's ratio of the layer material. A value of $\nu=0.3$ is chosen. The derivation of the oedometric modulus of elasticity [76, 78, 77, 79] is described in detail in appendix A.

In case of a steady (local) dry contact, the physical limit for the layer thickness is $l=0$ and the strain $\varepsilon=1$ can not be exceeded. Equation (4.5) reduces to:

$$
\lim _{\varepsilon \rightarrow 1} E=p
$$

To ensure that this asymptotic behaviour is obtained for all $l\left(x_{1}, x_{2}\right) \geq 0$, a non-linear elastic modulus of elasticity $E\left(x_{1}, x_{2}, t\right)$ is defined. As a first step, a generic relation is chosen based on the local pressure and strain. When the strain value equals $1(l=0)$, the modulus of elasticity equals the local pressure. For pressures below $E_{o}$, the local modulus of elasticity is fixed at the value $E_{o}$ (independent of the local strain), and the strain will asymptotically go to:

$$
\lim _{t \rightarrow \infty} \varepsilon=\frac{p}{E_{o}}
$$

Here the following relations are introduced to obtain this behaviour:

$$
\begin{array}{ll}
p>E_{o}: & E=E_{o}+0.5\left(p-E_{o}\right)+0.5\left(p-E_{o}\right) \operatorname{erf}(4 \pi(\varepsilon-0.5)) \\
p \leq E_{o}: & E=E_{o}
\end{array}
$$

Note that there are more possible relations that also yield the desired behaviour as discussed above.

Figure 4.3 shows the resulting modulus of elasticity for several pressure- and strain values. For $p_{\text {ref }}$ the maximum Hertzian pressure is chosen. Note that it is possible for $p\left(x_{1}, x_{2}, t\right)$ to exceed $p_{\text {ref }}$.

The dynamic viscosity for the damper is taken piezo-viscous and chosen of the form:

$$
\eta(p)=\mathcal{C} \cdot \eta_{0} \cdot e^{\left(\left(\ln \left(\eta_{0}\right)+9.67\right)\left(-1+\left(1+\frac{p}{p_{0}}\right)^{z}\right)\right)}
$$

Here, $\eta_{0}$ is the temperature dependent viscosity at ambient pressure, $z$ is the pressure viscosity index and $p_{0}$ is a constant. For $\mathcal{C}=1$, this relation is equal to the relation proposed by Roelands, see [59]. However, the dynamic viscosity-pressure relation proposed by Roelands works in the shear direction. The dynamic viscosity used in the element is basically different from a shear viscosity; it works in the normal direction, and in the layer model no lubricant is allowed to flow in the lateral directions. In the present work a value of $\mathcal{C}=5.5 \cdot 10^{5}$ was empirically determined and found to give reasonable/good results, see section 4.4.1 when compared to the results obtained with the conventional EHL model. 

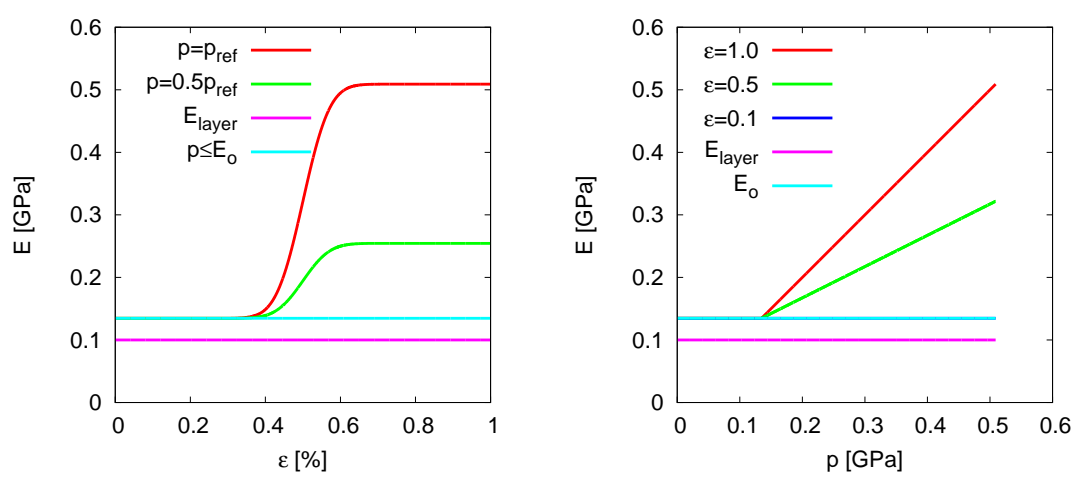

Figure 4.3: Modulus of elasticity $E$ as a function of strain (left) and pressure (right) for various pressure- and strain values respectively.

\subsubsection{Dimensionless element equations}

The dimensionless model equations can be obtained by introducing dimensionless forms of the spatial coordinates, the time variable, the modulus of elasticity and the dynamic viscosity of the layer as follows:

$$
\begin{gathered}
\bar{x}_{1}=\frac{x_{1}}{a_{h}} \quad \bar{x}_{2}=\frac{x_{2}}{a_{h}} \quad \bar{x}_{3}=\frac{x_{3} \cdot R}{a_{h}^{2}} \\
\bar{t}=\frac{t \cdot u_{1}}{a_{h}} \quad \bar{\eta}=\frac{\eta}{\eta_{0}} \quad \bar{E}_{l}=\frac{E}{p_{h}}
\end{gathered}
$$

with $a^{h}$ and $p_{h}$ the Hertzian contact radius and the maximum Hertzian pressure for a circular contact, respectively.

The dimensionless equation for the gap height reads:

$$
\bar{h}\left(\bar{x}_{1}, \bar{x}_{2}, \bar{t}\right)=\bar{l}_{0}(\bar{t})+\frac{\bar{x}_{1}^{2}}{2 R}+\frac{\bar{x}_{2}^{2}}{2 R}+\frac{2}{\pi^{2}} \int_{\bar{x}_{2, a}}^{\bar{x}_{2, b} \int_{\bar{x}_{1, a}}^{\bar{x}_{1, b}}} \frac{\bar{p}\left(\bar{x}_{1}^{\prime}, \bar{x}_{2}^{\prime}, t\right) d \bar{x}_{1}^{\prime} d \bar{x}_{2}^{\prime}}{\sqrt{\left(\bar{x}_{1}-\bar{x}_{1}^{\prime}\right)^{2}+\left(\bar{x}_{2}-\bar{x}_{2}^{\prime}\right)^{2}}}-\bar{l}\left(\bar{x}_{1}, \bar{x}_{2}, \bar{t}\right)
$$

with

$$
\bar{l}\left(\bar{x}_{1}, \bar{x}_{2}, \bar{t}\right)=\bar{l}_{0}\left(\bar{x}_{1}, \bar{x}_{2}\right)\left(1-\varepsilon\left(\bar{x}_{1}, \bar{x}_{2}, \bar{t}\right)\right)
$$

The dimensionless differential equation (4.5) for the layer reads:

$$
\left(\frac{\eta_{0}}{p_{h}}\right)\left(\frac{u_{1}}{a_{h}}\right) \bar{\eta} \frac{\partial \varepsilon}{\partial \bar{t}}+\bar{E}_{l} \varepsilon=\bar{p}
$$

The dimensionless Deborah number, $\mathcal{D} e$, appears in the dimensionless form of the 
differential equation (4.5). For the case of constant $E$ and $\eta, \mathcal{D} e$ is defined as:

$$
\mathcal{D} e=\frac{\tau}{t}=\frac{\frac{\eta}{E}}{\frac{2 a_{h}}{u_{1}}}
$$

De relates the relaxation time $\tau$ to the residence time of an element in the contact. However, it is not a constant as $E$ and $\eta$ vary significantly inside the contact region. At the inlet side of the contact zone the local Deborah number is very low, i.e. the layer acts as a fluid. In the center region of the contact the Deborah number is much higher and the layer acts as a solid.

The dimensionless form of the force balance equation reads:

$$
\iint_{\bar{x}_{2, a}}^{\bar{x}_{2, b} \bar{x}_{1, b}} \bar{p}\left(\bar{x}_{1}, \bar{x}_{2}, \bar{t}\right) d \bar{x}_{1} d \bar{x}_{2}=\frac{2 \pi}{3}
$$

\subsection{Numerical solution}

The model equations are discretized in space on a rectangular spatial grid with a uniform mesh size in both the $x_{1}$ - and $x_{2}$-directions. Second-order accurate finite-difference approximations are used. The spatial coordinates are fixed to the contact, e.g. the relative motion between the computational grid and the centre of the ball is zero such that the surface with the layer moves though the grid in the $x_{1}$-direction with velocity $u_{1}$.

The layer strain equation (4.5) is discretized in time using second-order accurate explicit time stepping, see appendix B.

At each timestep the deformation integral and the gap equation are solved iteratively by using two different multilevel methods for efficiency, see Venner and Lubrecht [2].

For a detailed description of the solution method see appendix $C$. 


\subsubsection{Input parameters}

\begin{tabular}{|ll||l|}
\hline parameter set up & {$[$ unit ] } & condition \\
\hline radius of ball $(R)$ & $\mathrm{m}$ & $9.525 \cdot 10^{-3}$ \\
rolling velocity $(u)$ & $\mathrm{m} / \mathrm{s}$ & $(0.0) 0.01$ \\
loading force $(F)$ & $\mathrm{N}$ & 20 \\
\hline lubricant & & viscoelastic layer, HVI60 \\
initial layer thickness $\left(l_{0}\right)$ & $\mathrm{nm}$ & 25 \\
temperature & ${ }^{\circ} \mathrm{C}$ & 25 \\
dynamic viscosity $\left(\eta_{0}\right)[47]$ & $10^{-3} \mathrm{~Pa} \cdot \mathrm{s}$ & 44.7 \\
pressure constant $\left(p_{0}\right)[2]$ & $10^{8} \mathrm{~Pa}$ & 1.96 \\
viscosity pressure coefficient $\alpha$ & $10^{-8} \mathrm{~Pa}$ & 2.25 \\
$\mathcal{C}$ & $10^{5} \mathrm{~Pa} \cdot \mathrm{s}$ & 5.5 \\
modulus of elasticity layer $\left(E_{\text {layer }}\right)$ & $10^{8} \mathrm{~N} / \mathrm{m}^{2}$ & 1.0 \\
reduced modulus of elasticity $\left(E^{\prime}\right)$ & $10^{11} \mathrm{~N} / \mathrm{m}^{2}$ & 1.17 \\
\hline
\end{tabular}

Table 4.1: Conditions for numerical calculations.

To investigate the capability of the model to mimic conventional lubricated contact results, the input parameters used in the simulations are taken from optical interferometry model ball-on-disc conditions [60] and are given in table 4.1. The oil has a low viscosity, this was deliberately chosen to validate the absence of pressure flow even in this case. The following cases are considered:

- The formation of a 'fully flooded' contact: restarting from a layer obtained after a sudden stop. The rolling velocity is $0.01 \mathrm{~m} / \mathrm{s}$. The results of the developed steady contact are compared to the (numerical) results of a conventional EHL contact.

- A contact loaded in squeeze, starting with a sudden stop from steady pure rolling at $u_{1}=0.01 \mathrm{~m} / \mathrm{s}$.

- Surface and layer features travelling through a contact: a dent in the ball, a bump on the ball and a hole in the layer.

For the lubricated case under the conditions given in table 4.1 and a rolling velocity of $u_{1}=0.01 \mathrm{~m} / \mathrm{s}$, a central film thickness of $h_{c} \approx 12.5 \mathrm{~nm}$ is predicted with the conventional Reynolds based EHL model. Based on the knowledge from starved contact behaviour that an inlet oil layer of at least $2 \cdot h_{c}$ provides a fully flooded contact, see e.g. Popovici [30], we take an initial layer thickness of $l_{0}=25 \mathrm{~nm}$ as input condition for the layer under these conditions. As a first step we will restrict ourselves to one operating condition for each case see table 4.1 leaving more extensive parameter variations to future research. 


\subsection{Results}

For the results in this section, the computational domain size is $\bar{x}_{1} \in[-1.25,1.25]$ and $\bar{x}_{2} \in[-1.25,1.25]$ with multiple grid levels in a $\mathrm{V}$-cycle using $257 \times 257$ grid points on the finest grid level. The number of time steps used per spatial interval (finest grid level) is $n_{t}=10$. i.e. $\Delta t=1.337603 \cdot 10^{-5} \mathrm{~s}$ for $u_{1}=0.01 \mathrm{~m} / \mathrm{s}$. For the squeeze problem a time step size of $\Delta t=5.35041 \cdot 10^{-5} \mathrm{~s}$ is used.

At each timestep the system is solved to a numerical error far below the discretization error. In appendix D grid convergence and timestep convergence results are shown to demonstrate that the system has a mathematically consistent grid-independent solution.

\subsubsection{Development of a steady rolling contact}
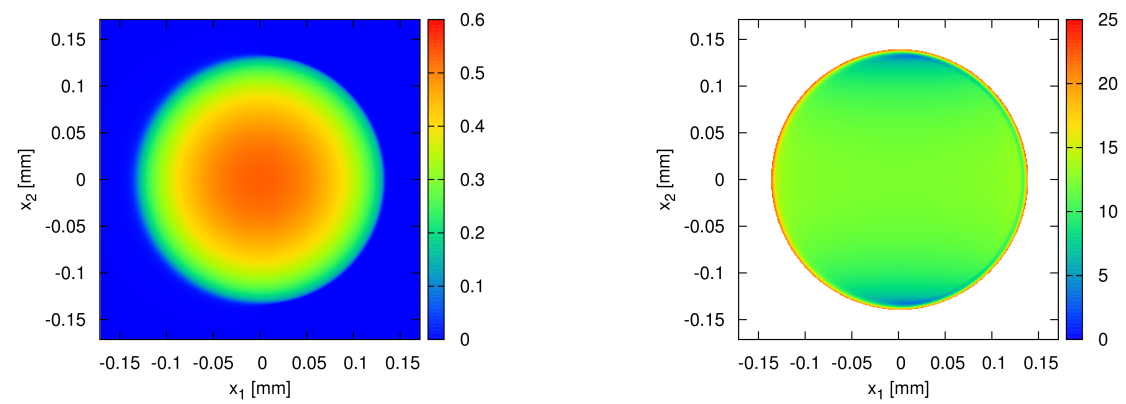

Figure 4.4: Contact pressure (left) and film thickness (right) results obtained with the Reynolds based EHL solver [61, 2]. $u_{1}=0.01 \mathrm{~m} / \mathrm{s}, F=20 \mathrm{~N}$.

Figure 4.4 shows the steady pressure- and film thickness results obtained with a Reynolds based EHL solver, Venner and Lubrecht [61, 2]. The rolling velocity is $u_{1}=0.01$ $\mathrm{m} / \mathrm{s}$ and the loading is $F=20 \mathrm{~N}$ at a temperature of $25{ }^{\circ} \mathrm{C}$. A total of 6 grid levels in a multigrid $\mathrm{W}$-cycle are employed to solve the equations. The finest grid level has $257 \times 257$ grid points. In figure 4.4 (right) the horse shoe shaped deformation with the lower film thickness in the side lobes is clearly recognizable. Here the central film thickness is $h_{c}=12.3 \mathrm{~nm}$.

In general, a contact has been lubricated previously during rolling. The film formation then starts with a low or zero film thickness in the contact zone. The present model is used to simulate the formation of a layer in a steady pure rolling contact. At $t=0$ the simulation starts from the solution of a fully squeezed layer with initial (undeformed) thickness $l_{0}=25 \mathrm{~nm}$ confined between a rolling ball and disc. The squeezed layer will be discussed later in section 4.4.2. The rolling velocity is $u_{1}=0.01 \mathrm{~m} / \mathrm{s}$. The layer deforms in time until a steady deformed layer has formed with a central film thickness of 
$h_{c}=11.6 \mathrm{~nm}$. The central- and minimal- layer thickness together with the maximum pressure during steady layer formation is shown in figure 4.5 as a function of time. The layer thickness distribution $\left(l\left(x_{1}, x_{2}\right), l\left(x_{1}, 0\right)\right)$ and the pressure distribution $\left(p\left(x_{1}, 0\right)\right)$ for the arbitrary chosen times $t_{1}, t_{2}, t_{3}$ and $t_{\text {steady }}$, marked in this figure, are shown in figure 4.6. After approximately $0.068 \mathrm{~s}$ the layer has reached a steady state. The ball has travelled a distance of approximately 5 contact radii during that time. The calculated layer thickness distribution at steady state shows all the characteristics as encountered in experiments and predicted by a conventional EHL solver. In figure 4.6 (bottom) the horse shoe shaped deformation with the lower layer thickness in the side lobes is clearly visable. Note that the same steady state solution can be obtained when a uniform layer is taken as initial solution.

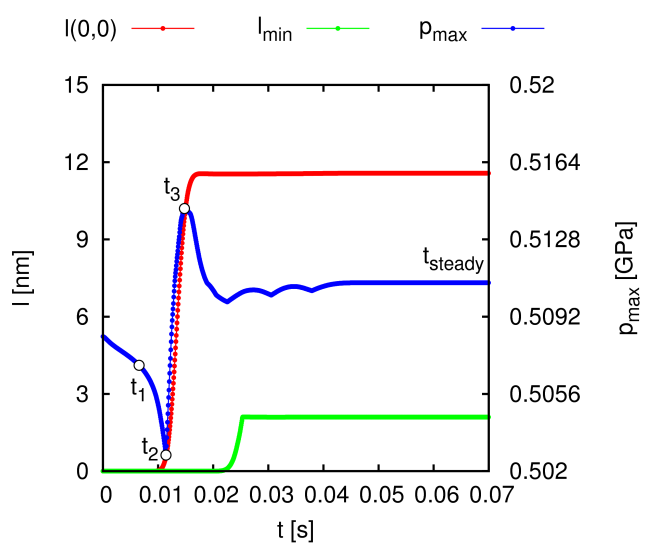

Figure 4.5: The maximum pressure and minimum- and central- layer thickness developing in time in a steady rolling contact, $u_{1}=0.01 \mathrm{~m} / \mathrm{s}, F=20 \mathrm{~N}, \Delta t=1.337603 \cdot 10^{-5} \mathrm{~s}$. Restart from a squeezed layer $l_{0}=25 \mathrm{~nm}$.

The results are remarkably similar to the start-up results presented by Popovici et al. [85] and Holmes et al. [86] using a Reynolds model.

In figure 4.7 the steady layer-thickness and pressure-distribution results in the plane $x_{2}=0$ are compared to results found with the Reynolds-based EHL solver and with dry contact results. It can be seen that the present model yields approximately the same central layer thickness as the EHL model, but a larger deformation along the perimeter of the contact, i.e. larger lobes. Although there are differences between the present model and the EHL model, the present model does yield the important features in the layer. This confirms the fact that the pressure driven flow is very small due to the high shear viscosity, the basic assumption of the present model.

However, the pressure spike occuring at the outlet side, commonly seen in EHL contacts at higher velocities, will not be predicted by the model. This is because at this location, pressure driven flow does have an effect, but the velocity profile of the proposed model $u_{1}\left(x_{1}, x_{2}\right)$ is constant over the film thickness and $u_{2}\left(x_{1}, x_{2}\right)=0$. The layer ele- 
ments do not model mass transport as in a real fluid. The velocity profiles of the Reynolds equation $u_{1}$ and $u_{2}$ are parabolic velocity profiles in the $x_{3}$-direction at this location, see e.g. van Emden et al. [60] for more details about what lubricant particles experience when travelling though an EHL contact. For the present conditions (low velocity, thin film), the Reynolds-based model also does not predict a significant pressure spike. 

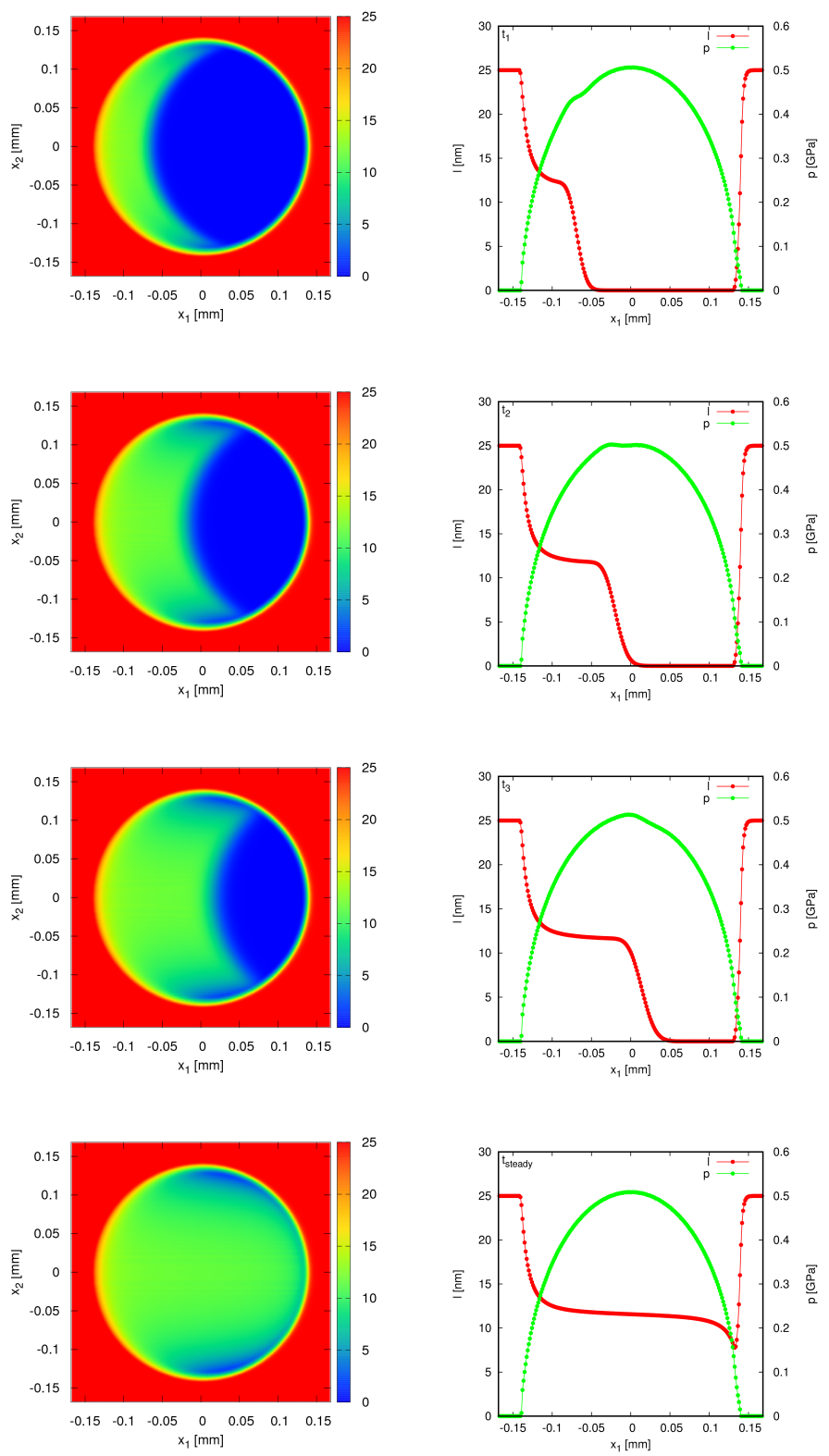

Figure 4.6: Layer thickness distribution (left) and pressure and layer distribution for $x_{2}=0$ (right) in the contact zone developing in time from top, $t_{1}$ to bottom $t_{\text {steady }}$ (steady rolling). Present model, restarted from a squeezed layer $l_{0}=25 \mathrm{~nm}, u_{1}=0.01 \mathrm{~m} / \mathrm{s}$, $F_{3}=20 \mathrm{~N}, \Delta t=1.337603 \cdot 10^{-5} \mathrm{~s}$. 

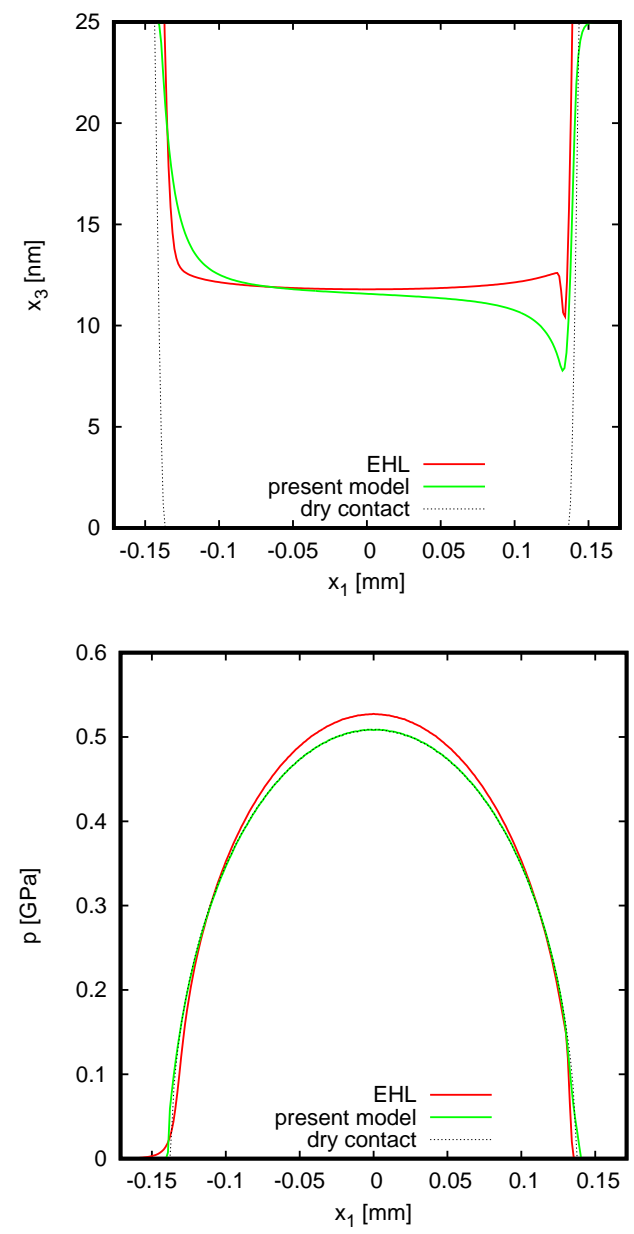

Figure 4.7: Layer thickness distribution (top) and pressure distribution (bottom) for $x_{2}=$ 0 in the contact zone for the steady state situation. The results of the present model restart from a squeezed layer are compared to the results of Reynolds-based EHL and dry contact. $u_{1}=0.01 \mathrm{~m} / \mathrm{s}, F_{3}=20 \mathrm{~N}, l_{0}=25 \mathrm{~nm}, \Delta t=1.337603 \cdot 10^{-5} \mathrm{~s}$.

\subsubsection{Squeeze}

When an EHL contact undergoes a pure squeeze motion, a dimple shaped hole filled with lubricant is formed inside the central region of the contact zone, caused by the high lubricant viscosity due to the high pressures at that location. Under normal load, the captured lubricant flows outwards into the flooded region of lubricant surrounding the contact zone. This leaking flow causes the depth and diameter of the dimple to decrease. 
Squeeze contacts, under constant load- or speed conditions, have extensively been studied both experimentally, e.g. Christensen [87], and theoretically, e.g. Yang and Wen [88], Larsson and Höglund [89], Chu et al. [90] and Kaneta et al. [91]. In the numerical studies only the initial stage of squeeze is normally simulated, i.e. the simulation is stopped when peripheral contact of the sphere with the flat surface occurs.

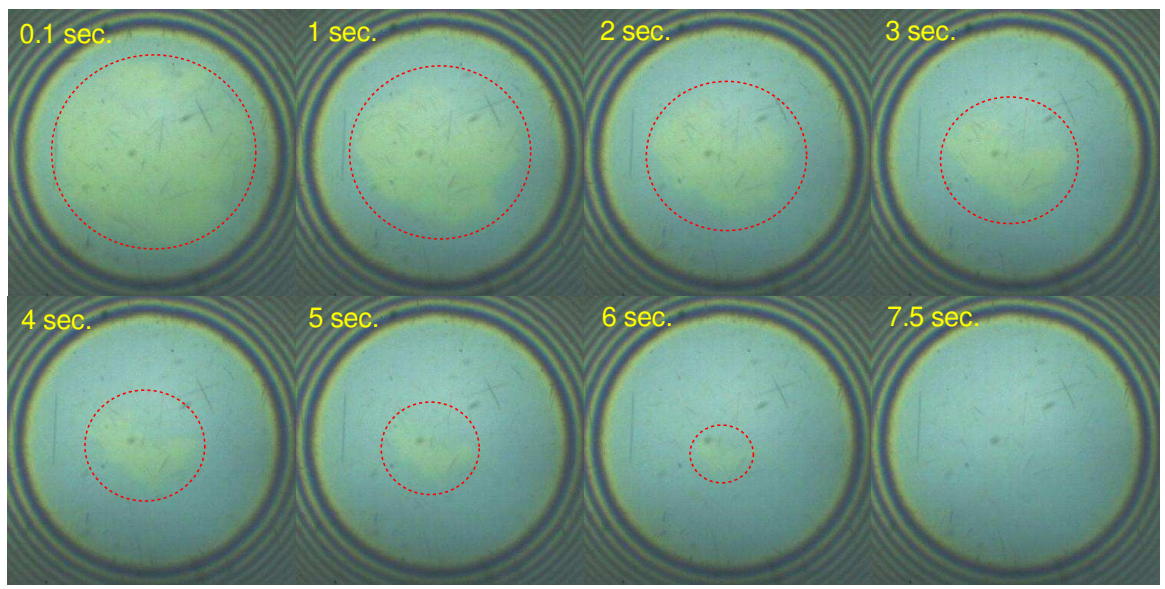

Figure 4.8: Optical interferometry images of a squeezed contact. Captured lubricant: HVI60 at room $24{ }^{\circ} \mathrm{C}, F_{3}=20 \mathrm{~N}$ (stopped after a sudden halt when pure rolling at $\left.u_{1}=11 \mathrm{~mm} / \mathrm{s}\right)$. The images are extruded from a movy made with a high speed camera (10× lens), $100 \mathrm{fps}$. In approximately $7.5 \mathrm{~s}$ all lubricant has been squeezed out of the contact.

Squeeze also occurs after a sudden stop of a rolling point contact. An illustration of a very thin sqeezed lubrication film is given in figure 4.8. The central film thickness at $t=0$ $\mathrm{s}$ is expected to be in the order of $12.5 \mathrm{~nm}$. The figure shows images of a contact in a sudden stop obtained from SLIM experiments by the authors using optical interferometry, see also [60]. The initial oil film is formed under fully flooded conditions at pure rolling with a velocity of $u_{1}=11 \mathrm{~mm} / \mathrm{s}$, with a normal load applied of $F_{3}=20 \mathrm{~N}$ at room temperature. The images have been taken after a sudden halt at $t=0 \mathrm{~s}$ from $u_{1}=11$ $\mathrm{mm} / \mathrm{s}$ to $u_{1}=0 \mathrm{~mm} / \mathrm{s}$. The time elapses from the upper left image to the lower right image. It can be seen that the oil is captured in the center of the contact region, marked by the red dotted circles. The amount of oil captured inside the contact decreases in time due to squeeze. A rough estimate was made that after approximately 7.5 seconds all oil has been squeezed out of the contact zone. This is shown in the rightmost bottom image. The lubricant is squeezed out of the contact via surface irregularities, acting as channels through which the captured lubricant can flow out of the contact.

The present model is used to simulate squeeze, starting with a sudden stop from steady pure rolling at $u_{1}=0.01 \mathrm{~m} / \mathrm{s}$ and an initial layer thickness $l_{0}=25 \mathrm{~nm}$, (section 4.4.1). At $t_{0}(t=0)$ the rolling is abruptly stopped, $u_{1}=0 \mathrm{~m} / \mathrm{s}$, while the normal loading 
$F=20 \mathrm{~N}$ is kept constant. Besides the first stage in which the contact area deforms due to the high viscous layer, we also study how the layer reaches a thickness of zero everywhere in the contact, starting from the outer contact circle evolving in time towards the center of the contact. The calculation continues until the pressure distribution inside the contact zone has a steady solution and the layer in central contact region is zero.

Figure 4.9 (top) shows the layer distribution results for $x_{2}=0$ at different instances in time. The line $t_{0}$, represents the initial layer distribution developed during steady rolling. Figure 4.9 (bottom) shows how the maximum pressure, central- and minimallayer thickness develop in time.

At the start of squeeze the initial layer is not rotationally symmetric, the layer thickness for $x_{2}=0$ is minimal in the contact region near the outlet side. Subsequently, the layer thickness especially along the perimeter of the contact area decreases. For $t_{1}$ and $t_{2}$, there is still a layer present $(l>0)$ everywhere in the domain. After approximately $0.2 \mathrm{~s}$, at $t_{4}$ the maximum pressure in the domain is reached. The ball and the disc have touched over a region at the peripheric surroundings of the contact zone; the layer thickness at $r \approx 0.13 \mathrm{~mm}$ is zero. For $t>t_{4}$, the pressure maximum slightly decreases in time to a value of $0.5083 \mathrm{GPa}$ for the steady state solution. Until the steady state solution is reached, the contact diameter still grows in time.

Steady state, i.e. when the local pressure- and layer thickness results remain constant in time, is attained after approximately $5 \mathrm{~s}$. A rotationally symmetric solution for layer thickness and pressure distribution has been formed. The time needed to reach steady state is less than the rough estimate for the experiment shown in figure 4.8. However, this is not an unacceptable situation considering that in reality the draining of the captured lubricant out of the contact center is highly dependent on the roughness of the surfaces. This is not a parameter in the model.

The overall impression of the film thickness decay in time shown in figure 4.9 (top) shows good agreement with results presented by Holmes et al. [38] who used the standard EHL model with finite deceleration instead of a sudden stop. However, the simulations of Holmes et al. end at peripheral contact.

The final contact diameter belonging to the steady state solution is approximately $0.286 \mathrm{~mm}$ (of which $0.257 \mathrm{~mm}$ the layer thickness equals $l\left(x_{1}, 0, t_{\text {steady }}\right)=0$ ). In contrast, the contact diameter in case of no layer, i.e. dry contact $\left(l_{0}=0 \mathrm{~nm}\right)$, is approximately $0.274 \mathrm{~mm}$, see figure 4.10. Characteristic for the dry contact solution is the circular shaped contact area, having a contact radius $r=a_{h}$, and a rotationally symmetric, parabolic pressure distribution with a maximum pressure $p_{h}$ in the center of the contact, see Hertz [3]. In the contact zone the gap between the ball and the disc is zero. In the presence of a layer the contact area is defined by the region for which the layer is deformed. In presence of a layer, a slightly lower maximum pressure for the steady state is obtained since the loading is distributed over a larger area. At the perimeter of the contact zone the layer has a finite thickness $\left(0<l<l_{0}\right)$ that carries part of the load. This is due to the model not allowing lateral displacements. This is different from fluid behaviour for which the lubricant can escape sideways. The model behaves more solid-like, which explanes the differences in contact radii. 


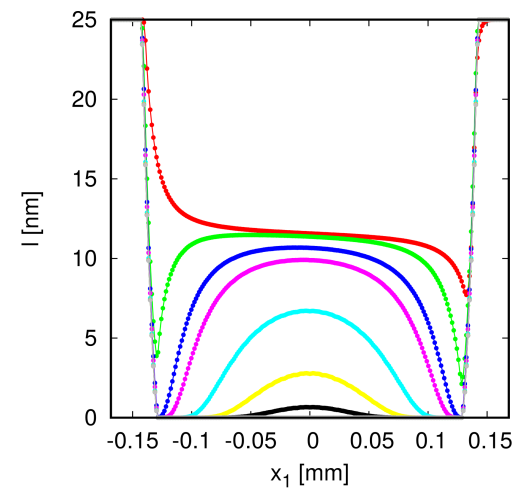

$$
\begin{array}{r}
t_{0} \longrightarrow \\
t_{1}=0.005 \mathrm{~s} \longrightarrow \\
t_{2}=0.026 \mathrm{~s} \longrightarrow \\
t_{3}=0.053 \mathrm{~s} \longrightarrow \\
t_{4}=0.2 \mathrm{~s} \longrightarrow \\
t_{5}=0.54 \mathrm{~s} \\
t_{6}=1 \mathrm{~s} \longrightarrow . \\
t_{\text {steady }} \approx 5 \mathrm{~s} \longrightarrow
\end{array}
$$
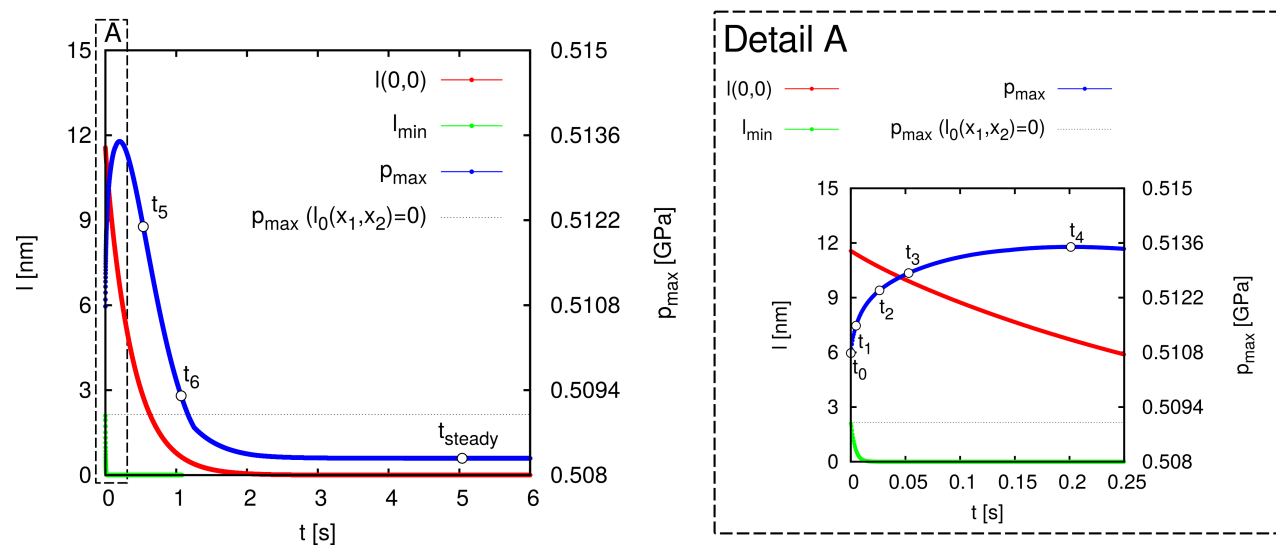

Figure 4.9: Contact layer development of a squeeze simulation type 1 obtained with the present model. Contact layer deformation, minimal- and central- layer thickness and maximum pressure results evolving in time. Sudden stop from $u_{1}=0.01 \mathrm{~m} / \mathrm{s}$ and $l_{0}=25$ $\mathrm{nm}, F=20 \mathrm{~N}, \Delta t=5.35041 \cdot 10^{-5} \mathrm{~s}$. 


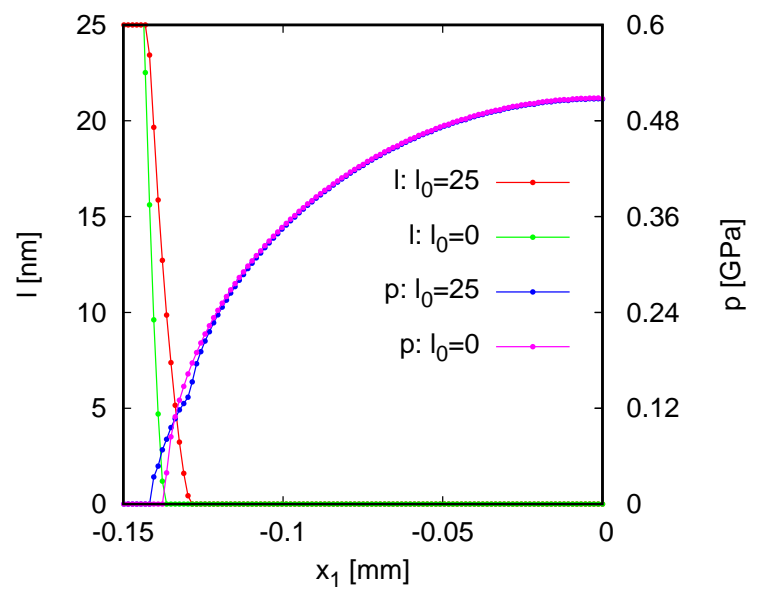

Figure 4.10: Pressure- and layer thickness results of a squeeze simulation after a sudden stop obtained with the present model compared to dry contact results. $F=20 \mathrm{~N}$, $u_{1}=0.01 \mathrm{~m} / \mathrm{s}$ and $l_{0}=25 \mathrm{~nm}, \Delta t=5.35041 \cdot 10^{-5} \mathrm{~s}$.

\subsubsection{Irregularities on the ball}

We also investigate the potential of the model to simulate surface irregularities e.g. bumps and dents on the rolling surfaces. In this section, results are presented for a deep dent in the ball entering a steady rolling contact as presented in section 4.4.1. The dent enters the contact of a layer at steady rolling with $u_{1}=0.01 \mathrm{~m} / \mathrm{s}$, for which the initial layer thickness is $l_{0}=25 \mathrm{~nm}$. The conditions in table 4.1 are employed.

The dimensionless geometry of the dent is given in equation (4.18):

$$
\bar{b}=\mathcal{H} \cdot \bar{l}_{0} \cdot 10\left(\frac{\left(\bar{x}_{1}(\bar{t})-\bar{x}_{1 b}\right)^{2}+\left(\bar{x}_{2}-\bar{x}_{2 b}\right)^{2}}{\mathcal{K}^{2}}\right)
$$

with $\mathcal{H}$ an amplitude for the height and $\mathcal{K}$ a factor for the width. The geometry $\bar{b}$ is added to dimensionless form of equation (4.1). The initial location of the center of the dent is $\left(\bar{x}_{1_{b}}=-1.25, \bar{x}_{2_{b}}=0\right)$. The present model is tested for a dent with a height factor $\mathcal{H}=1000$ and a width factor $\mathcal{K}=0.1$.

Figure 4.11 shows the layer thickness distribution $\left(l\left(x_{1}, x_{2}\right)\right)$ on the left, the pressure distribution $\left(p\left(x_{1}, x_{2}\right)\right)$ in the center and both the layer- and pressure distribution for $x_{2}=0$, on the right for five successive time instances during the passage of the dent through the contact.

For the simulated case there is no contact between the ball and the layer at the location of the dent, and the contact pressures are locally zero. As expected for the present model, the local layer thickness will increase inside the dent to a maximum of $l_{0}$. This is because 
the layer is modeled as a viscoelastic 'oedometric' layer for which the thickness varies between zero and $l_{0}$. Unlike a fluid, the layer elements do not exchange material with their neighbours. Therefore the initial layer thickness $l_{0}$ for the unloaded condition can not be exceeded.

Kaneta et al. [92] and Félix [93] studied the passage of a dent in an EHL contact experimentally and theoretically, respectively. They showed that under pure rolling conditions the film thickness fluctuations introduced by the dent remain confined near by the dent when crossing the high pressure region of the contact. In experiments Kaneta et al. [92] found a micro-constriction in the film almost symmetrically around the dent, while Félix [93] predicted with a conventional Reynolds-based EHL solver a moon shaped constriction in the film in front of the dent. Neither of these contractions are predicted with the present model. Furthermore, inside the high pressure region the dent is more or less elliptical shaped having the largest diameter oriented in the rolling direction. This is due to the time delay of strain relaxation after pressure release, introduced by the viscosity $\eta$ in the model. As shown in figure 4.11 the pressure maximum values are located near by the edges of the dent, causing high viscosity values preventing the layer thickness to decrease.

Although not shown here in detail, simulations for a more shallow dent, and a bump in the ball have also been performed. For a shallow dent filled completely with lubricant layer the model predicts a finite but low pressure rise inside the dent, which causes the layer thickness inside the dent to decrease more than in the surrounding region, see figure 4.12 This means that at the location of the dent, the elastic deformation of the ball is lower, causing the dent to become a bump. This is not expected, both physically and based on simulations with a conventional Reynolds-based EHL solver. The model reaction causes the layer to become too 'soft' at the location of the shallow dent in the ball. This is due to the oedometric assumption preventing lateral displacements of the layer. For a bump, at the location of the bump both the pressure and the layer thickness reach a local maximum, see figure 4.13. The local maximum of the layer thickness is due to the high layer viscosities caused by the high pressures. As a consequence, the bump on the ball is highly deformed, which is also not expected, both physically and based on simulations with a conventional Reynolds-based EHL solver. The EHL solver predicts $h=h\left(x_{1}-t\right)$ from the moment the surface feature has passed the inlet.

This behaviour is related to the local time response of the viscoelastic layer behaviour. To make the model suitable for simulations with surface features, the relations for $\eta(p)$ and $E(p, \varepsilon)$ should be tuned to these situations, and/or a kind of mass principle could be included for these conditions. 

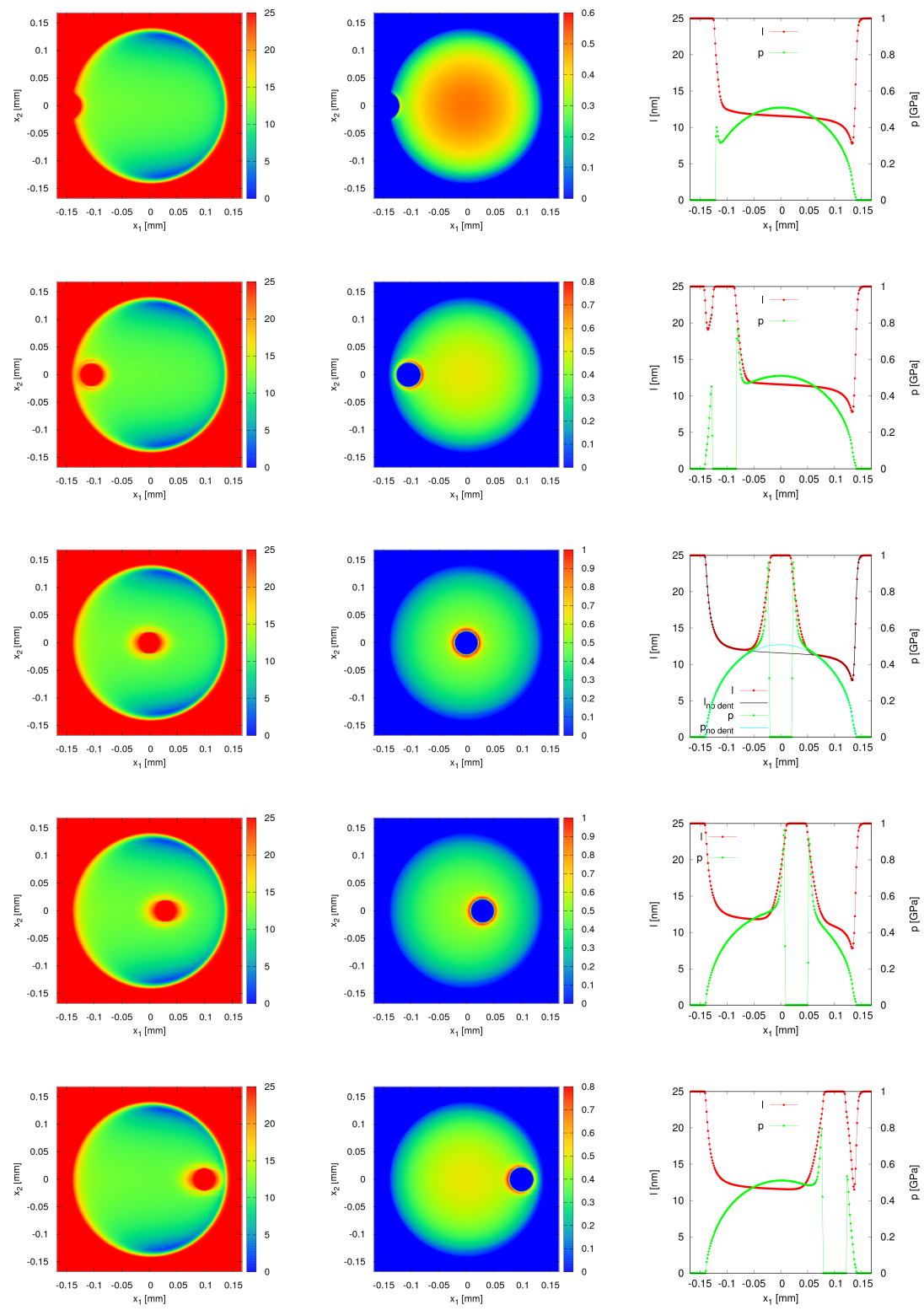

Figure 4.11: Development of pressure and film thickness in time for a dent in the ball passing a pure rolling contact. Layer thickness distribution (left) pressure distribution (center) and pressure and layer distribution for $x_{2}=0$ (right) in the contact zone developing in time from top to bottom. Present model, $u_{1}=0.01 \mathrm{~m} / \mathrm{s}, F_{3}=20 \mathrm{~N}, l_{0}=25$ $\mathrm{nm}, \Delta t=1.337603 \cdot 10^{-5} \mathrm{~s}, \mathcal{H}=1000, \mathcal{K}=0.1$. 

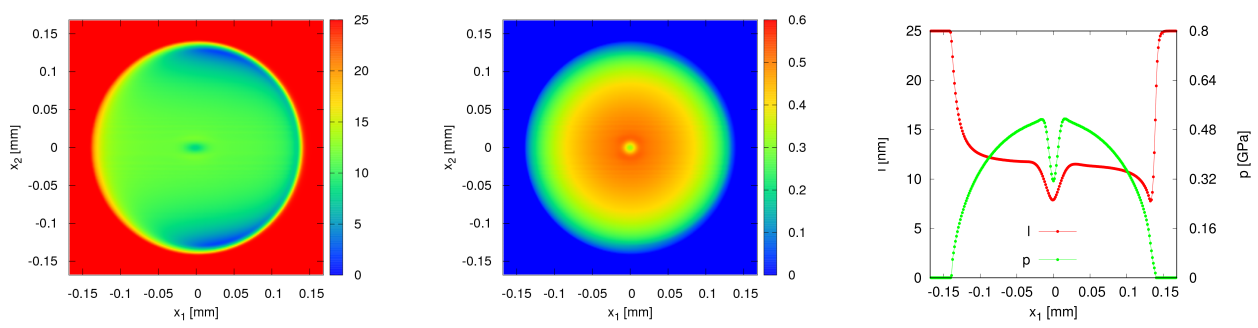

Figure 4.12: Pressure and film thickness for a shallow dent in the ball passing a pure rolling contact. Layer thickness distribution (left) pressure distribution (center) and pressure and layer distribution for $x_{2}=0$ (right) in the contact zone. Present model, $u_{1}=0.01 \mathrm{~m} / \mathrm{s}$, $F_{3}=20 \mathrm{~N}, l_{0}=25 \mathrm{~nm}, \Delta t=1.337603 \cdot 10^{-5} \mathrm{~s}, \mathcal{H}=1.25, \mathcal{K}=0.1$.
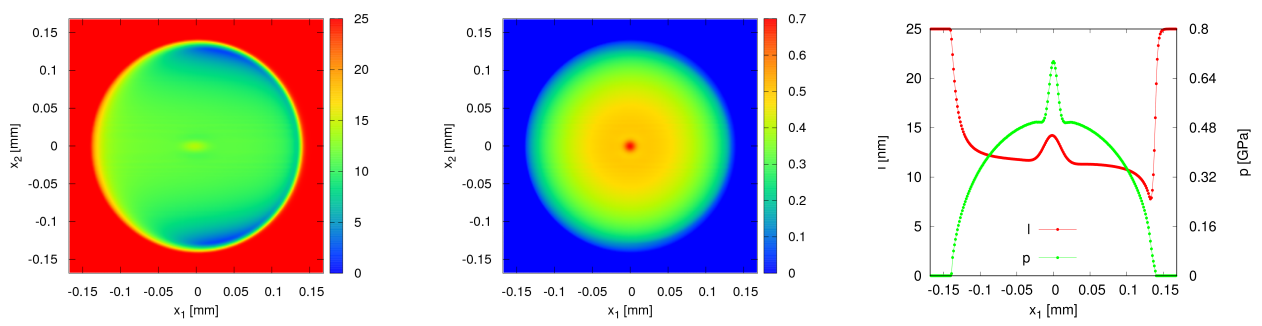

Figure 4.13: Pressure and film thickness for a bump in the ball passing a pure rolling contact. Layer thickness distribution (left) pressure distribution (center) and pressure and layer distribution for $x_{2}=0$ (right) in the contact zone. Present model, $u_{1}=0.01 \mathrm{~m} / \mathrm{s}$, $F_{3}=20 \mathrm{~N}, l_{0}=25 \mathrm{~nm}, \Delta t=1.337603 \cdot 10^{-5} \mathrm{~s}, \mathcal{H}=1.25, \mathcal{K}=0.1$. 


\subsubsection{A hole in the layer}

Finally, the present model is used to simulate a local mixed lubrication case by supplying a steady rolling contact with a layer that contains a circular hole with zero layer thickness, representing a dry spot in the lubricant supply to the inlet of the contact. The results are presented in this section. The conditions in table 4.1 are employed, together with a dimensionless radius of the hole $\bar{R}=0.2$.

In figure 4.14 the layer thickness- and pressure distribution is shown at the instance in time when the hole is located at the center of the contact, see also the layer- and pressure- distributions at $x_{2}=0$.

For this case, the central pressure decreases approximately $2.3 \%$ compared with the steady situation. Towards the edges in the hole the pressure first decreases to a local minimum and then at the edges strongly increases to higher values than for the case without a hole, see figure 4.14. So, the peak pressures are on the edge of the layer and the local minima are just inside the hole where the ball does not touch the disc yet. Further away from the center the pressures decrease again towards the solution without a hole.

The minimum and maximum values near by the edges of the hole vary. This is also shown in figure 4.14 (bottom) which represents the central pressure and layer thickness as a function of time. At the time instant $t_{1}$ the first edge of the hole reaches the center and at time instant $t_{2}$ the second edge reaches the center. 

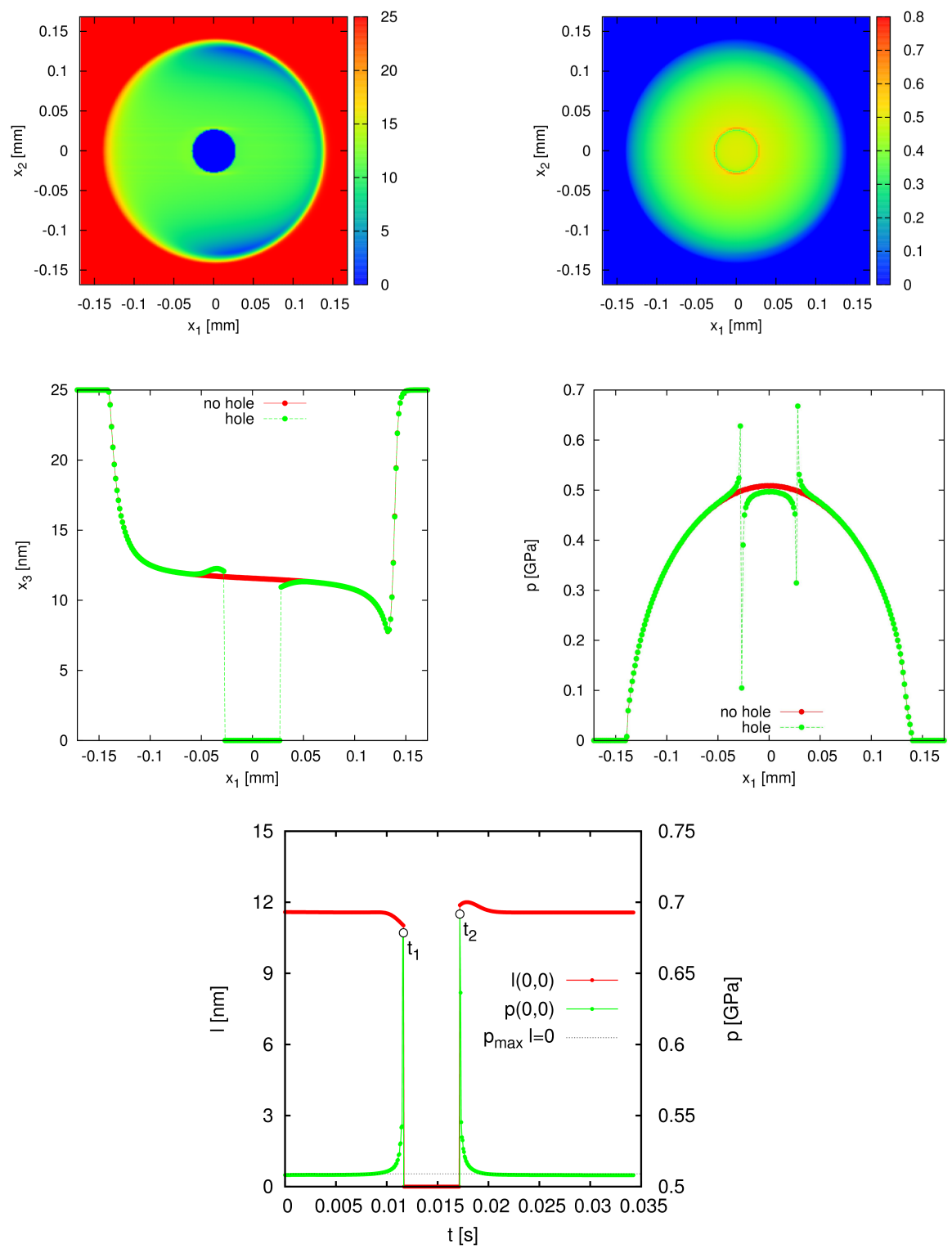

Figure 4.14: Top and center: layer- (left) and pressure distribution (right) in the contact zone, hole at $(0,0)$. Bottom: central pressure and central layer thickness as a function of time when a hole in the layer enters the rolling contact. Present model, $u_{1}=0.01 \mathrm{~m} / \mathrm{s}$, $F_{3}=20 \mathrm{~N}, l_{0}=25 \mathrm{~nm}, \Delta t=1.337603 \cdot 10^{-5} \mathrm{~s}$. 


\subsection{Conclusion}

This paper explores the possibility to simulate characteristic behaviour of a circular EHL contact with a viscoelastic solid oedometric layer model. A layer is modeled with multiple one-dimensional viscoelastic elements, which only allow displacements in the direction of the layer thickness. Each viscoelastic element consists of a pressure- and strain-dependent spring connected in parallel to a pressure-dependent viscous damper. The proposed model is based on a standard dry contact model and the layer is included in the gap equation.

In spite of challenges faced, the proposed model is able to show characteristic features of an EHL contact. Furthermore, the model allows the layer thickness to vanish locally, which opens new possibilities for mixed lubrication modeling. Results for several different cases have been presented, including steady rolling, squeeze simulations, features entering the contact and mixed lubrication.

The results of the layer thickness- and pressure distribution for steady rolling obtained with the present model have been compared to results obtained with a conventional Reynolds-based EHL solver. It can be seen that the present model yields approximately the same central layer thickness as the EHL model, but has a larger deformation along the perimeter of the contact, i.e. larger lobes.

In the squeeze simulations, the model is able to simulate how the layer reaches a thickness of zero everywhere in the contact, starting from the outer contact circle towards the center.

The model predictions for features fixed on the geometry of the ball show local differences with physical expectations, this leads to interesting insights in the viscoelastic behaviour of contact features which merit further investigation. The relations for the viscosity and modulus of elasticity should be further developed to drive the model towards more accurate physical behaviour. Furthermore, further development including parametrical studies including e.g. higher velocities and different load conditions is recommended. 
Nomenclature

\begin{tabular}{|ll|}
\hline$F_{3}$ & loading force in the $x_{3}$-direction \\
$R$ & radius of ball \\
$E^{\prime}$ & reduced modulus of elasticity \\
$a_{h}$ & Hertzian contact radius $a_{h}=\left(\frac{3 F R}{2 E^{\prime}}\right)^{\frac{1}{3}}$ \\
$p_{h}$ & Hertzian contact pressure $p_{h}=\frac{3 F}{2 \pi a_{h}^{2}}$ \\
$u_{1}$ & rolling velocity in $x_{1}$-direction \\
$\Delta t$ & time step \\
$n_{f}$ & number of spatial intervals \\
$n_{t}$ & number of time steps in a spatial interval \\
$x_{i}$ & the spatial direction vector \\
$p$ & pressure \\
$h$ & gap height \\
$h_{c}$ & central film thickness \\
$h_{0}$ & mutual approach \\
$f$ & undeformed geometry \\
$w$ & elastic deformation \\
$l$ & layer thickness \\
$l_{0}$ & initial undeformed lubricant layer thickness \\
$\eta$ & dynamic viscosity \\
$\eta_{0}$ & temperature dependent viscosity at atmospheric pressure \\
$p_{0}$ & pressure constant \\
$z$ & pressure viscosity index \\
$\mathcal{C}$ & constant \\
$E_{l a y e r}$ & modulus of elasticity of the layer $(\varepsilon=0)$ \\
$E_{o}$ & oedometric modulus of elasticity of the layer \\
$E$ & modulus of elasticity of the layer depending on $p$ and $\varepsilon$ \\
$\nu$ & Poisson's ratio \\
$b$ & bump, dent geometry \\
$\mathcal{H}$ & height factor \\
$\mathcal{K}$ & width factor \\
$L$ & characteristic length in $x_{1}-$ and $x_{2}$-direction \\
$\sigma_{i j}$ & stress tensor \\
$\varepsilon_{i j}$ & strain tensor \\
$\delta_{i j}$ & Kronecker delta \\
$u_{i}$ & velocity vector \\
$G, \lambda$ & Lame parameter \\
\hline
\end{tabular}


Chapter 4. Viscoelastic Behaviour in AN EHL CONTACT

\section{Acknowledgment}

The authors would like to thank Dr. Stefan Lammens, Director SKF Engineering and Research Centre, for his kind permission to publish this article. This research was supported by SKF ERC. 


\section{Appendix A: Derivation of the oedometric modulus of elasticity}

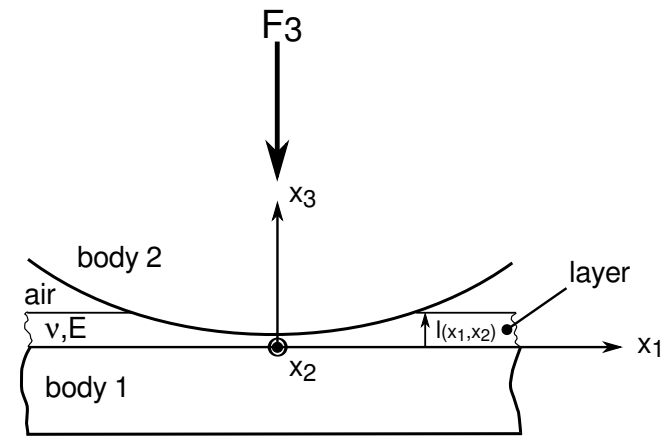

Figure 4.15: A confined layer between two bodies.

This appendix gives the derivation of the oedometric modulus of elasticity for a thin layer confined between two bodies, based on the works of Auslender, Trifa, Sidoroff and Georges [76, 77, 78, 79], Tijdeman [94], Timoshenko [84], Johnson [83] and Love [95].

The equilibrium equations (4.19) must be satisfied.

$$
\frac{\partial \sigma_{i j}}{\partial x_{j}}=0 \quad i, j=1,2,3
$$

The relations between the displacement field $u_{i}$ and the strains $\varepsilon_{i j}$ are given in (4.20).

$$
\varepsilon_{i j}=\frac{1}{2}\left(\frac{\partial u_{i}}{\partial x_{j}}+\frac{\partial u_{j}}{\partial x_{i}}\right) \quad i, j=1,2,3
$$

The layer material in figure 4.15 is considered isotropic and homogeneous, therefore the stress tensor $\sigma_{i j}=\sigma_{j i}$ is symetrical. The material is assumed linear elastic, so the contributions of each normal stress component individually can be superimposed and calculated:

$$
\begin{aligned}
& \varepsilon_{11}=\frac{1}{E}\left(\sigma_{11}-\nu \sigma_{22}-\nu \sigma_{33}\right) \\
& \varepsilon_{22}=\frac{1}{E}\left(\sigma_{22}-\nu \sigma_{11}-\nu \sigma_{33}\right) \\
& \varepsilon_{33}=\frac{1}{E}\left(\sigma_{33}-\nu \sigma_{11}-\nu \sigma_{22}\right)
\end{aligned}
$$

with $\nu$ Poisson's ratio.

For small deformations the angular strains are proportional to the shear stress:

$$
\varepsilon_{i j}=\varepsilon_{j i}=\frac{\sigma_{i j}}{2 G} \quad \text { for } \quad i \neq j \quad \text { and } \quad i, j=1,2,3
$$


The consitutive relation between stress and strain can be written in the following form of Hooke's law:

$$
\sigma_{i j}=\lambda \varepsilon_{k k} \delta_{i j}+2 G \varepsilon_{i j} \quad i, j, k=1,2,3
$$

with the Lame parameters $G$ and $\lambda$, which are related to $E$ and $\nu$ according to:

$$
G=\frac{E}{2(1+\nu)} \quad \lambda=\frac{\nu E}{(1+\nu)(1-2 \nu)}
$$

The layer shown in figure 4.15 is assumed to adhere perfectly to both surfaces: zero slip. The boundary conditions therefore are:

$$
\begin{array}{lll}
\text { for } x_{3}=0 & u_{1}=u_{2}=u_{3}=0 & \\
\text { for } x_{3}=l\left(x_{1}, x_{2}\right) & u_{1}=u_{2}=0 & u_{3}=\Delta l\left(x_{1}, x_{2}\right)
\end{array}
$$

The characteristic lengths of the contact in the $x_{1}$ - and $x_{2}$-directions are considerably larger than the layer thickness $l\left(x_{1}, x_{2}\right)$ in the $x_{3}$-direction:

$$
\bar{x}_{1}=\frac{x_{1}}{L} \quad \bar{x}_{2}=\frac{x_{2}}{L} \quad \bar{x}_{3}=\frac{x_{3}}{l} \quad L \gg l \quad \bar{\sigma}_{i j}=\frac{\sigma_{i j}}{\sigma}
$$

with $L$ the characteristic length scale in $x_{1}$ and $x_{2}$ direction and $l$ the layer tickness in $x_{3}$ direction.

When the equilibrium equations (4.19) are rewritten in dimensionless equations by substitution of the definitions given in equations (4.26) and the application of $L \gg l$, it can be concluded that all stresses in the $x_{3}$ direction only depend on $x_{1}$ and $x_{2}$ and are independent of the $x_{3}$-direction $\left(\frac{\partial \sigma_{31}}{\partial x_{3}}=0, \frac{\partial \sigma_{32}}{\partial x_{3}}=0\right.$ and $\frac{\partial \sigma_{33}}{\partial x_{3}}=0\left(\sigma_{i j}=\sigma_{j i}\right.$ so $\frac{\partial \sigma_{13}}{\partial x_{3}}=0$ and $\left.\frac{\partial \sigma_{23}}{\partial x_{3}}=0\right)$ ). So, the thin layer approximation results in the complementary assumptions:

$$
\sigma_{i 3}=\sigma_{i 3}\left(x_{1}, x_{2}\right) \quad i=1,2,3
$$

For an isotropic and homogeneous material $\sigma_{i 3}=\sigma_{3 i}$. In figure 4.15 the upper body (body 2 ) is loaded with a force in $x_{3}$-direction, leading to:

$$
\sigma_{33}=\sigma_{33}\left(x_{1}, x_{2}\right)=p\left(x_{1}, x_{2}\right)
$$

When the definitions of (4.26) are substituted into the strain-displacement relations of (4.20):

$$
\begin{array}{ccc}
\varepsilon_{11}=\frac{1}{L} \frac{\partial u_{1}}{\partial \bar{x}_{1}} & \varepsilon_{22}=\frac{1}{L} \frac{\partial u_{2}}{\partial \bar{x}_{2}} & \varepsilon_{33}=\frac{1}{l} \frac{\partial u_{3}}{\partial \bar{x}_{3}} \\
\varepsilon_{12}=\frac{1}{2 L} \frac{\partial u_{1}}{\partial \bar{x}_{2}}+\frac{1}{2 L} \frac{\partial u_{2}}{\partial \bar{x}_{1}} & \varepsilon_{13}=\frac{1}{2 l} \frac{\partial u_{1}}{\partial \bar{x}_{3}}+\frac{1}{2 L} \frac{\partial u_{3}}{\partial \bar{x}_{1}} & \varepsilon_{23}=\frac{1}{2 l} \frac{\partial u_{2}}{\partial \bar{x}_{3}}+\frac{1}{2 L} \frac{\partial u_{3}}{\partial \bar{x}_{2}}
\end{array}
$$

From (4.29) can be conluded that the terms $\frac{\partial u_{1}}{\partial x_{3}}$ and $\frac{\partial u_{2}}{\partial x_{3}}$ are dominant in $\varepsilon_{13}$ and $\varepsilon_{23}$, and that the strains $\varepsilon_{12}, \varepsilon_{11}$ and $\varepsilon_{22}$ are small compared to $\varepsilon_{33}$.

From incorporation of the thin layer approximations in the stress components of Hooke's law (4.23) follows:

$$
\sigma_{11}=\sigma_{22}=\frac{\nu}{(1-\nu)} \sigma_{33}
$$


and the stress tensor reads:

$$
\sigma_{i j}=\left[\begin{array}{ccc}
\frac{\nu}{(1-\nu)} \sigma_{33} & 0 & \sigma_{13} \\
0 & \frac{\nu}{(1-\nu)} \sigma_{33} & \sigma_{23} \\
\sigma_{31} & \sigma_{32} & \sigma_{33}
\end{array}\right]
$$

Substitution of the relations (4.30) in the stress-strain relations in (4.21) leads to the strain tensor describing oedometric squeeze:

$$
\varepsilon_{11}=0 \quad \varepsilon_{22}=0 \quad \varepsilon_{33}=\frac{1}{E}\left(1-\frac{2 \nu^{2}}{1-\nu}\right) \sigma_{33}
$$

The relation for oedometric modulus of elasticity is:

$$
E_{0}=\frac{E}{1-\left(\frac{2 \nu^{2}}{(1-\nu)}\right)}
$$

Following from the relations (4.32) and (4.20) the layer deformations in $x_{1}$ - and $x_{2^{-}}$ direction read:

$$
\begin{aligned}
& u_{1}\left(x_{1}, x_{2}, x_{3}\right)=0 \\
& u_{2}\left(x_{1}, x_{2}, x_{3}\right)=0
\end{aligned}
$$

While the strain in $x_{3}$-direction reads:

$$
\varepsilon_{33}=\frac{\partial u_{3}}{\partial x_{3}}=\frac{1}{E}\left(1-\frac{2 \nu^{2}}{1-\nu}\right) \sigma_{33}
$$

When considering the situation shown in figure 4.15 meaning that $\sigma_{33}=p\left(x_{1}, x_{2}\right)$ and pure rolling applies, so $\sigma_{13}=\sigma_{23}=0$. Then the oedometric deformation $\Delta l\left(x_{1}, x_{2}\right)$ is described by:

$$
\Delta l\left(x_{1}, x_{2}\right)=\int_{0}^{l_{0}\left(x_{1}, x_{2}\right)} \varepsilon_{33} d x_{3}=\frac{1}{E}\left(1-\frac{2 \nu^{2}}{1-\nu}\right) p\left(x_{1}, x_{2}\right) l_{0}\left(x_{1}, x_{2}\right)
$$

and,

$$
\Delta u_{3}\left(x_{1}, x_{2}, x_{3}\right)=\frac{\Delta l}{l_{0}\left(x_{1}, x_{2}\right)} x_{3}
$$




\section{Appendix B: Discretization}

The dimensionless equations are discretized on a rectangular grid with a uniform mesh size in both the $\bar{x}_{1}$ - and $\bar{x}_{2}$-directions. The grid points are defined by:

$$
\begin{array}{ll}
\bar{x}_{1, i}=\bar{x}_{1, a}+i \cdot \bar{h}_{x_{1}} & \bar{h}_{x_{1}}=\frac{\left(\bar{x}_{1, b}-\bar{x}_{1, a}\right)}{n_{x_{1}}} \\
\bar{x}_{2, j}=\bar{x}_{2, a}+j \cdot \bar{h}_{x_{2}} & \bar{h}_{x_{2}}=\frac{\left(\bar{x}_{2, b}-\bar{x}_{2, a}\right)}{n_{x_{2}}}
\end{array}
$$

The second order approximation of the dimensionless discrete gap height equation reads:

$$
\bar{h}_{i, j, n}^{h}=\bar{h}_{0_{n}}+\frac{\bar{x}_{1_{i}}^{2}}{2}+\frac{\bar{x}_{2_{i}}^{2}}{2}+\frac{2}{\pi^{2}} \Sigma_{i^{\prime}} \Sigma_{j^{\prime}} \bar{K}_{i, i^{\prime}, j, j^{\prime}}^{h, h} \bar{p}_{i^{\prime}, j^{\prime}, n}^{h}-\bar{l}_{i, j, n}^{h}
$$

with the coefficients of the kernel $\bar{K}_{i, i^{\prime}, j, j^{\prime}}^{h, h}$ defined as:

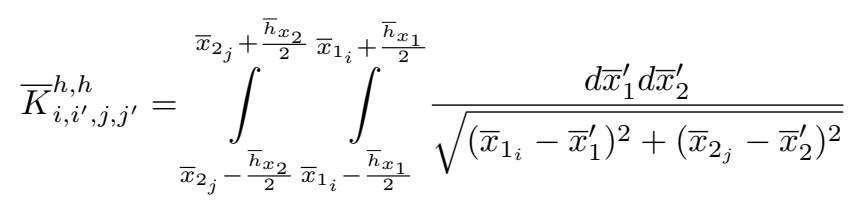

and,

$$
\bar{l}_{i, j, n}^{h}=\bar{l}_{0_{i, j}}^{h}\left(1-\varepsilon_{i, j, n}^{h}\right)
$$

and the second-order accurate finite-difference approximation of the dimensionless differential equation reads:

$$
\left(\frac{\eta_{0}}{p_{h}}\right)\left(\frac{u_{1}}{a_{h}}\right) \bar{\eta}_{i, j, n}^{h}\left(\frac{3 \varepsilon_{i, j, n+1}^{h}-4 \varepsilon_{i, j, n}^{h}+\varepsilon_{i, j, n-1}^{h}}{2 \Delta \bar{t}}\right)+\bar{E}_{l_{i, j, n}}^{h} \varepsilon_{i, j, n}^{h}=\bar{p}_{i, j, n}^{h}
$$

will be numerically solved for the strain $\varepsilon_{i, j, n+1}^{h}$ using the dimensionless time step:

$$
\Delta \bar{t}=\frac{\left(\bar{x}_{1, b}-\bar{x}_{1, a}\right)}{n_{f} \cdot n_{t}}
$$

With $n_{f}$ the number of spatial intervals on the finest level in $x_{1}$-direction in the compuational domain, and $n_{t}$ the number of time intervals in a spatial interval.

Finally, the discrete force balance equation reads:

$$
\int_{i^{\prime}} \int_{j^{\prime}} \bar{p}_{i^{\prime}, j^{\prime}, n}^{h}=\frac{2 \pi}{3}
$$




\section{Appendix C: Description solution method}

The numerical solution method follows the steps described below:

A. The start of the solution process: $\bar{t}=0$ :

1. The input parameters for the initial layer thickness and modulus of elasticity are chosen.

2. The initial layer $\bar{l}_{0}\left(\bar{x}_{1}, \bar{x}_{2}\right)$ is applied between the unloaded ball and disc.

3. The initial layer is instantaneously loaded in the intermediate grid points (using the mean pressure values of the 4 surrounding grid points) with the Hertzian pressure distribution of a circular contact, corresponding to the chosen setup.

4. The local strains in the layer are determined in the intermediate grid points by solving equation (4.15) numerically for $\varepsilon\left(\bar{x}_{1}, \bar{x}_{2}, \bar{t}\right)$.

5. Then the deformed layer $\bar{l}\left(\bar{x}_{1}, \bar{x}_{2}, \bar{t}\right)$ is determined in the intermediate grid points by substitution of the strain results in equation (4.14).

6 . The deformed layer results $\bar{l}\left(\bar{x}_{1}, \bar{x}_{2}, \bar{t}\right)$ are interpolated to the original grid points using the mean value of the 4 surrounding intermediate grid points.

B. For each time step $\Delta \bar{t}: \bar{t}>0$ :

1. Update the gap height equation (4.13) with the deformed layer results of the previous time step.

2. Determine the local dimensionless modulus of elasticity- and viscosity- of the layer according to (4.1014.12) and (4.114.12) respectively in the intermediate grid points, using the pressure and strain results of the previous time step.

3. The pressure results and the value for $\bar{h}_{0}$ of the previous time step are used as an initial guess to solve the gap height equation.

4. The gap height equation (4.13) is numerically solved by multigrid $V$-cycles using a full approximation scheme (FAS), see Brandt [96]. The presssures are solved using distributive relaxation. For more details about the implementation see Venner and Lubrecht [2]. On each grid level in the V-cycle, the elastic deformation integral is solved by the Multilevel Multi-Integration Method (MLMI), see Brandt [96] and Brandt and Lubrecht [97]. For more general information see also Venner [61, Venner and Lubrecht [2], and Wijnant [62] for example. After each V-cycle the global value $\bar{h}_{0}$ is updated on the finest grid. When both the gap equation and the force balance equation are converged to an error below the disctretization error, the V-cycles are stopped.

5. The pressure results obtained in B4 are used to determine the pressure values in the intermediate points to calculate the local strains in the layer in the intemediate grid points by solving equation (4.15) numerically for $\varepsilon\left(\bar{x}_{1}, \bar{x}_{2}, \bar{t}\right)$.

6 . Then the deformed layer $\bar{l}\left(\bar{x}_{1}, \bar{x}_{2}, \bar{t}\right)$ is determined in the intermediate grid points by substitution of the strain results in equation (4.14). 
7. The deformed layer results $\bar{l}\left(\bar{x}_{1}, \bar{x}_{2}, \bar{t}\right)$ are interpolated to the original grid points using the mean value of the 4 surrounding intermediate grid points.

The solution method described in B is repeated until a steady state solution is obtained, or until a prescribed end time has been reached.

The layer is defined on a staggered grid, using the mean pressure value of the 4 staggered grid points to avoid decoupling of the odd- and even- gridpoints. Afterwards, the layer results are interpolated to the original grid points using the mean value of the 4 surrounding intermediate grid points. 


\section{Appendix D: Grid convergence}

Spatial grid and time step convergence tests are done with the proposed model. The input parameters given in table 4.1 are applied and the domain size is $x_{1} \in[-1.25 a, 1.25 a]$ and $x_{2} \in[-1.25 a, 1.25 a]$. The initial layer thickness is $25 \mathrm{~nm}$. The results for the central layer thickness and the minimal layer thickness are given in figure 4.17 and the size of the marked mesh is used for the calculations throughout this study.

For the spatial grid convergence tests, the applied finest grid levels have $65 \times 65$, $129 \times 129,257 \times 257$ and $513 \times 513$ grid points. The results are shown in figure 4.17 (top) with $n_{f}$ the total number of grid points on the finest grid level. Here, the applied number of time steps in a spatial interval is $n_{t}=10$.

For the time step convergence tests, the applied number of time steps in a spatial interval are $n_{t}=1$ up to $n_{t}=50$, for a spatial grid with $257 \times 257$ grid points on the finest grid level, see figure 4.17 (bottom). The results indicate that $n_{t}=10$ and $257 \times 257$ grid points are sufficient.

Spatial grid and time step convergence tests are done with the proposed model. The input parameters given in table 4.1 are applied and the domain size is $x_{1} \in[-1.25 a, 1.25 a]$ and $x_{2} \in[-1.25 a, 1.25 a]$. The initial layer thickness is $25 \mathrm{~nm}$. The results for the central layer thickness and the minimal layer thickness are given in figure 4.17 and the size of the marked mesh is used for the calculations throughout this study.

For the spatial grid convergence tests, the applied finest grid levels have $65 \times 65$, $129 \times 129,257 \times 257$ and $513 \times 513$ grid points. The results are shown in figure 4.17 (top) with $n_{f}$ the total number of grid points on the finest grid level. Here, the applied number of time steps in a spatial interval is $n_{t}=10$.

For the time step convergence tests, the applied number of time steps in a spatial interval are $n_{t}=1$ up to $n_{t}=50$, for a spatial grid with $257 \times 257$ grid points on the finest grid level, see figure 4.17 (bottom). The results indicate that $n_{t}=10$ and $257 \times 257$ grid points are sufficient. 

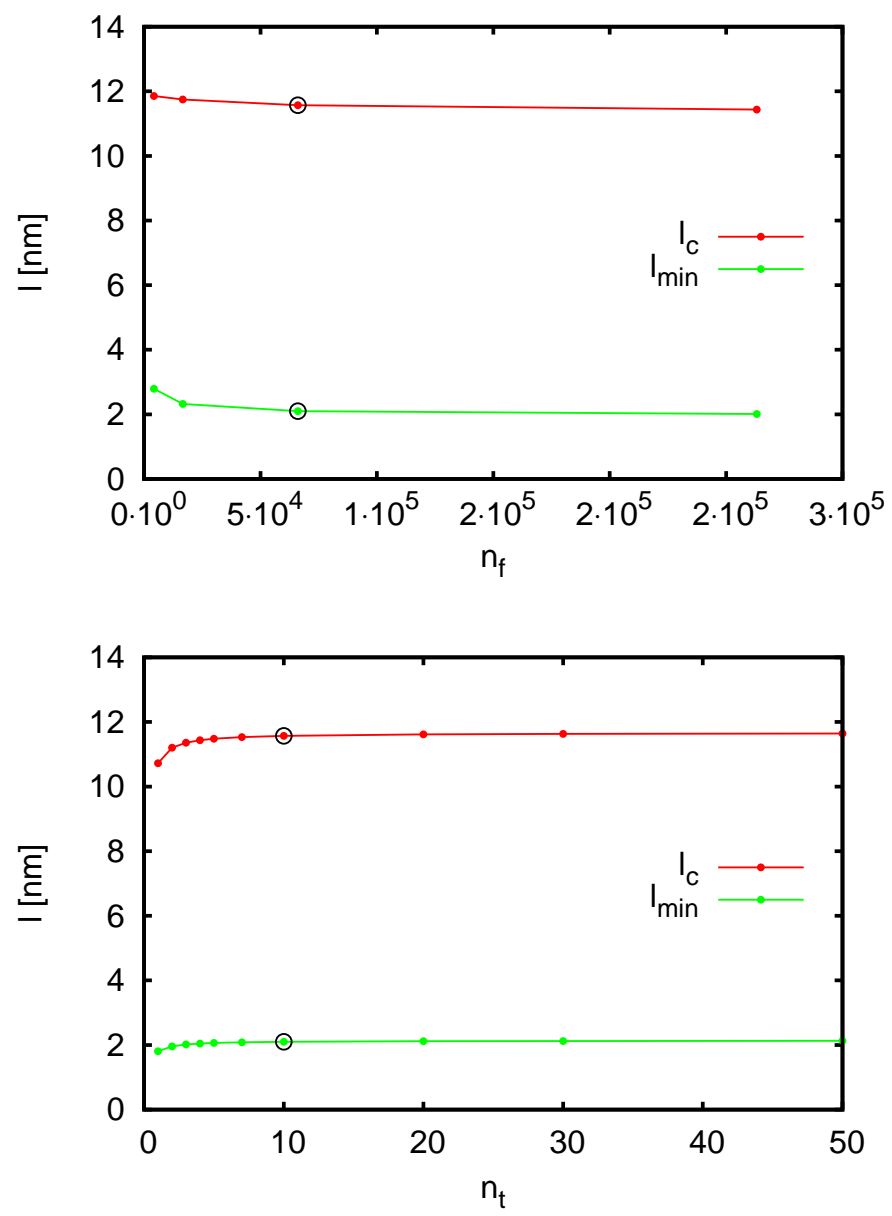

Figure 4.16: Central layer thickness and minimal layer thickness versus mesh size $n_{t}=10$ (top), versus number of time steps $n_{t}$ (bottom). 

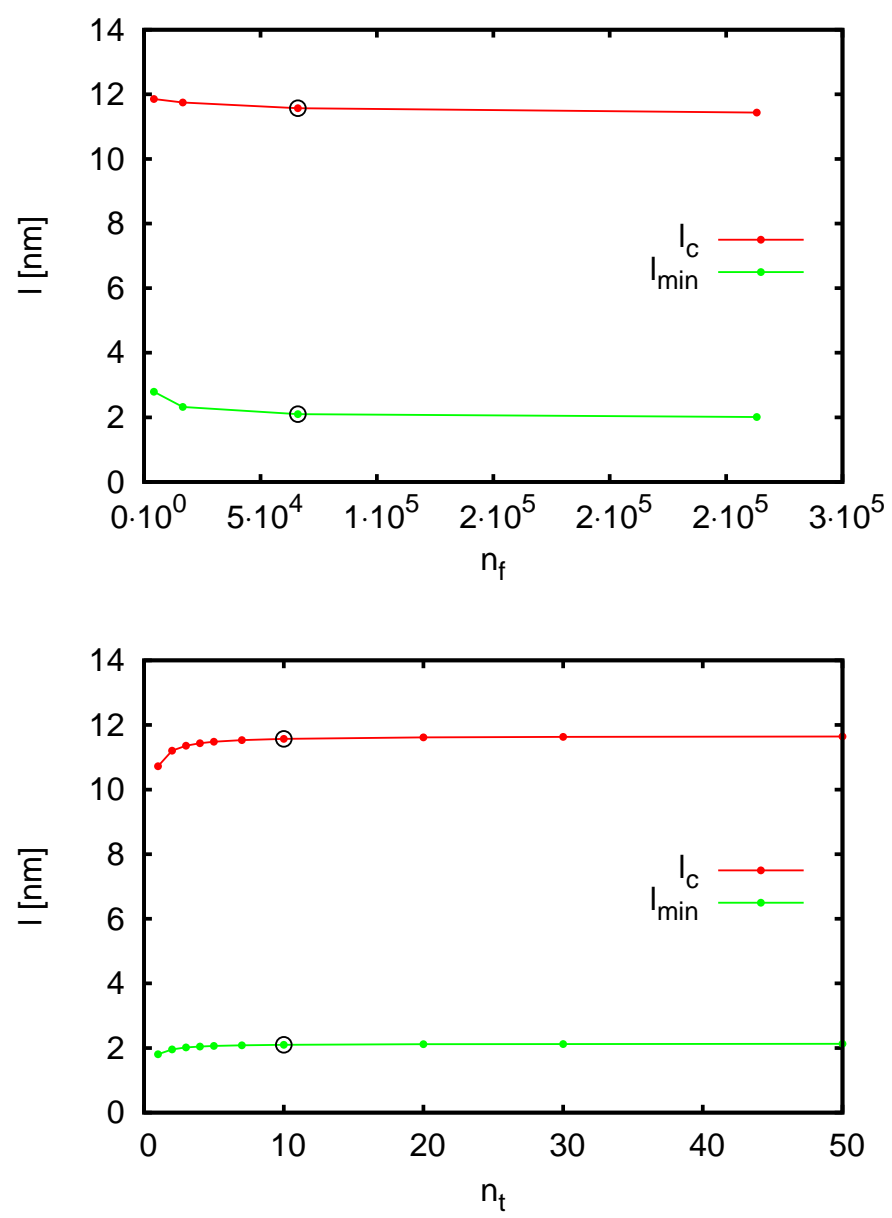

Figure 4.17: Central layer thickness and minimal layer thickness versus mesh size $n_{t}=10$ (top), versus number of time steps $n_{t}$ (bottom). 



\section{Chapter 5}

\section{Conclusions And ReCOMmendations}

In the present study the flow in and around an elasto-hydrodynamically lubricated ballon-disc contact has been studied in detail. Furthermore, an exploratory model has been developed for mixed lubrication from first principles regarding the physics of contact and flow that allows for a natural transition to dry contact. The next sections present the conclusions of this study and the recommendations for future research.

\subsection{Conclusions}

\subsubsection{Flow in and around an EHL contact}

\section{Experiments}

In experiments using an optical interferometry apparatus for an oil-lubricated ball-anddisc configuration during steady rolling in the low velocity regime, two steady states are observed. The appearing state depends on the rolling speed and the lubricant supply conditions:

- The first state, flow pattern I, appears when the lubricant supply at the inlet side is sufficient. The entire Hertzian contact region is enveloped by a flooded region. The outer meniscus of this flooded region is closed an a cavitation bubble is present at the outlet side of the contact.

The following observations about the cavitation bubble in the low velocity regime have been made:

- The bubble length grows linearly with the rolling velocity and with the square root of the lubricant viscosity.

- The bubble length is observed to be independent of the Hertzian contact radius (load).

A function has been formulated relating the ratio of cavitation bubble length and Hertzian contact radius to a combination of the Reynolds, cavitation and Weber number. 
- The second state, flow pattern II, appears for decreased lubricant supply, e.g. when the rolling velocity is increased and no extra lubricant is added. Typical for this state is a concave-shaped inlet meniscus and an open downstream wake. In a starved situation state II dominates and the flooded region is butterfly-shaped.

The formation of a flow pattern will be accelerated in case a surface has been wetted previously, compared to the case of starting from a dry situation. However, both types of start-up, dry or wetted, eventually lead to similar flow patterns.

Irrespective of the flow pattern, when the movement of the disc stops an island of oil is trapped inside the Hertzian contact region. The trapped oil in the contact slowly spreads by squeeze effects. The flooded region becomes circular shaped with the Hertzian contact region in its center due to the surface tension of the oil. In case of state I, after a sudden stop the cavitation bubble at the outlet side of the contact breaks up in one or more smaller bubbles leaving the flooded region through the outlet meniscus.

\section{Numerically prediction of a cavitation bubble}

A standard EHL model has been coupled with an elementary 2-phase model, which adds a pressure-density relation that yields a faster density decrease than the Dowson-Higginson relation for negative gauge pressures. Regarding the simulation results, the following conclusions can be drawn:

- A cavitation bubble at the outlet side of an EHL contact can be predicted.

- The predicted bubble length is highly underpredicted when compared to low velocity experiments. This applies to both cavitation criteria used in this work, i.e. the pressure- and the principal stress criterion. The numerically predicted bubble length based on the pressure criterion and the principal stress criterion $\left(\sigma_{1}\right)$ is not significantly different. Furthermore:

- The computed cavitation bubble length relative to the Hertzian contact radius shows a linear dependence on the velocity in the low-velocity regime.

- The slope of the linear trend, found in the experiments is much larger than in the simulations.

- The ratio of cavitation bubble length and Hertzian contact radius gradually switches towards a different linear trend in the high-velocity regime (with a lower slope).

- The predicted bubble width near the contact is larger than observed in the experiments.

- The pressure minima in the cavitation bubble have values that are not physical (too low).

The values for the pressure minima can be improved by increasing the steepness $(\mathcal{D})$ of the pressure-density relation in the 2 -phase model. It causes the gauge pressure 
minima to become less negative. However, the steepness of the pressure-density relation in the 2-phase model does not significantly affect the cavitation bubble length prediction.

- The numerical results found for the ratio of the cavitation bubble length to the Hertzian contact radius scale linearly with the combination of Moes parameters $M$ and $L$ for elastic-piezoviscous regime [61], and thereby it is proportional to the dimensionless Moes film thickness parameter $H^{M}$.

It has been shown that it is not possible to predict correct values for the cavitation bubble length when using a standard EHL model together with the modifications presented in this study and using a 2-phase density-pressure model for cavitation modeling. The cavitation lengths are strongly underpredicted, suggesting a lack of essential physics included in the model. Hence, the accurate prediction of cavitation still is an issue.

\subsubsection{Viscoelastic layer model}

A model has been developed to explore the possibility to predict the characteristic behaviour of a circular shaped EHL contact with a viscoelastic solid layer. A layer is modeled with multiple one-dimensional viscoelastic elements, which only allow displacements in the direction of the layer thickness. Each viscoelastic element consists of a pressure- and strain-dependent spring connected in parallel to a pressure-dependent viscous damper. The proposed model follows a 'bottom-up' approach, starting from the dry contact equations for which the layer thickness is zero inside the contact. Then, a viscoelastic layer is added to the gap-height equation to open the possibilities for mixed lubrication modeling in pure rolling as it allows a natural transition to dry contact.

Results for several different cases have been presented, including:

- squeeze simulations,

- film formation during steady rolling from a squeezed situation,

- features on the solid parts entering the contact,

- mixed lubrication, a part of the layer with film thickness zero entering the contact.

In general, the proposed model is able to show the characteristic behaviour of an EHL contact in these situations. However, the model predictions for features fixed on the ball geometry show local differences with physical expectations.

The results of the layer thickness- and pressure distribution for steady rolling obtained with the present model compared to results obtained with an EHL solver show that the present model yields approximately the same central layer thickness as the EHL model, but has a larger deformation along the perimeter of the contact, i.e. larger lobes.

\subsection{Recommendations}

For both subjects several recommendations can be made for future research. 


\subsubsection{Flow in and around an EHL contact}

The results of this study are an invitation to exploit full 3D 2-phase flow CFD models which allow modeling of a $3 \mathrm{D}$ cavitation region to analyse the flow in the wake of rolling EHL point contacts in order to better understand the phenomenon of cavitation bubble formation and its length.

To improve the prediction on the cavitation and cavitation bubble length it is recommended to:

- Perform optical interferometry measurements for an oil lubricated ball-and-disc configuration in steady rolling and a higher velocity regime than tested in this study, to the determine the relation between cavitation bubble length and the rolling velocity across the complete velocity spectrum.

- For the numerical prediction, more advanced models need to be found and implemented to better capture the 3D aspects of a 2-phase flow. Furthermore, it is recommended to include the effect of surface tension.

\subsubsection{Viscoelastic layer model}

Since this model is meant as an exploratory model, the results are an invitation to search for viscoelastic element properties that drive the model towards more accurate physical behaviour. The relations for the viscosity and modulus of elasticity should be further developed. Furthermore, parametrical studies including e.g. higher velocities and different load conditions is recommended. Since the model in this form only applies to pure rolling conditions, it is recommended to invent a way to couple the elements in such a way that the simulation of slip is also possible. 


\section{BIBLIOGRAPHY}

[1] Reynolds, O., "On the Theory of Lubrication and its Application to Mr. Beauchamps Tower's Experiments, Including an Experimental Determination of the Viscosity of Olive Oil," Journal Phil. Trans., Vol. 177, 1886, pp. 157-234.

[2] Venner, C. H. and Lubrecht, A. A., Multi-Level methods in lubrication, Elsevier Tribology Series, Amsterdam., 2000.

[3] Hertz, H., "Über die Berührung Fester Elastischer Körper," Journal für die reine und angewandte Mathematik, Vol. 92, 1881, pp. 156-171.

[4] Martin, H. M., "Lubrication of gear teeth," Engineering, Vol. 102, 1916, pp. 119121.

[5] Gümbel, L., "Uber geschmierte Arbeitsräder," Z.ges. Turbinenwesen, Vol. 13, 1916, pp. 357.

[6] Ertel, A. M., "Hydrodynamic Lubrication Based on New Principles," Akad. Nauk SSSR Prikadnaya Mathematica i Mekhanika, Vol. 3,2, 1939, pp. 41-52.

[7] Grubin, A. N., "Fundamentals of the Hydrodynamic Theory of Lubrication of Heavily Loaded Cylindrical Surfaces," Central Scientific Research Institute for Technology and Mechanical Engineering, Vol. Book no. 30, 1949, pp. 115-166.

[8] Pertusevich, A. I., "Fundamental Conclusions from the Contact Hydrodynamic Theory of Lubrication," Izv. Akad. Nauk SSR (OTN), Vol. 3, 1951, pp. 209-223.

[9] Barus, C., "Isothermals, isopiestics and isometrics relative to viscosity," Am. J. of Science, Vol. 45, 1893, pp. 78-96.

[10] Dowson, D. and Higginson, G. R., Elastohydrodynamic Lubrication, the fundamentals of roller and gear lubrication, Pergamon Press, Oxford, Great Britain., 1966.

[11] Hamrock, B. J. and Dowson, D., "Isothermal Elastohydrodynamic Lubrication of Point Contacts-Part I-Theory," Technical Report NASA USA, 1976.

[12] Dowson, D., History of Tribology, Professional Engineering Publishing Ltd, London, Burry St Edmunds, UK, 2nd ed., 1998.

[13] Chittenden, R. J., Dowson, D., Dunn, J. F., and Taylor, C. M., "A Theoretical Analysis of the Isothermal Elastohydrodynamic Lubrication of Concentrated Contacts I. Direction of Lubricant Entrainment Coincident with the Major Axis of the Hertzian Contact Ellipse," Proc. R. Soc. London., Vol. A 397, 1985, pp. 245-269. 
[14] Chittenden, R. J., Dowson, D., Dunn, J. F., and Taylor, C. M., "A Theoretical Analysis of the Isothermal Elastohydrodynamic Lubrication of Concentrated Contacts II. General Case, with Lubricant Entrainment along Either Principal Axis of the Hertzian Contact Ellipse or at some Intermediate Angle," Proc. R. Soc. London., Vol. A 397, 1985, pp. 271-294.

[15] Okamura, H., "A Contribution to the Numerical Analysis of Isothermal Elastohydrodynamic Lubrication," Proc. 9th Leeds-Lyon Symp. on Tribology., 1982, pp. 313-320.

[16] Evans, H. P. and Snidle, R. W., "Inverse Solution of Reynolds Equation of Lubrication under Point-contact Elastohydrodynamic Conditions," ASME JOT., Vol. 103, 1981, pp. 539-546.

[17] Gohar, R. and Cameron, A., "Optical measurement of oil film thichness under elastohydrodynamic lubrication," Nature, Vol. 200, 1963, pp. 458-459.

[18] Foord, C. A., Wedeven, L. D., Westlake, F. J., and Cameron, A., "Optical elastohydrodynamics," Proceedings of ImechE; Part J., Journal of Engineering Tribology, Vol. 184, No. 1, 1969-1970, pp. 487-505.

[19] Cameron, A. and Gohar, R., "Theoretical and experimental studies of the oil film in lubricated point contact," Proceedings of the Royal Society of London A, Vol. 291, No. 1427, 1966, pp. 520-536.

[20] Wedeven, L. D., Evans, D., and Cameron, A., "Optical analysis of ball bearing starvation," Journal of Lubrication Technology, 1971, pp. 349-361.

[21] Johnston, G. J., Wayte, R., and Spykes, H. A., "The measurement and study of very thin lubricant films in concentrated contacts," STLE Tribology Transactions, Vol. 34, No. 2, 1991, pp. 187-194.

[22] Cann, P. M. E., Spikes, H. A., and Hutchinson, J., "The development of a spacer layer imaging method (SLIM) for mapping elastohydrodynamic contacts," STLE Tribology Transactions, Vol. 39, No. 4, 1996, pp. 915-921.

[23] Krupka, K., Sperka, P., and Hartl, M., "Effect of surface roughness on lubricant film break down and transition from EHL to mixed lubrication," Tribology International, Vol. 100, 2016, pp. 116-125.

[24] Touche, T., Cayer-Barrioz, J., and Mazuyer, D., "Friction of textured surfaces in EHL and mixed lubrication: effect of groove topography," Tribology letters, Vol. 63, No. 25, 2016, pp. 1-14.

[25] Van Zoelen, M. T., Thin layer flow in rolling element bearings, Ph.D thesis, University of Twente, 2009.

[26] Pemberton, J. and Cameron, A., "A mechanism of fluid replenishment in elastohydrodynamic contacts," Wear, Vol. 37, 1976, pp. 185-190. 
[27] Chiu, Y. P., "An analysis and prediction of lubricant film starvationin rolling contact systems," Journal of Tribology, ASLE Transactions, Vol. 17, 1973, pp. 22-35.

[28] Stadler, K., Izumi, N., Morita, T., Sugimura, J., and Piccigallo, B., "Estimation of Cavity Length in EHL Rolling Point Contact," Journal of Tribology, Vol. 130, 2008, pp. 031502-1-9.

[29] Chevalier, F., Lubrecht, A., Cann, P. M. E., and Dalmaz, G., "The evolution of lubricant film defects in the starved regime," Tribology Series, Vol. 34, 1998, pp. 233242.

[30] Popovici, G., Effects of lubricant starvation on the performance of elastohydrodynamically lubricated contacts, Ph.D thesis, University of Twente, 2005.

[31] Venner, C. H., Van Zoelen, M. T., and Lugt, P. M., "Thin layer flow and film decay modeling for grease lubricated rolling bearings," Tribology International, Vol. 47, 2012, pp. 175-187.

[32] Jacod, B., Pubilier, F., Cann, P. M. E., and Lubrecht, A. A., "An analysis of track replenishment mechanisms in the starved regime," Lubrication at the Frontier, 1999, pp. 483-492.

[33] Lugt, P. M., Grease Lubrication in Rolling Bearings, Wiley Tribology Series, United Kingdom, 2013.

[34] Dawson, P. H., "Effect of metallic contact on the pitting of lubricated rolling surfaces," Journal of Mech. Eng. Sc., Vol. 4, No. 1, 1962, pp. 16-21.

[35] Olver, A. V., "The mechanism of rolling contact fatique: an update," Proc. Instn. Mech. Engrs.; Part J., Journal of Engineering Tribology, Vol. 219, 2005, pp. 313330.

[36] Lainé, E., Olver, A. V., Hua, D. Y., Wang, P., and Beveridge, T., "The effect of antiwear additives on fatique damage," Extended abstract, STLE Meeting, Philadelphia, 2007.

[37] Hu, Y. Z. and Zhu, D., "A Full Numerical Solution to the mixed Lubrication in Point Contacts," ASME J. of Tribology, Vol. 122, 2000, pp. 1-9.

[38] Holmes, M. J. A., Evans, H. P., and Snidle, R. W., "Comparison of Transient EHL Calculations With a Shut-Down Experiment," Proc. 29th Leeds-Lyon Symp. on Tribology, Elsevier Tribology Series, D. Dowson et al., Vol. 41, 2002, pp. 91-99.

[39] Zhao, I. and Sadeghi, F., "Analysis of EHL Circular Contact Shut-Down," ASME J. of Tribology, Vol. 125, 2003, pp. 76-90.

[40] Venner, C. H., Wang, J., and Lubrecht, A. A., "Central film thickness in EHL point contacts under pure impact revisited," Tribology International, 2015. 
[41] Venner, C. H., "EHL film thickness computations at low speeds: risk of artificial trends as a result of poor accuracy and implications for mixed lubtication modeling," Proc. Instn. Mech. Engrs.; Part J., Journal of Engineering Tribology, Vol. 219, 2005, pp. 285-290.

[42] Morales-Espejel, G. E., Lugt, P. M., and Olver, A. V., "A limiting Solution for the dependence of film thickness on velocity in EHL contacts with very thin films," Tribology Transactions, Vol. 48, 2005, pp. 317-327.

[43] Chennaoui, M., Fowell, M., and Kadiric, A., In-situ measurement of oil films in a model rolling bearing, Presentation Imperial College London and SKF, 2014.

[44] Wedeven, L. D., Evans, D., and Cameron, A., "Optical Analysis of Ball Bearing Starvation," ASME J. Lubr. Technol., Vol. 93, 1971, pp. 349-361.

[45] Damiens, B., Cann, P. M. E., Venner, C. H., and Lubrecht, A. A., "Analysis of the oil distribution in starved elliptical EHD contacts," Proceedings 2002 Leeds Lyon Symposium on Tribology, Ed. D. Dowson et al., 2003, pp. 685-692.

[46] Damiens, B., Venner, C. H., Cann, P. M. E., and Lubrecht, A. A., "Starved lubrication of elliptical EHD contacts," ASME J. of Tribology, Vol. 126, 2004, pp. 105-111.

[47] Seeton, C., "Viscosity-temperature correlation for liquids," Tribology letters, Vol. 22, No. 1, 2006, pp. 67-78.

[48] Peiran, Y. and Shizhu, W., "Pure squeeze action in an isothermal elastohydrodynamically lubricated spherical conjunction Part 1 . Theory and dynamic load results," Wear, Vol. 142, 1991, pp. 1-16.

[49] Paul, G. R. and Cameron, A., "An absolute high-pressure microviscometer based on refractive index," Proc $R$ Soc Lond Ser A, Vol. 331, 1972, pp. 171-184.

[50] Kaneta, M., Ozaki, S., Nishikawa, H., and Guo, F., "Effects of impact loads on point contact elastohydrodynamic lubrication films," Proc Inst Mech Eng Part J: J Eng Tribol, Vol. 221, 2007, pp. 271-278.

[51] Larsson, R. and E., H., "Numerical simulation of a ball impacting and rebounding a lubricated surface," ASME J Tribol, Vol. 116, 1994, pp. 770-776.

[52] Buckingham, E., "On physically similar systems: illustrations of the use of dimensional equations," Physical Review, Vol. 4, 1914, pp. 345-376.

[53] Fox, R. W. and McDonald, A. T., Introduction to fluid mechanics, John Wiley and Sons, Inc. New York USA, 5th ed., 1998.

[54] Bayada, G. and Chupin, L., "Compressible fluid model for hydrodynamic lubrication cavitation," Journal of Tribology ASME Transactions, Vol. 135, 2013, pp. 1-13. 
[55] Bruyere, V., Fillot, N., Morales-Espejel, G. E., and Vergne, P., "A two-Phase flow approach for the outlet of lubricated line contacts," Journal of Tribology, Vol. 134, 2012, pp. 041503.

[56] Van Emden, E., Venner, C. H., and Morales-Espejel, G. E., "A challenge to cavitation modeling in the outlet flow of an EHL contact," Tribology International, Vol. 102, 2016, pp. 275-286.

[57] Kottke, P. A., Bair, S., and Winer, W. O., "Cavitation in creeping shear flows," Journal of AlChE, Vol. 51, No. 8, 2005, pp. 2150-2170.

[58] Padrino, J. C., Joseph, D. D., Funada, T., Wang, J., and Sirignano, W. A., "Stressinduced cavitation for the streaming motion of a viscous liquid past a sphere," Journal of Fluid Mechanics, Vol. 578, 2007, pp. 381-411.

[59] Roelands, C. J. A., Correlational aspects of the visosity-temperature-pressure relationship of lubricating oils, Ph.D thesis Technische Hogeschool Delft, 1966.

[60] Van Emden, E., Venner, C. H., and Morales-Espejel, G. E., "Aspects of Flow and Cavitation Around an EHL Contact," Tribology International, Vol. 95, 2015, pp. 435448.

[61] Venner, C. H., Multilevel Solution of the EHL Line and Point Contact Problems, Ph.D thesis University of Twente, 1991.

[62] Wijnant, Y. H., Contact Dynamics in the Field of Elastohydrodynamic Lubrication, Ph.D thesis University of Twente, 1998.

[63] Joseph, D. D., "Cavitation and the state of stress in a flowing liquid," Journal of Fluid Mechanics, Vol. 366, 1998, pp. 367-378.

[64] Jacobsson, B. and Flowberg, L., "The finite journal bearing considering vaporization," Transactions of Chalmers University of Technology, Vol. 190, 1957.

[65] Elrod, H. G. and Adams, M. L., "A computer program for cavitation and starvation problems," In: Dowson D, Godet M and Taylor CM, editors. Proceeding of the first Leeds-Lyon symposium on tribology-cavitation and related phenomena in lubrication, 1974, pp. 37-41.

[66] Van Odyck, D. E. A. and Venner, C. H., "Compressible Stokes Flow in Thin Films," Journal of Tribology, Vol. 125, 2003, pp. 543-551.

[67] Van Odyck, D. E. A., Stokes Flow in Thins Films, Ph.D thesis University of Twente, 2001.

[68] Van Wijngaarden, L., "One Dimensional Flow of Liquid Containing Small Gas Bubbles," Ann. Rev. Fluid. Mech, Vol. 4, 1972, pp. 369-396. 
[69] Bair, S. and Kottke, P., "Pressure-Viscosity Relationships for Elastohydrodynamics," Tribology Transactions, Vol. 46, No. 3, 2003, pp. 289-295.

[70] Bair, S., Khonsari, M., and Winer, W. O., "High-pressure rheology of lubricants and limitations of the Reynolds equation," Tribology International, Vol. 31, No. 10, 1998, pp. 573-586.

[71] Bair, S., Jarzynski, J., and Winer, W. O., "The temperature, pressure and time dependence of lubricant viscosity," Tribology International, Vol. 34, 2001, pp. 461468.

[72] Jacobson, B. O. and Vinet, P., "A model for the influence of pressure on the bulk modulus and the influence of temperature on the solidification pressure for liquid lubricants," ASME J. of Tribology, Vol. 109, 1987, pp. 709-714.

[73] Moes, H., "Optimum Similarity Analysis, an Application to Elastohydrodynamic Lubrication," Wear, Vol. 159, 1992, pp. 57-66.

[74] Hartinger, M., Dumont, M., loannides, S., Gosman, D., and Spikes, H., "CFD Modeling of a Thermal and Shear-Thinning Elastohydrodynamic Line Contact," Journal of Tribology, Vol. 130, 2008, pp. 041503-1-16.

[75] Tevaarwerk, J. and Johnson, K. L., "A simple non-linear constitutive equation for elastohydrodynamic oil films," Wear, Vol. 35, 1975, pp. 345-356.

[76] Auslender, F., Nanorheologie des couches minces confinees application aux appareils a forces de surface, These Lyon, France, 1996.

[77] Trifa, M., Nanorheologie du contact sphere-plan avec couch mince interfaciale, These Lyon, France, 1999.

[78] Auslender, F., Trifa, M., and Sidoroff, F., "Material compressibility effects for the squeeze of very thin films," Eur.J.Mech. A/Solids, Elsevier, Vol. 18, No. 1, 1999, pp. 499-515.

[79] Trifa, M., Sidoroff, F., and Georges, J. M., "Elastohydrodynamic squeeze of thin films for the sphere-plane contact," Lubrication at the Frontier, Vol. 18, No. 1, 1999, pp. 499-515.

[80] Pujari, S. P., Covalently Bound Fluorine-Containing Monolayers on Silicon and Oxides. Formation, Stability and Tribology, Ph.D thesis Wageningen University, 2013.

[81] Bhairamadgi, N. S., Organic Monolayers and Fluoropolymer Brushes, Ph.D thesis Wageningen University, 2014.

[82] Young, R. J. and Lovell, P. A., Introduction to polymers, Chapman \& Hall, 2nd ed., 1991. 
[83] Johnson, K. L., Contact Mechanics, Cambridge University Press, ISBN 0521347963, 1985.

[84] Timoshenko and Goodier, Theory of Elasticity, McGraw-Hill book company, 3rd ed., 1951.

[85] Popovici, G., Venner, C. H., and Lugt, P. M., "Effects of load system dynamics on the film thickness of EHL contacts during start up," ASME Journal of Tribology, Vol. 126, 2004, pp. 258-266.

[86] Holmes, M. J. A., Evans, H. P., and Snidle, R. W., "Comparison of transient EHL calculations with start-up experiments," Proceedings of $29^{\text {th }}$ Leeds-Lyon Symposium on Tribology, Elseviers Tribology Series, D. Dowson et al., Vol. 41, 2002, pp. 79-89.

[87] Christensen, H., "The oil film in a closing gap," Proc $R$ Soc London, Series $A$, Vol. 226, 1962, pp. 312-28.

[88] Yang, P. R. and Wen, S. Z., "Pure squeeze action in an isothermal elastohydrodynamically lubricated sheperical conjunction Part2. Constant speed and constant load results," Wear, Vol. 142, 1991, pp. 17-30.

[89] Larsson, R. and Höglund, E., "Elastohydrodynamic lubrication at pure squeeze motion," Wear, Vol. 179, 1994, pp. 39-43.

[90] Chu, H. M., Li, W. L., and Chen, M. D., "Elastohydrodynamic lubrication of circular contacts at pure squeeze motion with non-Newtonian lubricants," Tribology International, Vol. 39, 2006, pp. 897-905.

[91] Kaneta, M., Nishikawa, H., Mizui, M., and Guo, F., "Impact elastohydrodynamics in point contacts," Proceedings of ImechE; Part J., Journal of Engineering Tribology, Vol. 225, 2010, pp. 1-12.

[92] Kaneta, M., Kanada, T., and Nishikawa, H., "Optical interferometric observations of the effects of a moving dent on point contact EHL," Proceedings of the 1996 Leeds-Lyon Symposium on Tribology, Elsevier Science, Vol. 23, 1997, pp. 69-79.

[93] Félix-Quiñonez, A., An experimental and theoretical study of elastohydrodynamically lubricated contacts with well defined surface features, Ph.D thesis, University of Leeds, 2003.

[94] Tijdeman, H. and Spiering, R. M. E. J., Solid Mechanics I Elasticity $1^{e}$ deel, Reader, University of Twente no. 997, 1st ed., 2009.

[95] Love, A. E. H., A Treatise on the Mathematical Theory of Elasticity, New York Dover Publications, 4th ed., 1944.

[96] Brandt, A., Multigrid Techniques: 1984 Guide with Applications to Fluid Dynamics, available as G.M.D.-Studien No. 85, from G.M.D.-F1T, Postfach 1240, D-5202, St. Augustin 1, Germany, 1984. 
BIBLIOGRAPHY

[97] Brandt, A. and Lubrecht, A. A., "Multilevel Matrix Multiplication and Fast Solution of Integral Equations," Journal of computational physics, Vol. 90,2, 1990, pp. 348370. 


\section{ACKNOWLEDGEMENT}

I gratefully acknowledge all people who have contributed to this work, this thesis could not have been completed without their support.

First of all, I want to thank Kees Venner for his guidance, support and enthusiasm during the many years of this research. Kees, thank you for the opportunity you gave me to carry out this project and to learn about various multigrid methods.

Furthermore, I would like to thank Harry Hoeijmakers and Mico Hirschberg for making it possible to join the group, and for providing Kees and me the opportunity to search for an interesting $\mathrm{PhD}$ project.

This reseach project was supported by SKF Engineering and Research Centre in Nieuwegein, the Netherlands. From SKF, I would like to thank Guillermo Morales-Espejel for his cooperation, enthusiasm and support. Furthermore, thanks to Ralph Meeuwenoord for making dimpled balls for the experiments.

I would like to thank Gert-Willem Römer, Daniel Arnaldo del Cerro and Gerald Ebberink of Mechanical Automation and Mechatronics to look for possibilities to treat the glass disc used in the experiments with laser technics.

I would like to thank Stefan Karpitschka of Physics of Fluids for the surface-tension determination on HVI60.

I also would like to thank Herman Stobbe, Theo Punt and Norbert Spikker for manufacturing a stable table and camera stand for the optical interferometry apparatus.

Furthermore, I would like to thank Wouter den Breeijen for his help with computer related issues.

And, I would like to thank the former and present members and colleagues of the Engineering Fluid Dynamics group for creating a pleasant environment to work in.

My deepest gratitude goes to Hein and Jelle, thank you very much for everything, the patience and understanding. Every time you helped me through tough periods. I feel very lucky being with you. 

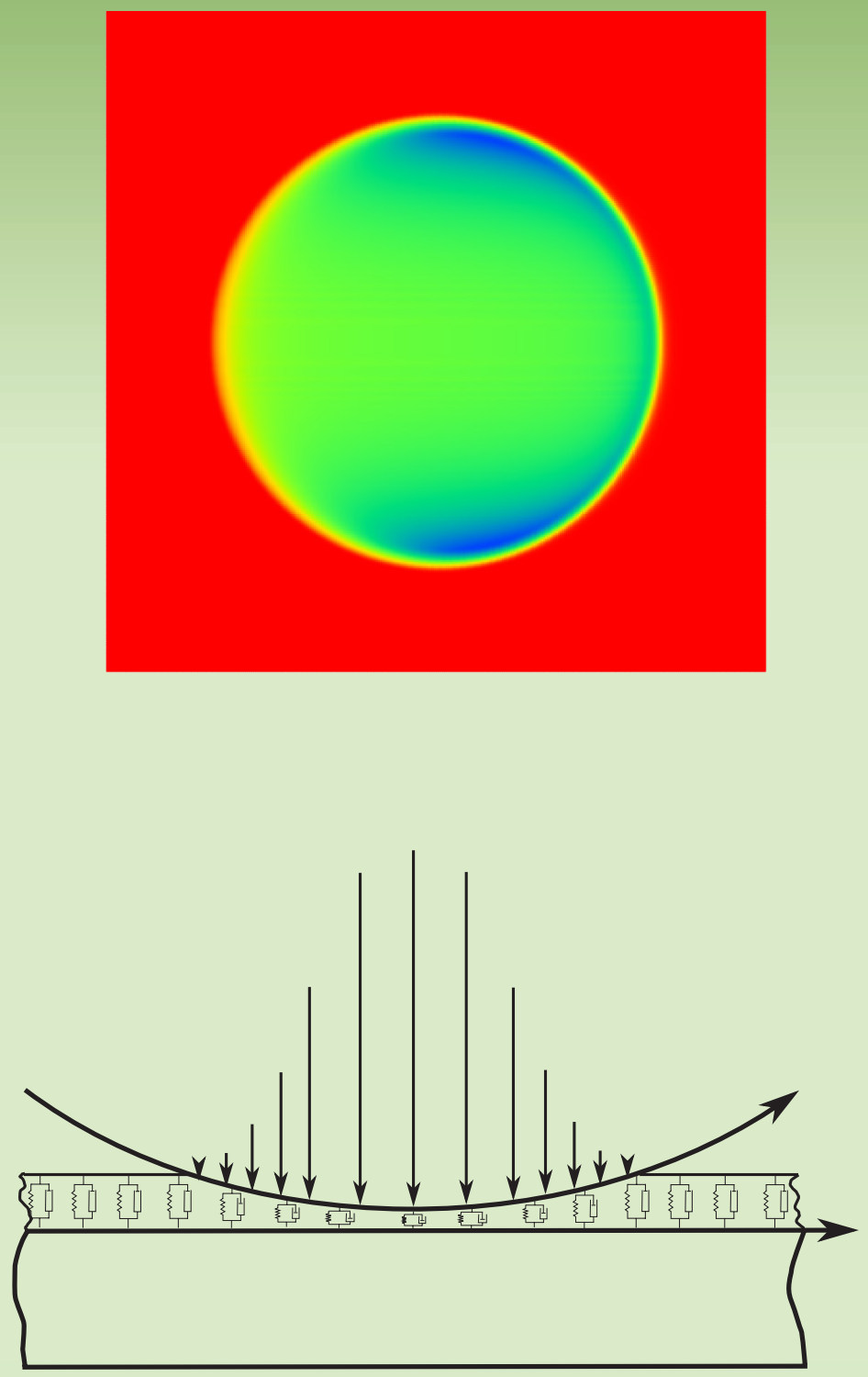